\title{
UNGLASSIFIED
}

504 251069

CRGGUATINE

Q⿻ COMC

BNWL-970

MCAL INFO

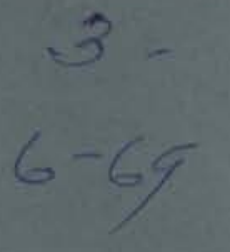

\section{FFTF MODIFIED FERMI CONTROL ROD DRIVE MECHANISM CONCEPTUAL DESIGN STUDY}

June 1969

AEC RESEARCH \& DEVELOPMENT REPORT

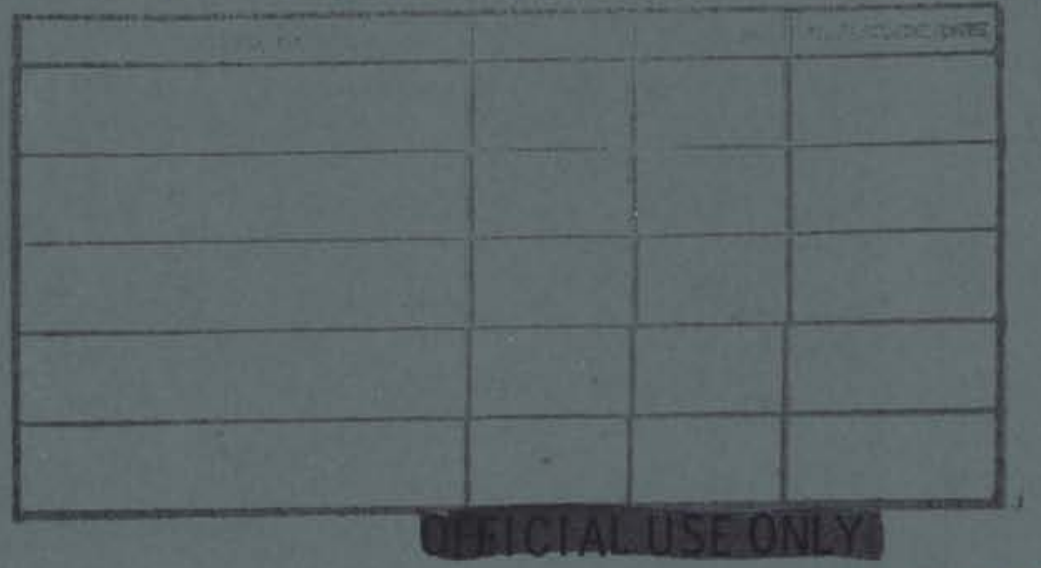




\section{INFORMATION CONCERNING USE OF THIS REPORT}

\section{PATENT STATUS}

This document copy, since it is fransmitted in odvance of potent clearance, is made available in confidence solely for use in performance of work under controcts with the U.S. Atomic Energy Commission. This document is not to be published nor its contents otherwise disseminated or used for purposes other than specified above before patent approval for such release or use has been secured, upon request, from the Chief, Chicago Patent Group, U. S. Atomic Energy Commistion. 9800 So. Cass Ave., Argonne, Illinois.

\section{PRELIMINARY REPORT}

This report contains information of a preliminary nature prepared in the course of work under Atomic Energy Commission Contract AT $(45 \cdot 1)-1830$. This information is subject to correction or modifica. tion upon the collection and evaluation of additional dota.

\section{LEGAL NOTICE}

This report was prepared as an account of Gavernment sponsored wark. Neither the United States, nor the Commission, nor any person acting on behalf of the Cormmission:

A. Makes any warranty or representation, expressed or implied, with respect to the occuracy, com: pleteness, or usefulness of the information contained In this report, or that the use of any information. apparatus, method, or process disclosed in this report may not infringe privately owned rights; or

B. Assumes any liabilifies with respect to the use of, or for domages resulting from the use of any information, apparatus, method, or process disclosed in this report.

As used in the above, "person octing on behalf of the Commission" includes any employee or contractor of the Commission, or employee of such contractor, to the extent that such employee or conIractor of the Commissioe, or employee of such contractor prepares, disseminates, or provides access to. any information pursuant to his employment or contract with the Commission, or his employment with such controctor.

\section{PACIFIC NORTHWEST LABORATORY}

RICHLAND, WASHINGTON

operated by

BATTELLE MEMORIAL INSTITUTE

for the

UNITED STATES ATOMIC ENERGY COMMISSION UNDER CONTRACT AT(45-1)-1830 


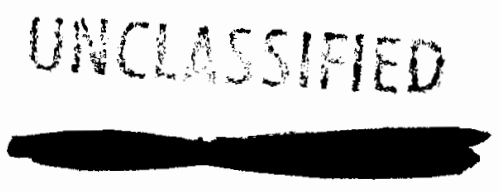

BNWL -970

\section{8}

FFTF MODIFIED FERMI CONTROL ROD

DRIVE MECHANISM

CONCEPTUAL DESIGN STUDY

By

J. R. McBride

B. C. Fryer

Mechanical Engineering Department Physics and Engineering Division

Approved By

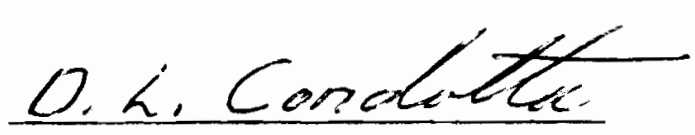

June 1969

BATTELLE MEMORIAL INSTITUTE

PACIFIC NORTHWEST LABORATORY

RICHLAND, WASHINGTON 99352

\section{UNCI.ASSIFIED}


- $=0$

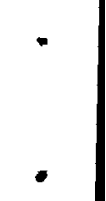




\section{TABLE OF CONTENTS}

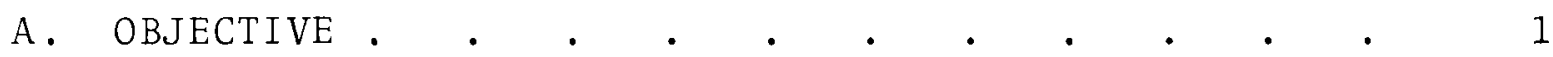

B. BACKGROUND. . . . . . . . . . . . 1

C. REACTOR CONTROL - GENERAL CONCEPT . . . . . . . 1

D. DESIGN PHILOSOPHY . . . . . . . . . . . . 2

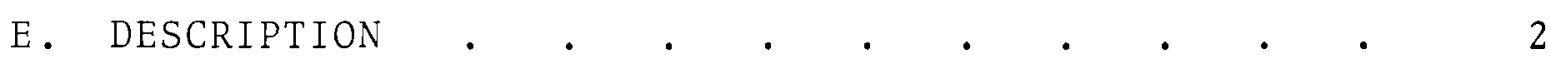

1. Control Mechanisms Operating Capabilities. . 2

2. Description of Sections . . . . . . . 3

F. DISCUSSION $. \quad . \quad . \quad . \quad . \quad . \quad . \quad . \quad . \quad . \quad . \quad . \quad 14$

1. Critical Areas in the Design . . . . . 16

2. Suggested Specification Modifications to Improve the Design . . . . . . . 20

3. Alternate Component Design Ideas . . . . 20

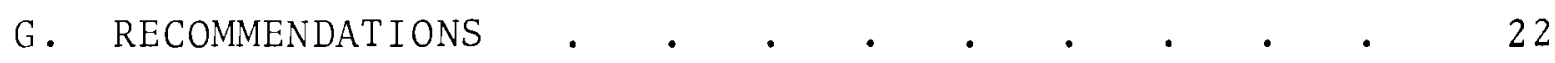

APPENDIX A DESIGN DRAWINGS . . . . . . . . . . .

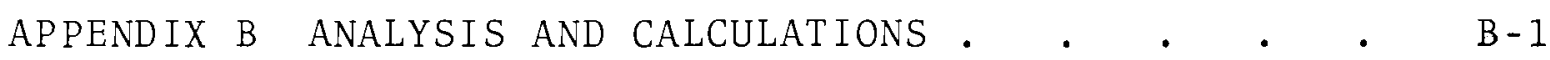

APPENDiX C DESIGN CALCUlations .

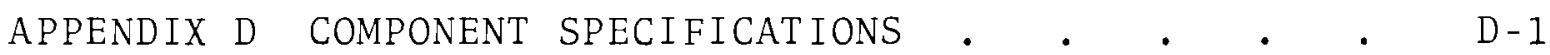

REFERENCES. • . . . . . . . . . . $\operatorname{Ref-1}$

DISTRIBUTION . . . . . . . . . . . . Distr-1 


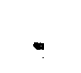

. 


\section{FFTF MODIFIED FERMI CONTROL ROD \\ DRIVE MECHANISM \\ CONCEPTUAL DESIGN STUDY \\ J. R. McBride \\ B. C. Fryer}

\section{A. OBJECTIVE}

The objective of this study was to develop a conceptual definition of shim/scram control rod drive mechanisms for the Fast Test Reactor (FTR), based on the Enrico Fermi Reactor safety rod concept.

\section{B. BACKGROUND}

The safety rod drive mechanism for the Enrico Fermi Fast Breeder Reactor ${ }^{(1,2)}$ served as a basis for the FTR control mechanisms conceptual design evaluated in this study. There is some deviation from the Enrico Fermi concept in the Modified Fermi Conceptual Design (MFCD) due to conditions unique to the FTR and improvements in technology since the Enrico Fermi Reactor was designed.

\section{REACTOR CONTROL - GENERAL CONCEPT}

The function of the reactor control rods is reactivity control. Reactivity is controlled by inserting or withdrawing neutron absorbing material (poison).

The shim/scram control rod has two modes of operation. In the shim mode the rod is inserted or withdrawn from the core with the drive to make adjustments in reactivity. When scrammed, the rod is released from the drive extension section by a mechanical latch and accelerated into the core by the combined forces of a spring and gravity. Rods are scrammed when an abnormal condition exists which endangers the reactor or auxiliary systems. 


\section{DESIGN PHILOSOPHY}

The conceptual design was based on Core Concept VIII (SK-3-12881),* however, it is adaptable to other core concepts with a minimum of change. When a final core concept has been selected, it will be necessary to check the design against the specifications. To aid this review process, capabilities of components specified and critical areas in the design are outlined in this report. In addition, improvements in the design which may be made by changing the current specifications are pointed out.

\section{E. DESCRIPTION}

\section{CONTROL MECHANISMS OPERATING CAPABILITIES}

$\frac{\text { Physical Envelope }}{\text { Diameter and length }}$

Drive Section

Stroke

Shim rate

Max. withdrawal rate

Max. insertion rate

Smallest jog increment

Capacity (push or puli)

Primary Position Indication**

Smallest increment

Accuracy (full stroke)

Reproducibility

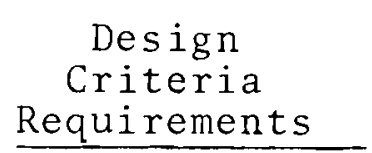

7.5 in. diam $x$

72 in. from

nozzle flange

to top

38.0 in.

$9.0 \mathrm{in} . / \mathrm{min}$

$9.0 \mathrm{in} . / \mathrm{min}$

Unspecified

0.05 in.

$10001 \mathrm{~b}$

$$
\begin{aligned}
& 0.010 \text { in. } \\
& 0.100 \text { in. } \\
& 0.050 \text { in. }
\end{aligned}
$$

Modified Fermi Conceptua 1

Design

Secondary Position Indication**

Smallest increment Accuracy (full stroke)

Reproducibility
Unspecified

Unspecified

Unspecified
7.5 in. diam $x$

71 in. from

nozzle flange

to top

$$
\begin{aligned}
& 39.0 \mathrm{in} . \\
& 9.0 \mathrm{in} . / \mathrm{min} \\
& 9.0 \mathrm{in} . / \mathrm{min} \\
& 90.0 \mathrm{in} . / \mathrm{min} \\
& 0.001 \mathrm{in} . \\
& 1060 \mathrm{~b}
\end{aligned}
$$

$0.001 \mathrm{in.}$

$0.060 \mathrm{in}$.

$0.006 \mathrm{in}$.

* SK-numbers refer to Pacific Northwest Laboratory engineering drawings.

** With respect to drive mounting head, neglecting differential thermal expansion. 


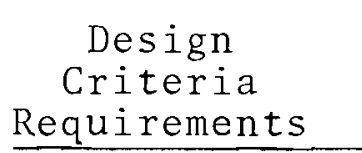

Poison Assembly

Scram Stroke

Maximum velocity

Scram time*

Maximum acceleration

Poison Assembly Weight
Modified Fermi

Conceptual Design

Environment

- At elevation $26 \mathrm{ft} 4 \mathrm{in.} \mathrm{(top} \mathrm{of} \mathrm{vessel} \mathrm{head):}$

$100 \mathrm{mr} / \mathrm{hr}$ gamma

$10^{3}$ neutrons $/ \mathrm{cm}^{2}-\mathrm{sec}$

$250^{\circ} \mathrm{F}$

- At elevation $21 \mathrm{ft}$ (bottom of plug):

$3 \times 10^{5} \mathrm{r} / \mathrm{hr}$ gamma

$10^{8} \mathrm{n} / \mathrm{cm}^{2}-\mathrm{sec}$ (less than $0.5 \mathrm{MeV}$ )

$1100{ }^{\circ} \mathrm{F}$

2. DESCRIPTION OF SECTIONS

Genera1

The control rod assembly consists of three major sections which are:

a. Drive section

b. Drive extension section

c. Poison section

The poison section is coupled to the lower end of the drive extension section with a mechanical latch. The whole assembly is raised and lowered with a translating nut type ball screw actuator powered with a stepping motor. The drive extension penetrates the shielding plug which is supported by

* Time from interruption of the electromagnet circuit to complete deceleration of rod by dashpot

** seven-rod bunale, $B_{4} C$ poison 
a tube from the top of the guide tube. Due to the high temperature at the bottom of the shield plug (estimated $1100^{\circ} \mathrm{F}$ ), it does not appear feasible to use a sliding contact type seal. Instead, a flow of purge gas will be maintained from the upper side to the lower side of the shield plug to minimize the amount of sodium vapor entering the drive cavity. As a backup, the ball screw is enclosed in a bellows seal, and all joints are sealed with static seals.

A cylindrical cam closes the latch fingers on a spool that is attached to the poison section. Once the fingers are cammed in, the cam is held with an electromagnet. The cam is connected to the electromagnet with a latch rod that extends up through the drive extension section. When the electromagnet is de-energized, the cam drops and the fingers open releasing the poison section. The poison section is acce1erated into the core by the combined forces of a spring and gravity. In the last 6 in. of stroke, it is decelerated by the dashpot type decelerator located at the bottom of the guide tube. The decelerator uses sodium as its damping medium.

The guide tube is supported by the reactor cover at the top, and the tube sheet at the bottom. In order to keep compressive loads on the guide tube low, a spring assembly built into the reactor cover is designed to carry two-thirds of the $1200 \mathrm{lb}$ assembly weight with the other one-third carried by the tube sheet. The spring will accommodate 1 in. of differential thermal expansion between the reactor vessel and guide tube. 
Specific

a. Drive Section

The drive section is shown on Sheets 1 and 2 of SK-3-13278.* Control movement is accomplished with a translating nut type ball screw actuator driven by a stepping motor. Primary rod position indication comes from a digital rotary shaft encoder, and as a backup, rod position is indicated by a 10-turn potentiometer. Rod full-in and fullout positions are indicated by an adjustable 10 -turn rotary limit switch.

The stepping motor is a versatile unit. A single stepping motor replaces the two motors, two speed reducers, two clutches, and a magnetic brake used on the Fermi drive, but flexibility of operation is not reduced. Stepping rate is adjustable from 50 to 1500 steps/sec which gives rod translational rates of 3 to $90 \mathrm{in./min}$, respectively. In normal operation the rod will move at 9 in./min (150 steps/sec). Upon scram, the drive will "chase" the poison section down at $90 \mathrm{in./min.} \mathrm{Suitable} \mathrm{control} \mathrm{interlocks} \mathrm{must} \mathrm{be} \mathrm{provided} \mathrm{to}$ ensure the rod cannot be withdrawn at more than $9 \mathrm{in./min}$.

In the Fermi Reactor, a control rod which was fully inserted buckled due to differential thermal expansion between the rod and guide tube. In order to avoid this problem in the FTR it is planned that the static holding torque of the stepping motor be reduced to a level which will allow the ball screw to back-drive the motor, thus relieving an excessive compressive load on the control rod. Reduction in holding torque can be accomplished by reducing the field coil excitation voltage with a fixed resistor in the field circuit. The resistor would be by-passed with a relay when the motor is stepped.

* See Appendix A for Drawings SK-3-13278 and SK-3-13288. 
A rotary shaft angle encoder coupled directly to the stepping motor and working in conjunction with a bidirectional counter located in the control room serves as the primary control rod position indication system. The encoder generates 200 pulses per shaft revolution. With a 0.2 in. screw lead, 1 in. of control rod movement is equal to 1000 encoder pulses.

Secondary position indication comes from a ten-turn potentiometer. A planetary speed reducer with a 20:1 ratio converts the $200 \mathrm{screw}$ revolutions required for 40 in. of linear travel into 10 revolutions of the potentiometer. A 10 -turn adjustable rotary limit switch is coupled to the potentiometer to indicate when the rod is in the full-in and full-out positions.

b. Drive Extension Section

The drive extension section is shown in detail on Sheets 3 through 6 of SK-3-13278. The drive extension section consists of the latch rod electromagnet, latch rod, latch rod seal bellows, and control rod mechanical latch.

The following outline of the latching and scramming sequences explains the operation of the drive extension section components.

Latching Sequence. With the poison section uncoupled and bottomed in the dashpot, the extension section is driven down. As the extension is driven down, the cocking tube seats on the poison section scram assist spring follower and begins to compress the spring. Driving further down, the latch cam contacts the spool bolt as shown in Figure 1A. The extension is driven further down causing differential motion between the latch fingers and cam, closing the fingers over the spool. At the same time, the electromagnet which is part of the drive extension, moves down to contact the armature. When the extension has moved 0.75 in. down from the point of initial 

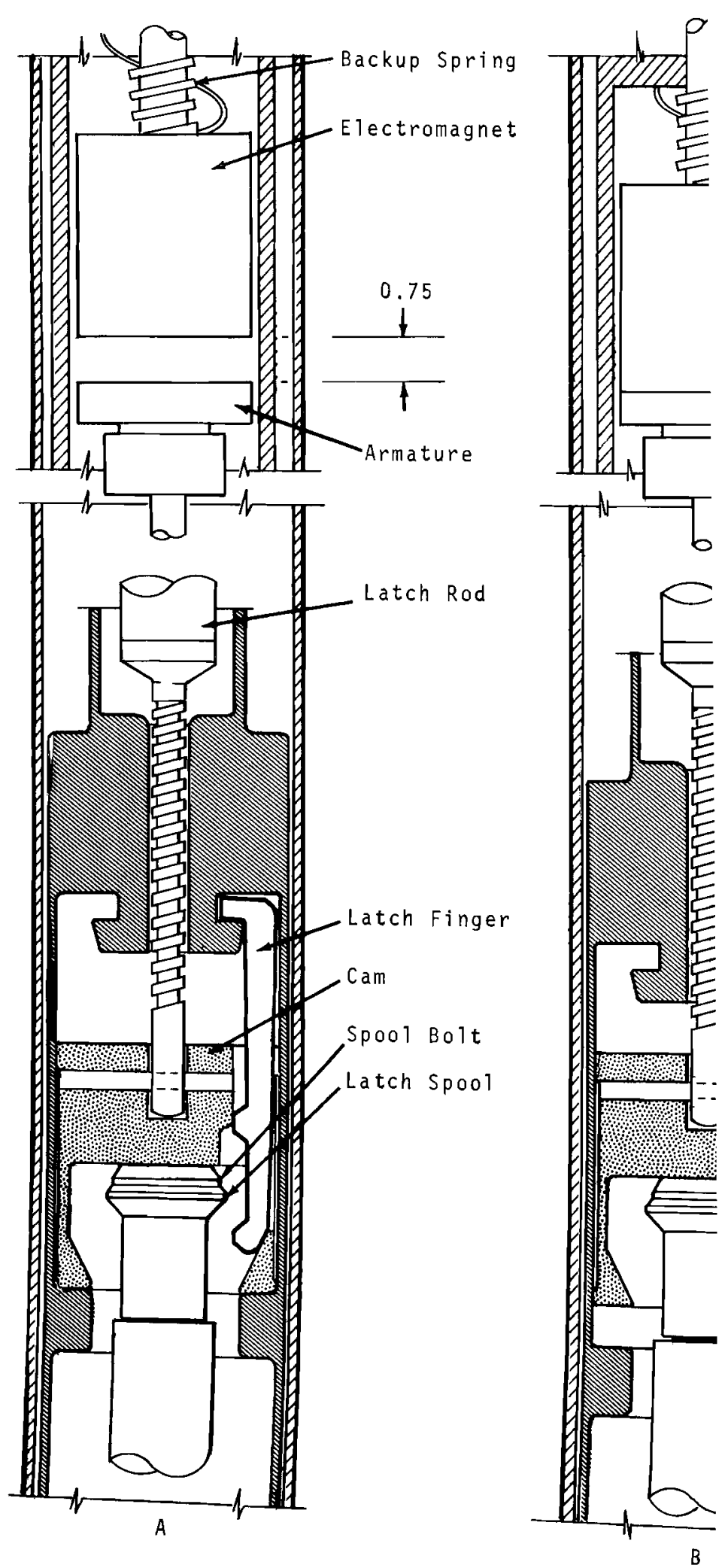
contact with the cam (Figure 1B), the electromagnet makes contact with the armature. To ensure good contact between the electromagnet and armature, the extension drives down another 0.25 in. compressing the electromagnet backup spring and actuating the limit switches which stop the drive and energize the electromagnet (Figure 1C). The drive is reversed and withdrawn 1 in. to the rod seated position (Figure 1D).

Scramming Sequence. With the poison section coupled to the drive extension and raised to the operating position, the following sequence of events take place when the rod is scrammed. Upon receipt of a signal to scram, the electromagnet is de-energized. The combination of the latch rod assembly weight, delatch assist spring force, and the resultant downward force on the cam caused by the outward force on the latch fingers causes the cam to move downward with respect to the fingers. As the cam moves downward, the acceleration spring and the weight of the poison section pull the latch spool out of the fingers. The cam moves further downward and cams the fingers out from the inside so that the fingers will fit over the spool when subsequently moved down for relatching.

There are several components in the drive extension which were changed from the Fermi concept in order to improve their performance.

To make alignment between the electromagnet and armature less critical, a self-aligning ball bushing was added to the armature. The angle on the bore of the cam (Figure 2) was increased from $2^{\circ} 26^{\circ}$ used in the Fermi Reactor to $40^{\circ}$ for the FTR. This increase in angle makes the latch self-opening when the latch magnet is released even if the delatch assist spring fails and the coefficient of friction is as high as 0.8. Increasing this cam angle increases the electromagnet 
BNWL - 970

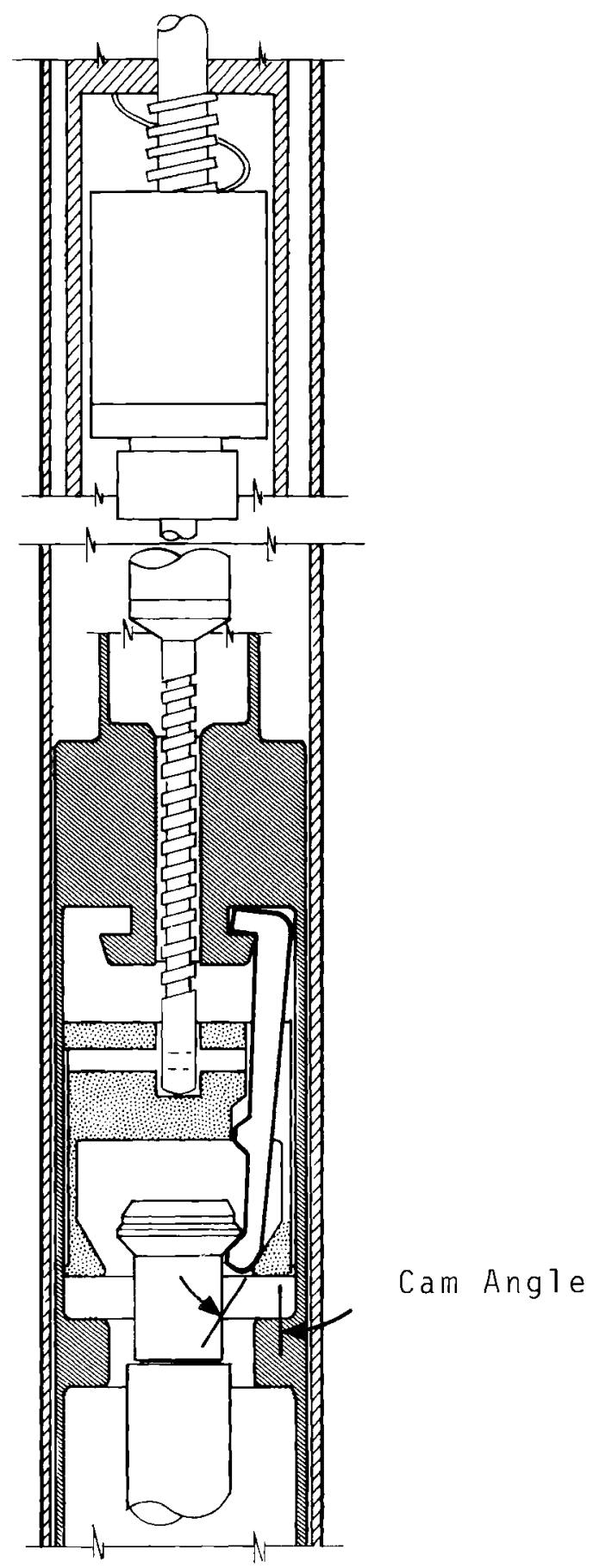

FIGURE 2. Cam Angle for FTR 
holding force required. Required electromagnet holding force versus drive lifting load for coefficients of friction of 0.4 and $0.8^{(3,4)}$ is shown in Figure 3 .

\section{c. Poison Section}

The Modified Fermi Conceptual Design for the FTR poison section is illustrated in Drawing SK-3-13288 (shown in the latched and fully retracted position). The original scrammable control rod poison section used in the Fermi Reactor is described in Reference 2. The basic components in the Modified Fermi Poison Section are the poison assembly and the dashpot. These basic components fit within the space envelope described by the guide tube. The major parts in the poison assembly are a latch spool, a scram assist spring assembly, a poison element and a ram. Parts in the dashpot area include the dashpot, the dashpot support tube, and the flow control orifice. A test section is illustrated in the Modified Fermi design drawing, but it may be eliminated in future work.

Since this was a conceptual design study, an effort was made to keep the design as flexible as possible to accommodate changes and to develop a general design basis that could be used to evaluate future modifications. In view of the fact that there were many unknowns pertaining to the poison section such as poison type and geometry, necessity of a test section, location of the poison during normal operation, required scram time, etc., it was necessary to choose a base design. This was done in order that a design description could be developed with sufficient detail to reveal feasibility problems.

The base design for this study contains a poison assembly with a 7 -rod bundle $\mathrm{B}_{4} \mathrm{C}$ poison element, a test section, a triple stepped ram, and a circular guide tube of variable cross section. The poison assembly is $19 \mathrm{ft} 7 \mathrm{in.} 1$ ong and weighs approximately $383 \mathrm{lb}$. In the latched and fully 
BNWL - 970

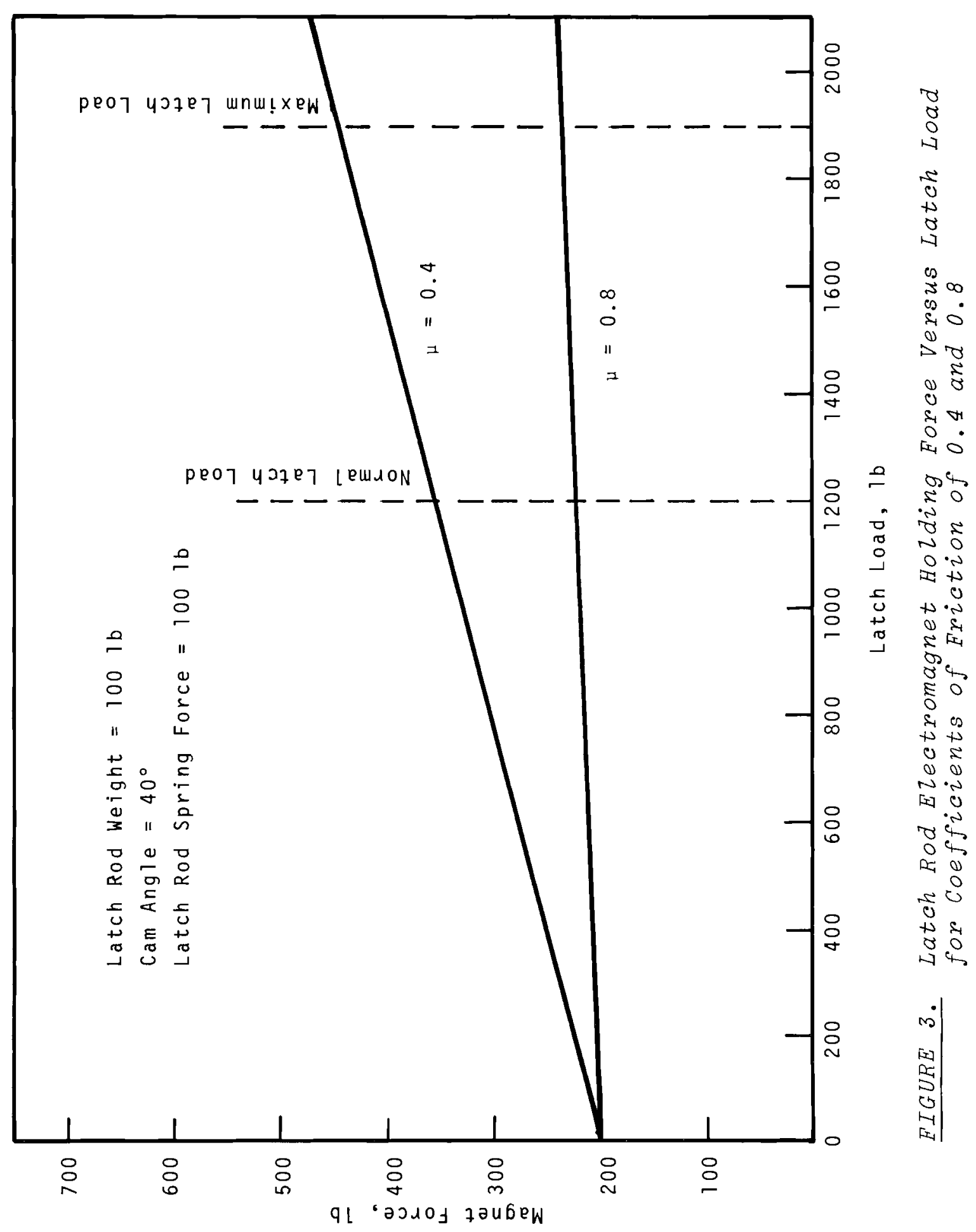


retracted position, the latch spool is 20 in. below the sodium pool surface. Annular clearance between poison assembly alignment pads and the guide tube was scaled up from the Fermi reactor design and is 0.035 in. This clearance will accommodate a combined poison assembly and guide tube bow of $0.070 \mathrm{in./20} \mathrm{ft}$ before jamming will be possible. In addition to the alignment pads, fluid dynamic lift forces tend to center the poison assembly in the guide tube. (5) Flow control orifices will have to be sized experimentally when coolant requirements are determined. A series of orifices will reduce erosion and cavitation.

Materials were selected for all poison section components except the poison element. A11 other poison assembly components except the scram assist spring, spool, and poison assembly pads will be made of 304 stainless steel, which is considered the standard structural material for FFFF reactor internals. Colmonoy 4, which was used for the Fermi poison assembly pads, was used in the FFTF design. The spring material selected was Incone $1 \mathrm{X}-750$, but Incone 1718 may be a better choice if sufficient data can be generated on this new a11oy (see Appendix B.)

For the base design it was necessary to make some assumptions as to the location of the poison section with respect to the core when the poison section is in the fully retracted position. The portion of total travel over which the scram assist force should act was also fixed in order to make the base design more definitive. The bottom of the poison section with the rod fully withdrawn was assumed to be 4 in. above the top of the core to reduce its effect on normal reactor operation. The first few inches of poison insertion into the core are the most significant in overcoming an excursion. On this basis, scram assist was provided for the first $10 \mathrm{in}$. of travel at which location the bottom of the poison will be 
inserted 6 in. into the core. The poison is fully inserted into the core after a 37 in. scram stroke. Deceleration occurs over the last 6 in. of travel.

Maximum temperature seen by the poison section components was assumed to be $1200^{\circ} \mathrm{F}$ (the ultimate operating bulk sodium outlet temperature) omitting gamma heating.

The base design is versatile enough to accommodate other poison types and geometries. A hexagonal guide tube and poison assembly represent a possibility if higher compactness is required. The test section could be eliminated with minor modifications. Changes in total trave1, scram assist trave 1 , and poison location in the fully retracted position could be accommodated but would require design modification. Changes in spring length would require only small modifications. Other scram assist devices such as pneumatic and hydraulic devices have been considered but would require considerable modification to the conceptual design.

Description of Scram Operation. The operation of the poison section will now be discussed. In normal reactor operation, the poison assembly is latched and withdrawn as required by the test program. Sodium coolant removes the heat generated in the poison section components due to radiation absorption. Sodium flows into the guide tube from the inlet plenum, through the flow control orifice, and past the dashpot and ram. Above the ram there are two parallel flow paths. One path is through the annular gap between the guide tube and the poison assembly. The other path is through the center of the poison assembly past the poison rods. When an excursion occurs, the poison assembly is unlatched and is accelerated into the core by gravitational and spring forces. It is retarded by fluid drag forces, bouyant forces, and sliding friction forces. In the last six inches of travel the ram enters the dashpot, pressure in the dashpot rises causing the assembly to decelerate to a smooth stop. Deceleration loads 
on the dashpot are transmitted directly to the upper tube sheet thus reducing guide tube stress.

Description of Design Performance. A dynamic and kinematic analysis was made of the poison assembly design to determine approximate scram times, velocities, accelerations, drag forces, dynamic loads, scram assist requirements, etc. The method of analysis is described in Appendix B. The analysis resulted in two computer programs, RODDYN and DRAG, which compute poison assembly dynamics and poison assembly drag coefficients, respectively, for the Modified Fermi Control Rod Design. Listings of these programs are also included in Appendix $B$.

The kinematics for the reference case of the base design are illustrated in Figure 4. Total scram time for the reference case of the base design was calculated at 0.60 second for 37 in. of travel. The time required for the first 10 in. of travel was $0.18 \mathrm{sec}$. Maximum acceleration was $70.1 \mathrm{ft} / \mathrm{sec}^{2}$ and maximum velocity $7.3 \mathrm{ft} / \mathrm{sec}$. Maximum drag force prior to entering the dashpot was $465 \mathrm{lb}$. Constant deceleration was assumed in the dashpot and was calculated at $40.3 \mathrm{ft} / \mathrm{sec}^{2}$ with an associated deceleration force of $867 \mathrm{lb}$. These values were based on an initial spring cocked force of $8001 \mathrm{~b}$ with a preload of $400 \mathrm{lb}$. However, for the reference case of the base design the spring was assumed to have relaxed $25 \%$ to a cocking force of $600 \mathrm{lb}$ and a preload of $200 \mathrm{lb}$. For a description of the reference case of the base design refer to Appendix $B$.

\section{F. DISCUSSION}

One of the goals of this report is to guide future work so that a successful design results. In the course of the study several critical areas in the design have been noted. Also, it has been noted that some modification of the original specifications, if possible, could result in significant improvements in the design. 


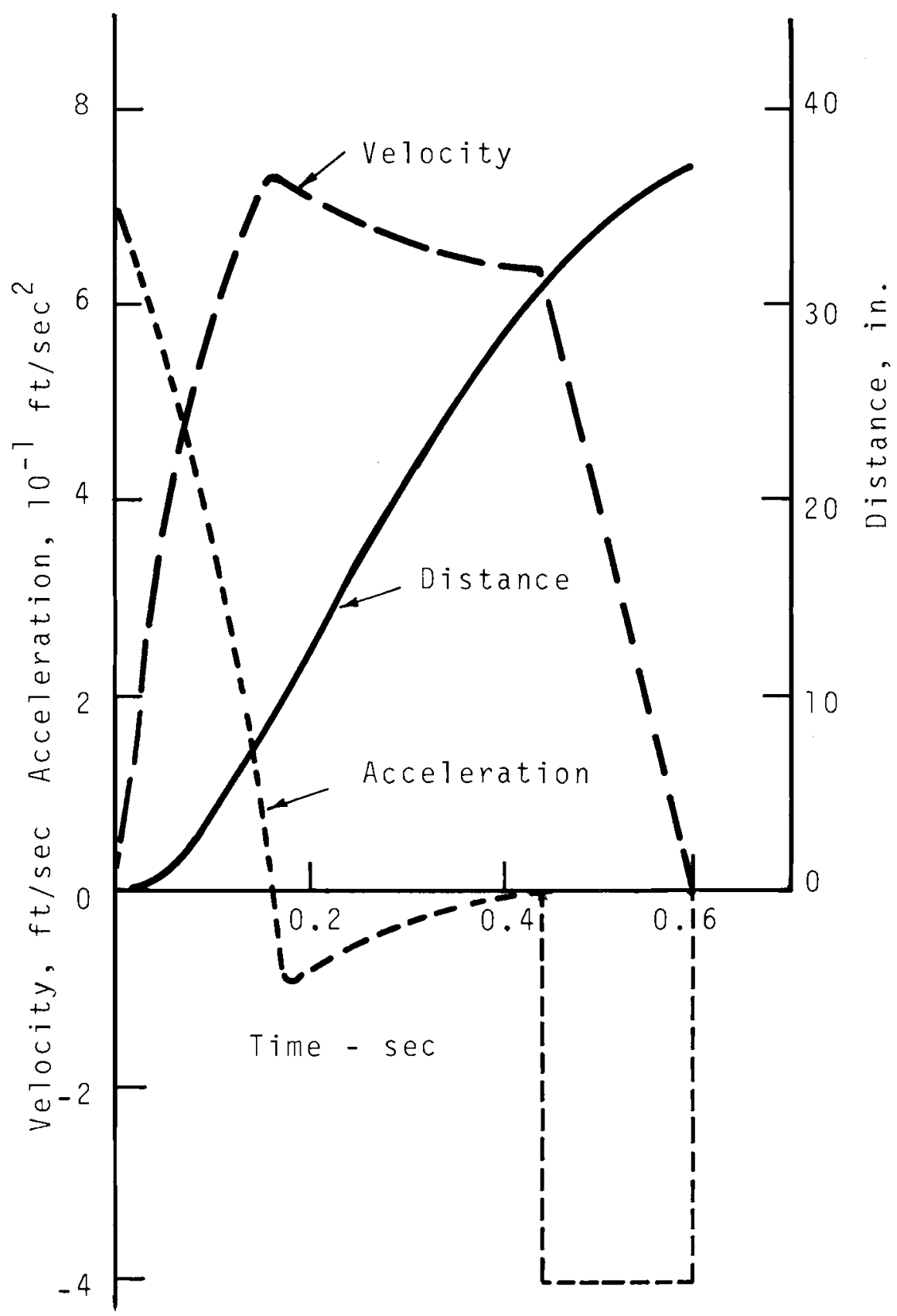

$\underline{\text { FIGURE 4. }}$. Base Design Poison Assembly Kinematics (Reference 


\section{CRITICAL AREAS IN THE DESIGN}

a. Scram Assist Spring

One of the most critical components in the MFCD affecting performance is the scram assist spring. The effects of irradiation, high temperature, and liquid sodium environment on the spring are not predictable, based on currently available spring materials data. There is data available on the effects of high temperature on spring materials, but only limited information on the effects of high temperature and high radiation combined. From the available thermal effects data, an Inconel $\mathrm{X}-750$ spring, if used in the conceptual design, would not relax more than $10 \%$ in one year when subjected to a steady $1200^{\circ} \mathrm{F}$ environment. However, if the combined effects of temperature and radiation are of the same magnitude as with Nimonic $80 \mathrm{~A},(6)$ a similar alloy, spring relaxation could be $60 \%$ in one year. In the conceptual design, $60 \%$ relaxation would mean an increase of $20 \%$ in the time required to scram compared to a spring which had no relaxation.

It is important that two points concerning the spring be resolved. The required scram time must be established so that the need for scram assist can be determined and the combined effects of temperature and radiation on the spring material must be determined in order to make a decision on use of a spring for a scram assist device.

b. Seals

Seals are another critical area in the design. In the FTR three different sealing methods are used. A noncontacting purge type sealing arrangement is used to isolate the cavity above the shielding plug from the cover gas-sodium vapor atmosphere that exists below the shielding plug. Annular clearance requirements, purge gas velocity required, and methods for supplying and disposing of purge gas will have to be resolved through a development and testing program. 
Two metal bellows type seals are specified in the design. One bellows is used to seal the latch rod penetration into the electromagnet case and the other bellows seals the ball screw. Bellows were used in a similar manner on the Fermi Reactor with success. In addition, tests on bellows in the FARET program showed that they can have quite a high cycle life.(7) From experience gathered at the Enrico Fermi Reactor, bellows quality of manufacture is a large factor in successful performance. Reliability testing under simulated operating conditions is recommended. In addition, it is recommended that a pressure monitoring arrangement like that furnished on Fermi be used on the FTR to monitor seal integrity and to prevent an inflow of sodium vapor if a seal were to leak.

For static seals it is anticipated that "O"-ring type organic seals will be employed where temperatures and radiation levels permit. At higher temperatures and radiation levels metal seals will be used. Proper application of the seals and prototype testing under anticipated operating conditions should result in reliable seals.

\section{c. Rod Position Indication During Scram}

Rod position indication is tied to drive rotation. When scrammed, the poison section uncouples from the drive, and rod position indication is lost until the drive is run down to recontact the poison section in the full-in position. It is desirable to have rod position indication at all times, but it appears that any mechanical attachment to the poison section to give position readout during scram would reduce reliability of the system. Noncontacting position indication is a possibility if a sensor capable of withstanding the severe environment can be developed. One possible scheme would be to monitor the backpressure in a manifold that would supply sodium to a series of ports located along the guide tube. As the poison section moved down through the guide tube it would 
close off the ports and thus increase the manifold backpressure. Backpressure could then be correlated to rod position. This scheme would depend upon the availability of a suitable pressure transducer and sufficient space for the manifold connecting the ports.

Future work on the Modified Fermi Conceptual Design should include consideration of possible continuous position indication schemes.

\section{d. Lubrication}

Certain components in the drive extension section and drive section must be lubricated. It is anticipated that those components below the drive coupling that require lubrication be treated with $\mathrm{MoS}_{2}$ or other suitable dry lubricant. This includes the electromagnet armature self-aligning bearing, the electromagnet sliding surfaces, the ball screw, the ball nut, and the drive coupling. Those components above the drive coupling would be lubricated with high temperature, radiation resistant grease. Components above the drive coupling include the drive motor, shaft encoder, planetary speed reducer, potentiometer and rotary limit switch.

Ball screw life should be tested under anticipated environmental and lubrication conditions.

e. Lead Wires and Electrical Connectors

Lead wires and remote electrical connectors present a significant design problem. Lead wires from the electromagnet and limit switches must withstand the high temperature environment in the drive cavity and accommodate the 39 in. of relative movement between the electromagnet and the drive head. It is proposed that the lead cable be shielded with a stainless steel sheath which is coiled into a helical spring, one end attached to the drive head and the other attached to the electromagnet. The helical section is to be guided on the inside diameter with the bal1 nut reaction torque tube. 
Additional design work is required on this concept and then a prototype assembly will be built and tested.

Connector requirements are dependent on whether or not remote handling is required. If manual connection is sufficient, commercially available sealed connectors should be suitable. However, if remote connection is required, special connectors will be necessary. In the remotely connected arrangement, connectors will be required to connect from the inner drive section cover to the connector mounted on the position readout component mounting frame, from the inner cover to the outer cover, and from the reactor room to the outer cover. The most difficult connector will be the unit which connects the inner and outer covers because it must accommodate 1 in. of movement between the two covers. f. Latch Mechanical Interferences

The original Enrico Fermi Reactor latch design jammed, causing the fingers to be bent during in-sodium tests. The latch had been successfully operated in air and water prior to the sodium tests. Malfunction was traced to mechanical interferences which were the result of insufficient clearances between moving parts and insufficient bevel angles on interacting parts. Large scale layouts of the parts showed these interferences. When the parts were modified to eliminate these interferences, no further problems were encountered. On the Modified Fermi Reactor latch, large clearances have been allowed and interacting parts have been beveled to ease engagement. To validate satisfactory performance it is recommended that the latch be tested in sodium.

g. Assembly and Disassembly

Assembly and disassembly of the control rod components must be further refined. The approach taken was to build modules which could be gaged for various dimensional settings 
and then combined to make up the overall assembly. It will be necessary to know what the requirements are concerning remote handling before the final assembly and disassembly sequences can be worked out for the control rod.

2. SUGGESTED SPECIFICATION MODIFICATIONS TO IMPROVE THE DESIGN

It is possible to make several improvements in the conceptual design by modifying the original specifications. These possible improvements are outlined so that they may be kept in mind if and when changes are made to the specifications.

a. Shorter Poison Section Stroke

Presently, specifications call for the bottom of the poison elements to be 4 in. above the core when the rod is fully withdrawn. If this could be changed to 4 in. below the top of the core for the safety rods, scram time could be reduced about $25 \%$. In addition, the height of the drive assembly could be reduced by the 8 in. reduction in stroke.

b. Eliminate or Perforate Material Test Section

Reduction of fluid drag on the poison section by either eliminating or perforating the material test section between the ram and the poison elements would reduce scram time.

c. Increase Guide Tube Diameter Above the Top of the

Sodium Pool

An increase in outside diameter of the guide tube from 5.25 to $6.25 \mathrm{in}$. by elimination of the guide liner tube would allow considerably more space for the drive and drive extension sections.

\section{ALTERNATE COMPONENT DESIGN IDEAS}

During the conceptual study a number of alternate component designs were considered. The following discussion describes alternate component designs considered and the reasons why they weren't used. 


\section{a. Reaction Torque Restraining Device}

With a translating nut type linear actuator, the nut must be restrained from rotating in order to cause it to translate.

The first approach taken was to use trunnion mounted needle bearing cam followers running in guide slots. Insufficient diameter space made this approach unusable. The approach finally selected was to have a stationary hexagonally shaped tube guiding a sliding inner hexagonally shaped tube connected to the ball nut. In addition, this arrangement uses the two hexagonal tubes to guide the electromagnet lead wires. b. Latch Rod Bellows Sea1

The Enrico Fermi latch rod had an upper and lower bellows seal. The lower bellows was immersed in sodium. On the Modified Fermi design the lower bellows seal was eliminated. It was felt that the potential disadvantages associated with a bellows immersed in $1200{ }^{\circ} \mathrm{F}$ sodium would far outweigh the advantages of two bellows seals.

c. Spring Scram Assist

Alternatives to the single spring scram assist design are designs incorporating multiple springs in a nested or nonnested arrangement and acting in series or parallel. Both parallel and series arrangements of multiple springs can result in shorter lengths than a single spring arrangement for the same maximum shear stress, spring constant, stroke, preload, and envelope diameter. The reduction in length would mean that the bottom of the multiple spring arrangements could be located at a distance farther above the core than the single spring arrangement, and thus alleviate possible spring relaxation problems due to high irradiation.

This advantage is offset by the increase in complexity resulting from an increase in the number of springs, and the 
problems associated with fastening them together and keeping them aligned. Another disadvantage of multiple springs is the increase in drag on the poison assembly due to a reduction in flow area.

The single spring arrangement was chosen for the conceptual design because of its inherent simplicity and lower drag. If spring relaxation due to irradiation proves to be too severe for the long single spring design, then a multiple spring design will have to be reconsidered.

\section{G. RECOMMENDATIONS}

1. At this time there are insufficient materials data to predict the scram assist spring's performance in an environment of sodium, high temperature (ultimate operating conditions), and radiation. Since the spring is an integral part of the Modified Fermi Conceptual Design, assurance that it will perform satisfactorily is essential. Therefore, it is recommended that alternate scram assist schemes be considered. This could mean using a device other than a spring or locating the spring out of the severe environment. The selection of an alternate scram assist scheme will probably mean a large modification of the drive design. Care must be taken to retain the desirable features now present in the design.

2. It is recommended that a study be undertaken to determine the effects of sodium, high temperature, and radiation on spring materials. If the study gives assurance that a spring will function satisfactorily in the environment, it would be possible to use it as originally planned.

3. To proceed to detailed design of a prototype control rod, the following points must be resolved.

a. Maximum allowable scram time must be established.

b. Those factors affecting scram time such as stroke, sodium flow rate, poison section geometry, and poison assembly weight must be finalized. 
c. Temperature and radiation profiles must be established to be sure that components selected are suitable.

d. Remote handling requirements must be established.

4. Problem areas outlined in the discussion section must be resolved through a combined development and test program. Problem areas include seals, lubrication, lead wires and connectors, latch interferences, assembly-disassembly of the control rod, and position indication of the poison section during scram.

5. In order to determine design requirements for the scram assist device and decelerator, it is necessary to know the dynamics of the poison assembly along its full scram stroke. Analytical work and the resulting computer programs, RODDYN and DRAG, used to compute the poison assembly dynamics and kinematics of the Modified Fermi Control Rod Design have thus far been based on the assumption of constant drag force coefficients during a scram and constant deceleration in the dashpot (see Appendix B). This limits the ability to predict poison assembly performance and leaves no provision for the design of ram geometry. The effects of variable flow path geometry and variable friction factors on drag coefficients could be accounted for by computing the drag coefficients as a simultaneous part of the solution to the equations of motion. This will be done by integrating the DRAG program into the RODDYN program. The deceleration force in the dashpot should be derived and incorporated into the RODDYN computer program so deceleration performance could be predicted and ram geometry determined. Scram performance from any position of rod withdrawal could also be evaluated with this modification in the program.

To validate the relationships derived, it is recommended that the following tests be performed using water to simulate the sodium coolant. 
a. Measure pressure drop across the ram for different annular clearances, flow velocities, and ram insertion depths into the dashpot. This static test will be performed to determine the correctness of analytical relationships previously derived to describe the pressure drop across the ram in terms of annular clearance, flow velocity, and ram insertion depth.

b. Perform dynamic tests with the goal of obtaining correlation between analytically predicted and actual performance. Drop tests will be performed with the ram and dashpot, during which ram dynamics for different ram entrance velocities, annular clearances, and weights could be monitored.

c. To verify poison assembly pressure drop calculations, a simulated poison assembly should be statically tested for pressure drop at different flow velocities.

d. A prototype poison assembly incorporating the optimized ram should be tested to verify predicted scram time. 
BNWL -970

\section{APPENDIX A}

\section{DESIGN DRAWINGS}

SK-3-12881

SK $-3-13288$

SK-3-13278 Sheets 1 through 15

A -1 


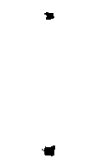




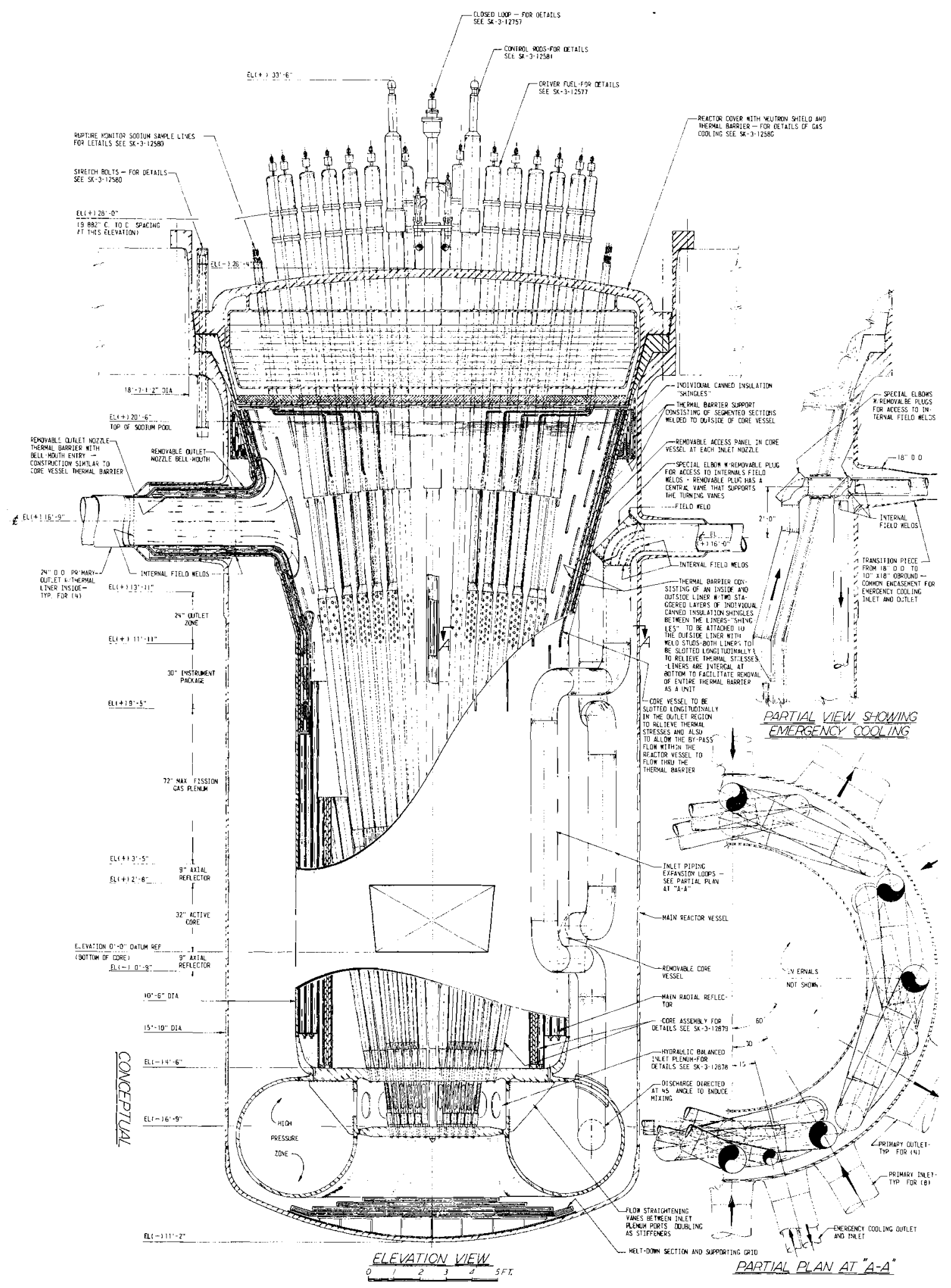



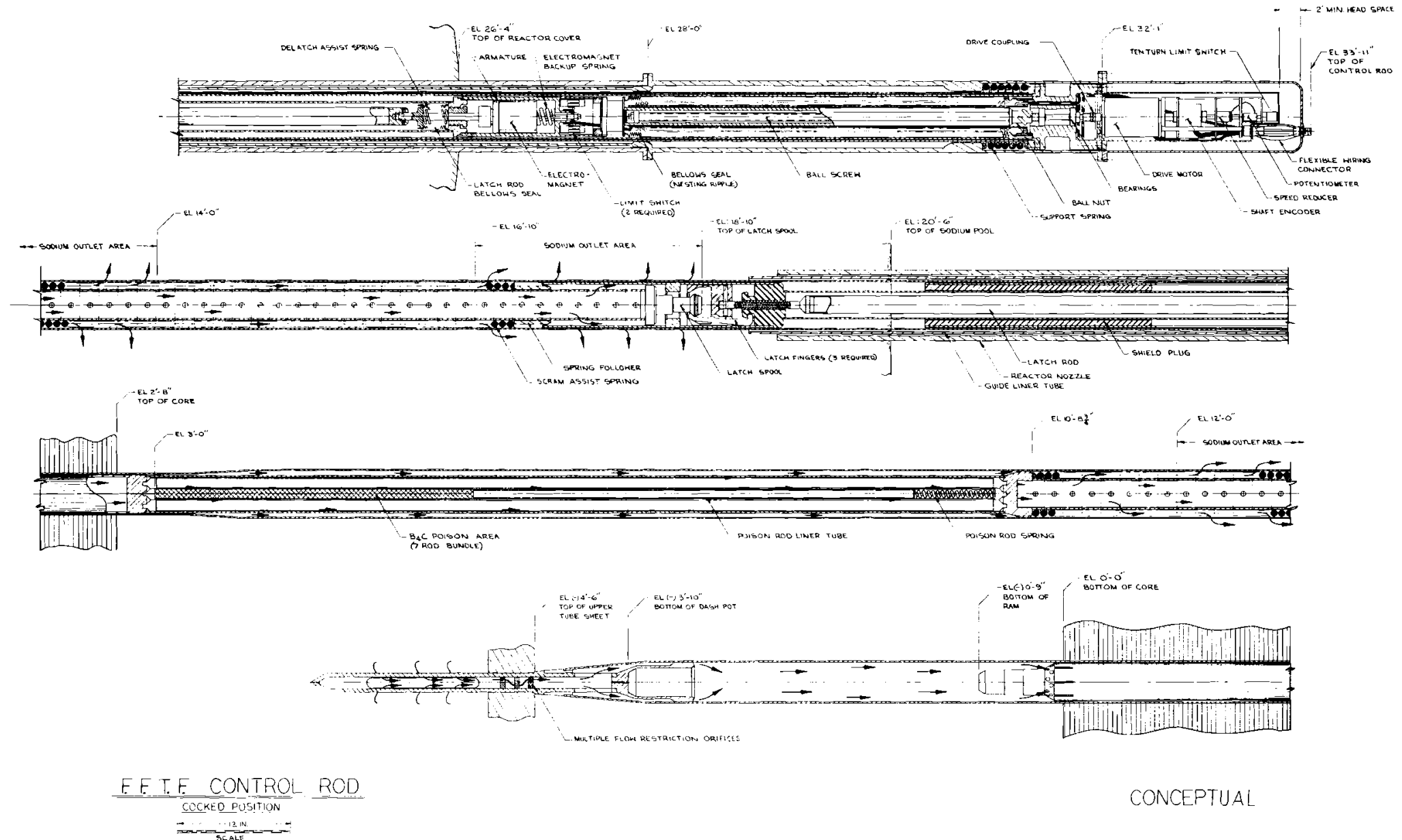


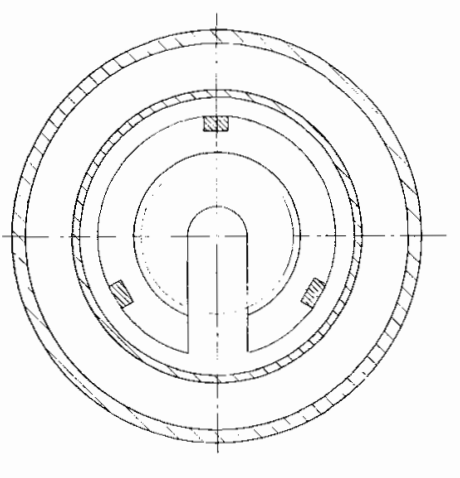

SECTION (: - C:

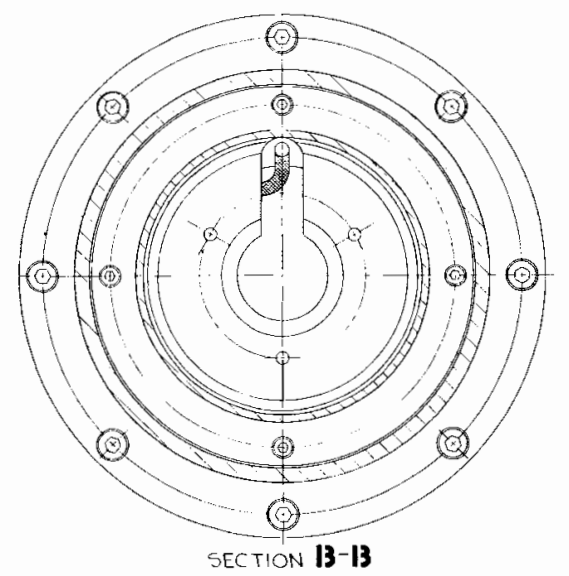

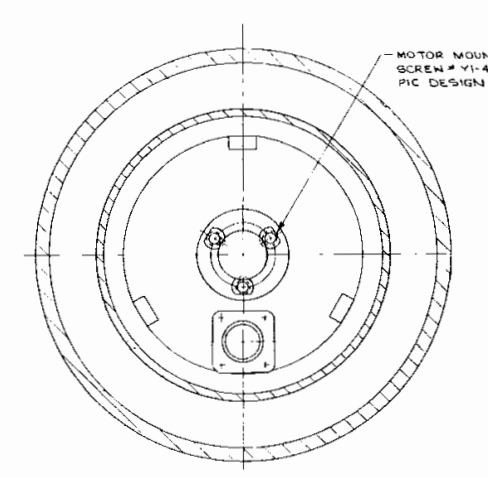

SECTION A-A

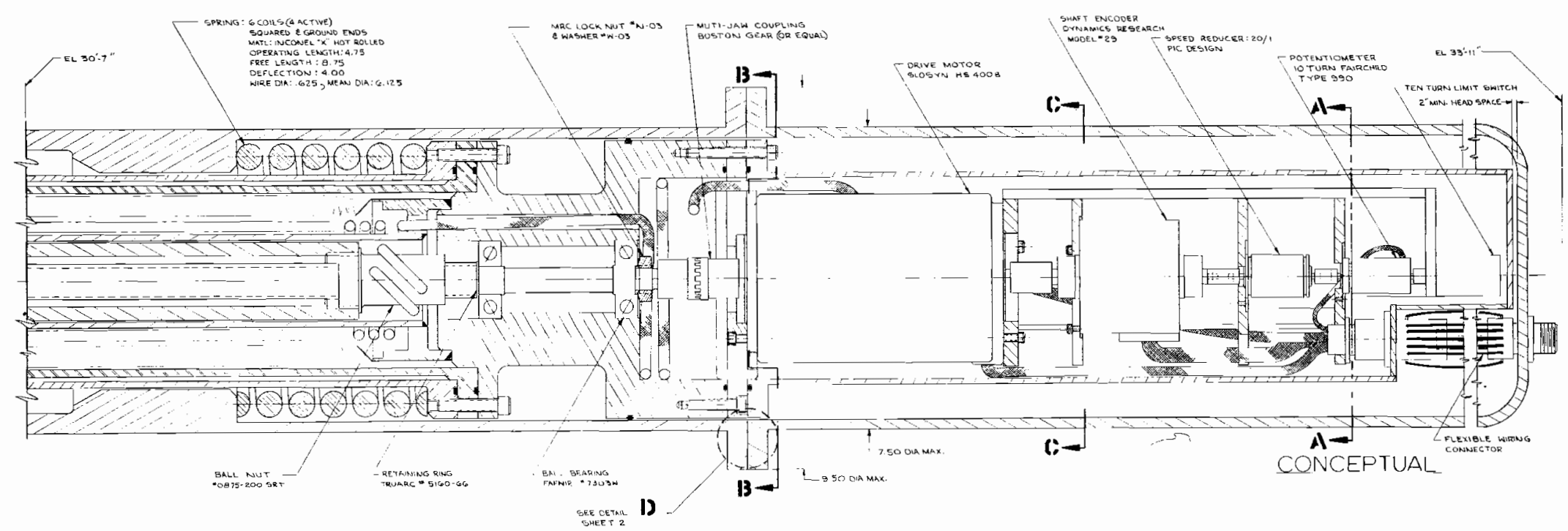

$S K-3-13278$

Sheet 1 of 15 


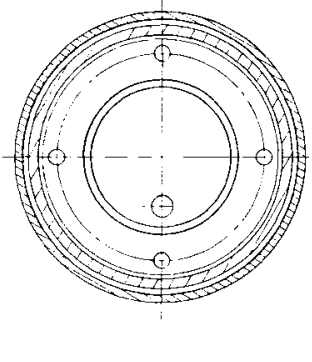

section F-je

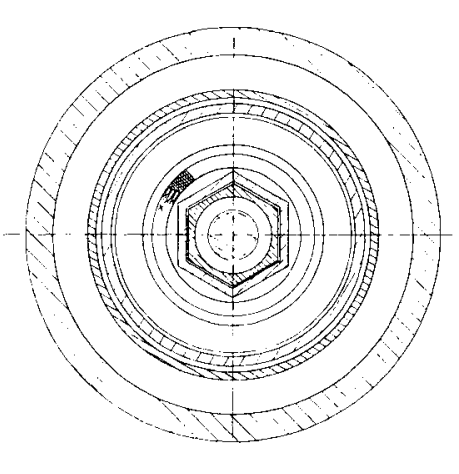

SECTION IE-IE

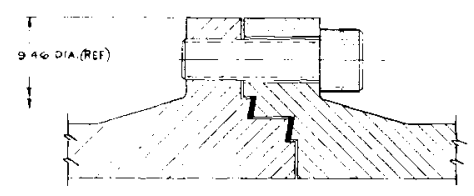

DETAIL D

2 


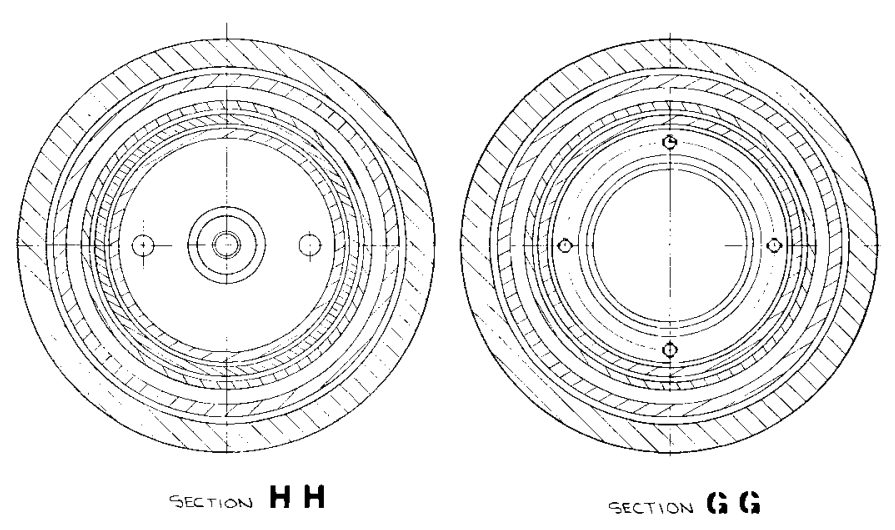

i

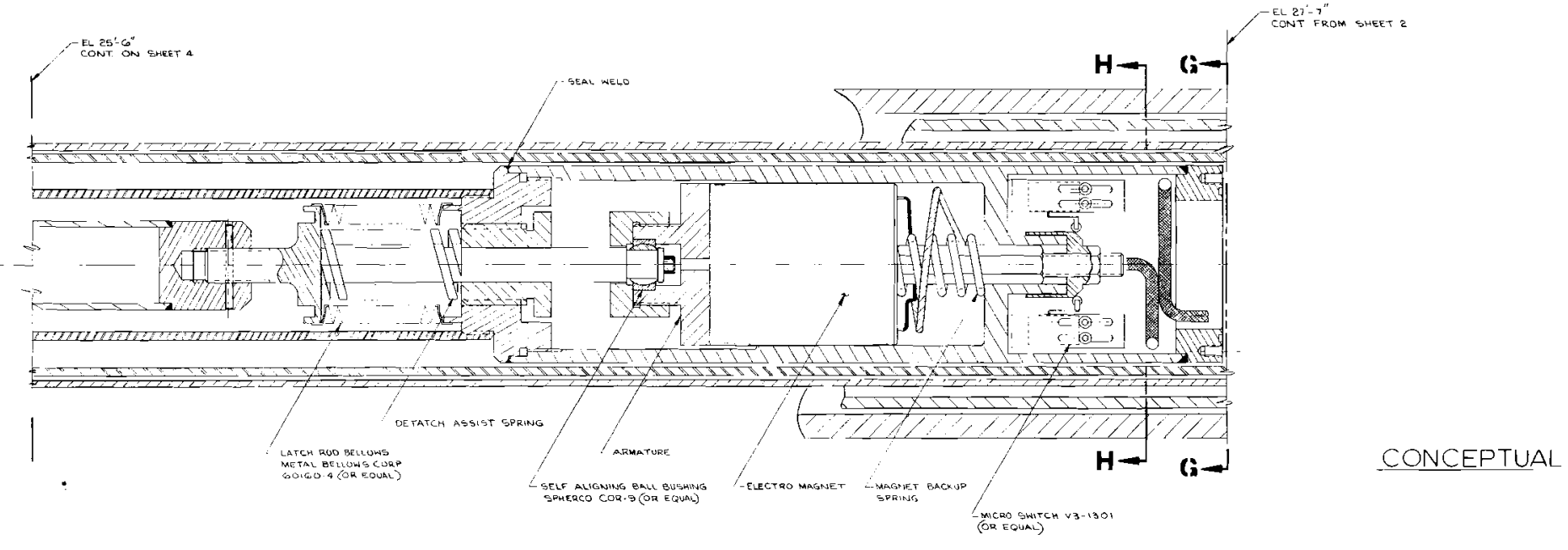




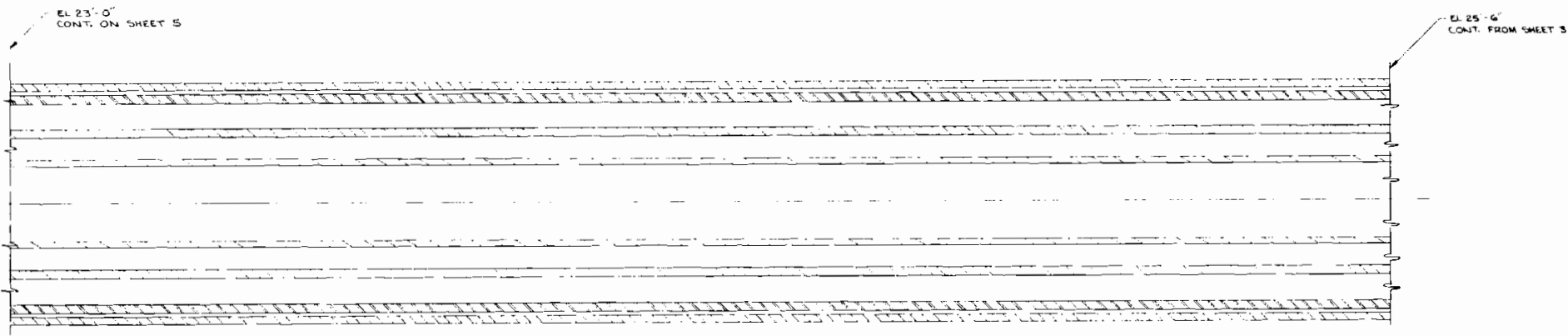

CONCEPTUAL

$S K-3-13278$

Sheet 4 of 15 

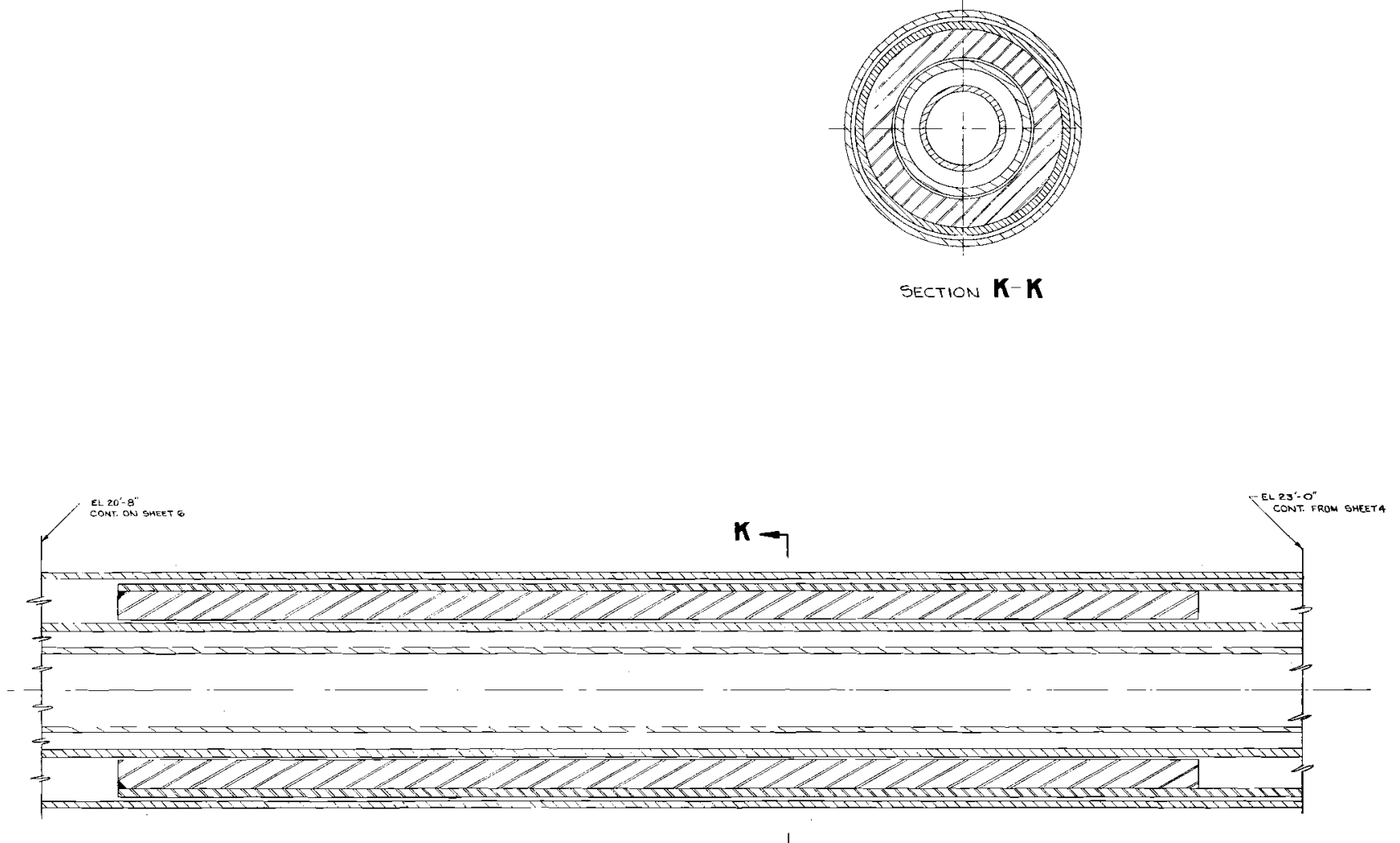

$k-$

CONCEPTUAL

$S K-3-13278$

Sheet 5 of 15 

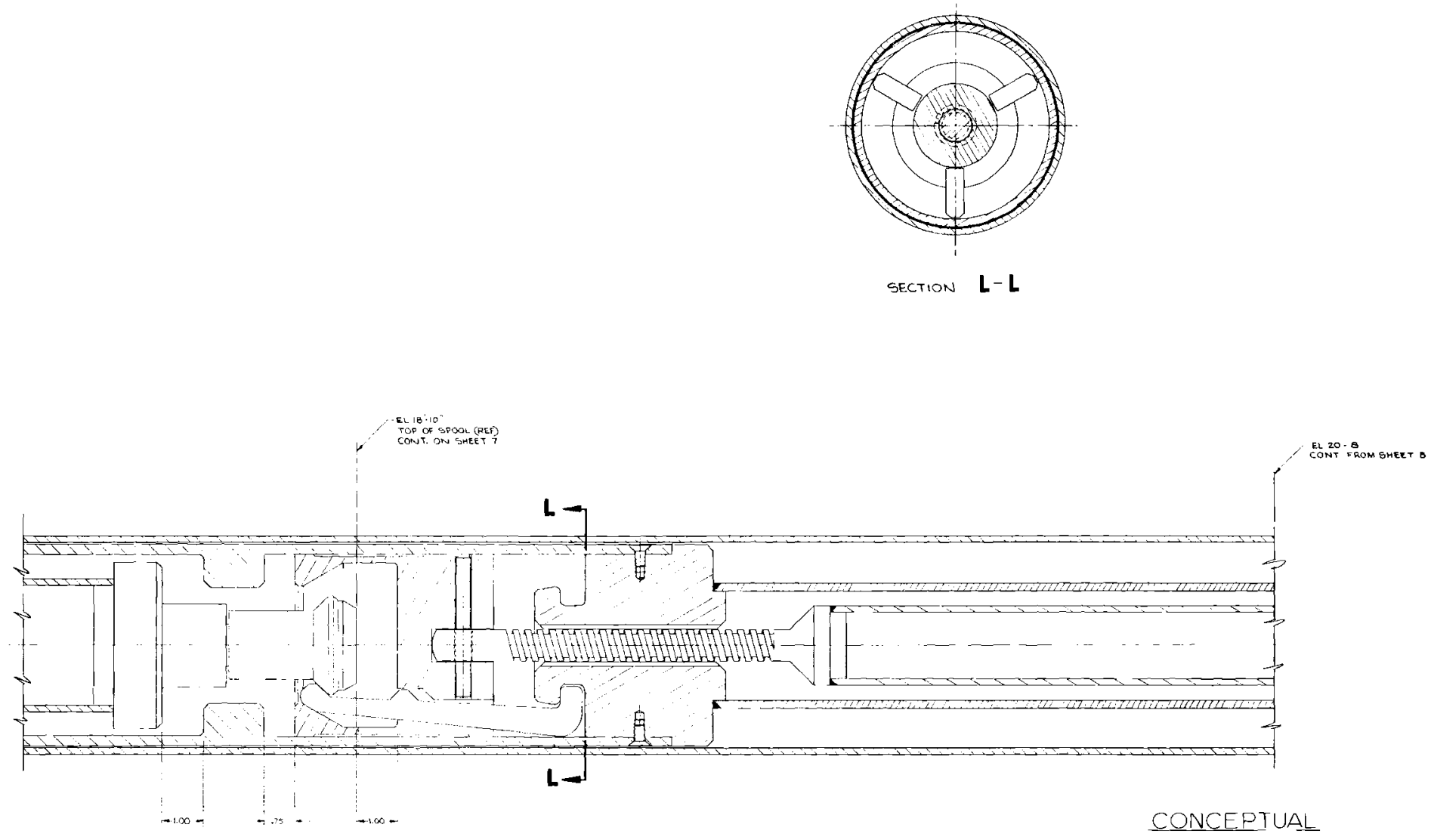

$S K-3-13278$ Sheet 6 of 15 

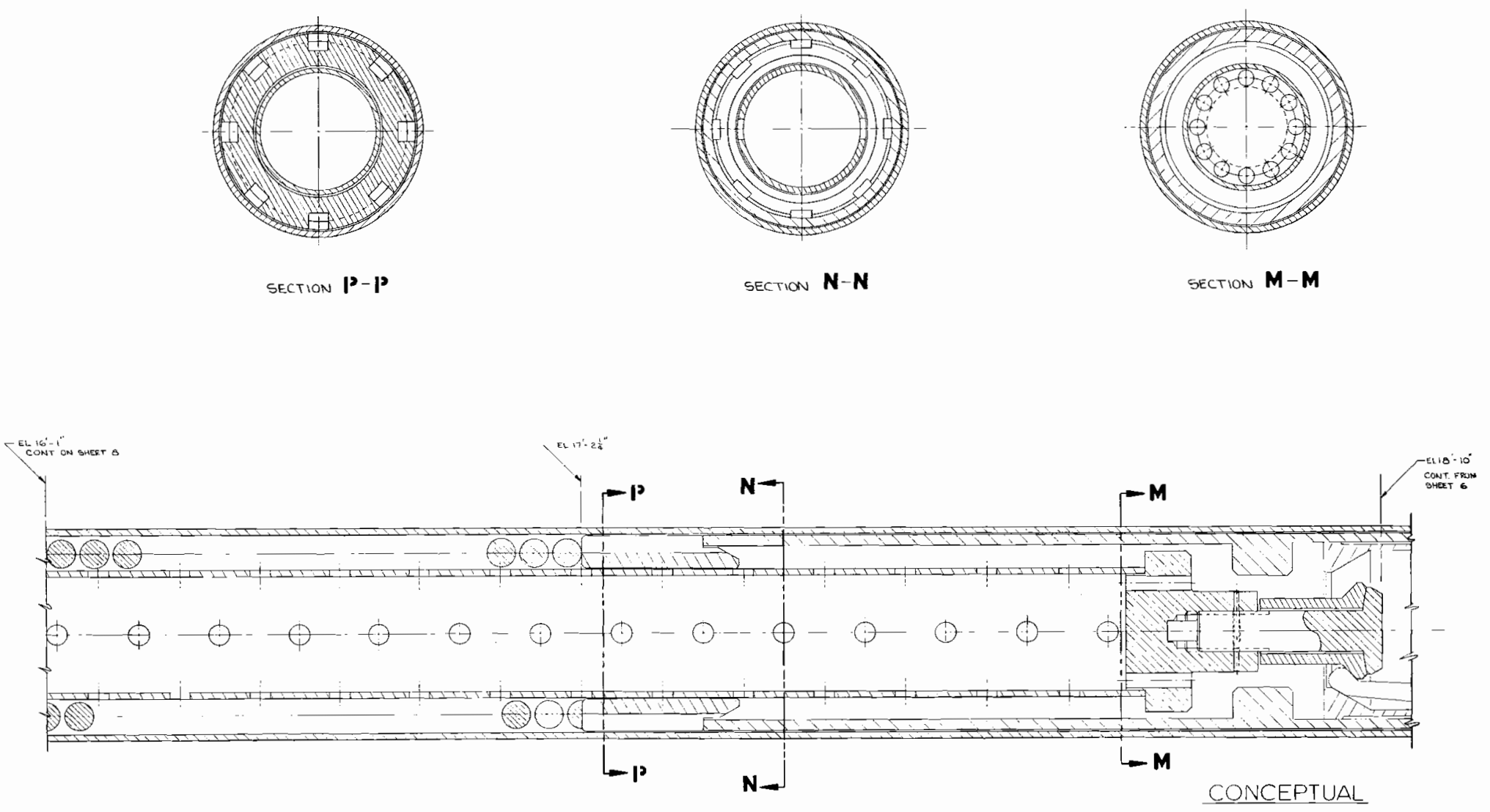

$S K-3-13278$

Sheet $?$ of 15 
$P$
1
0

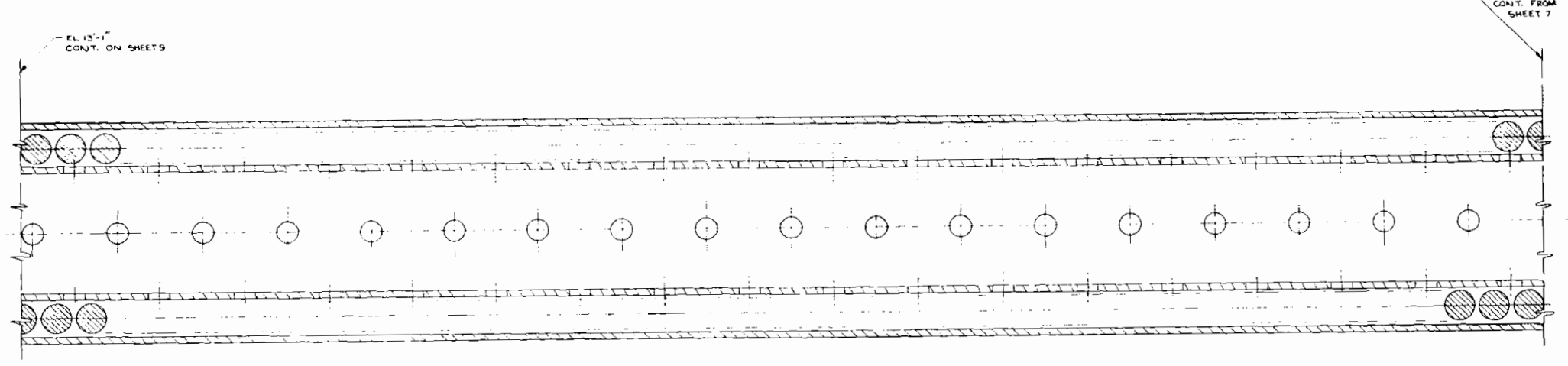

SONCEPIUAL

$S K-3-13278$

Sheet 8 of 15

$\square$
2
2
1
6
0
0 
$\stackrel{?}{\bullet}$
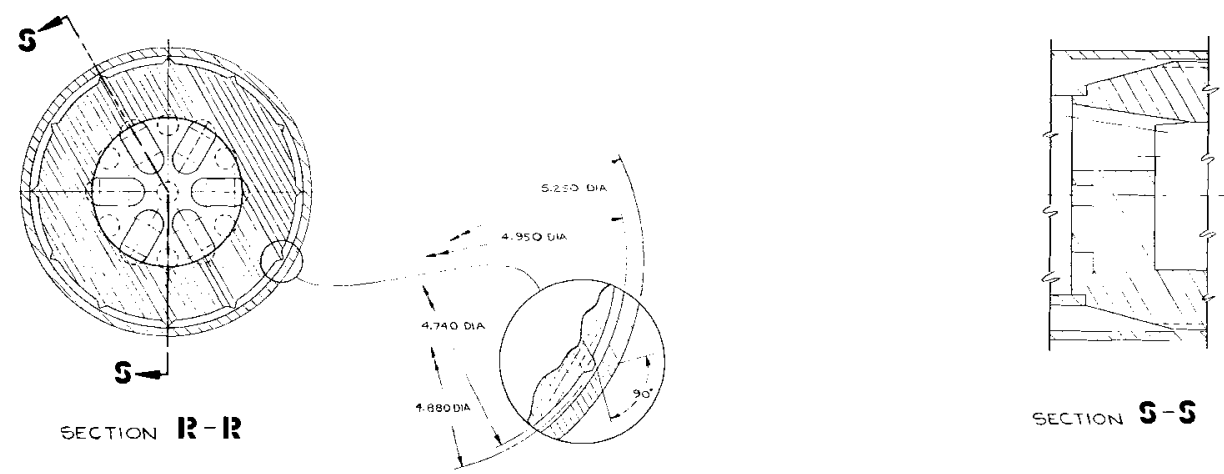

Section 3-3

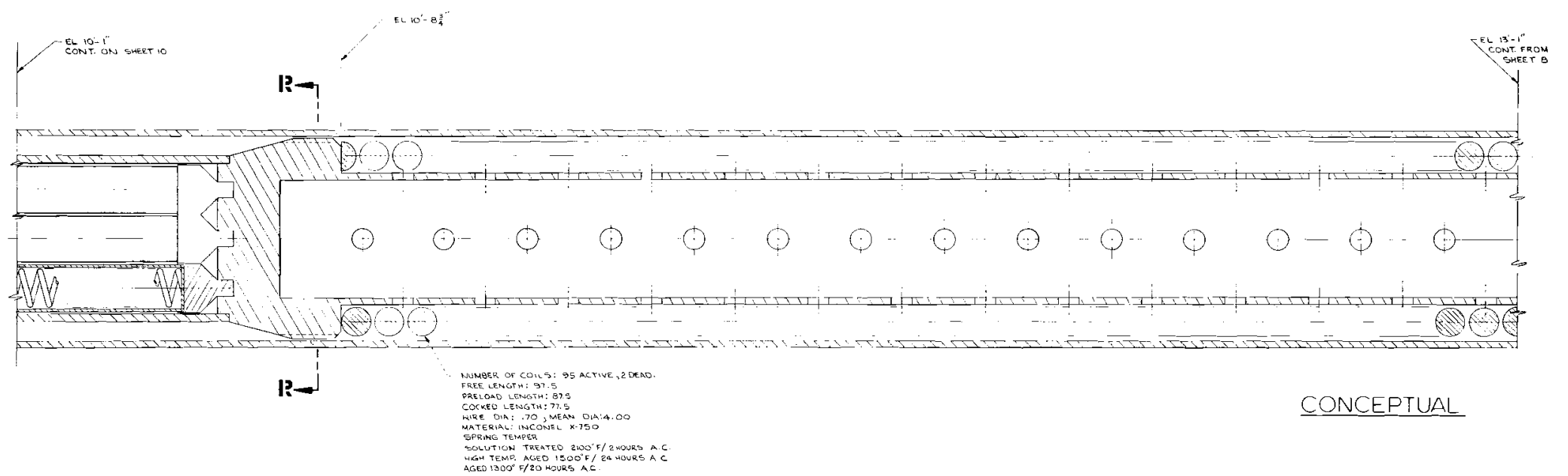

$S K-3-13278$

Sheet 9 of 15 


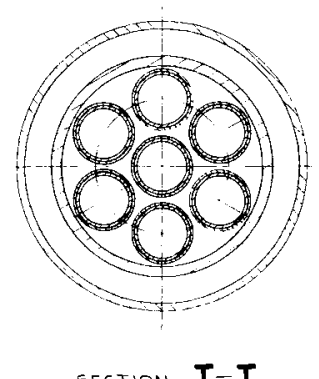

Section $\boldsymbol{T}-\boldsymbol{T}$

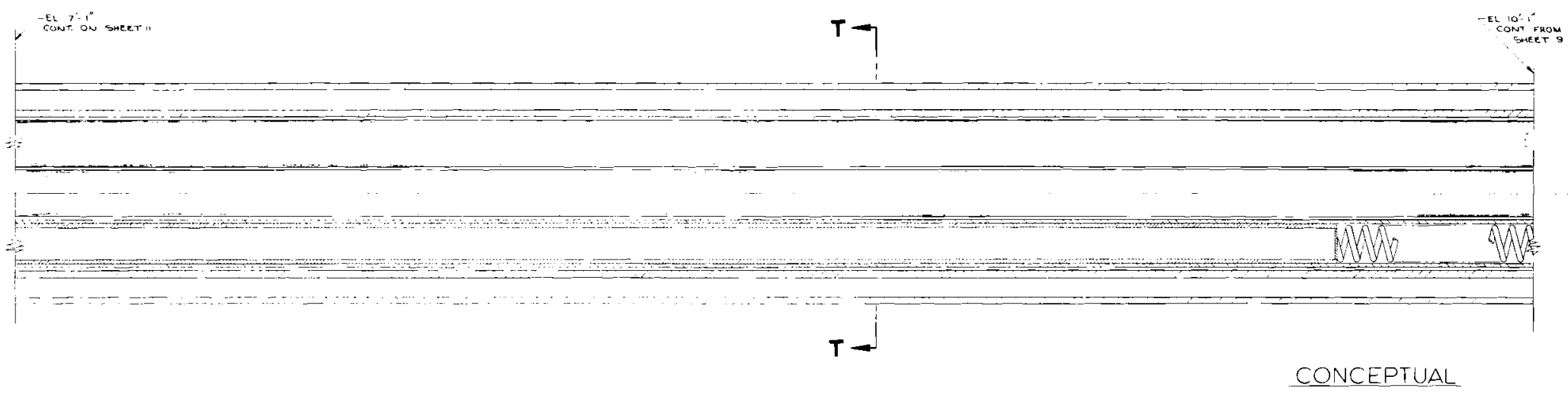

$S K-3-13278$

Sheet 10 of 15 


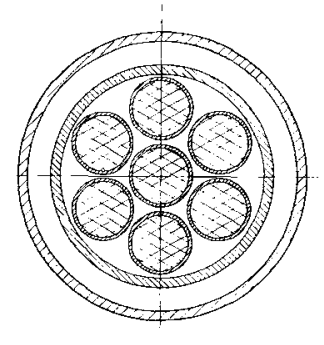

section U-U

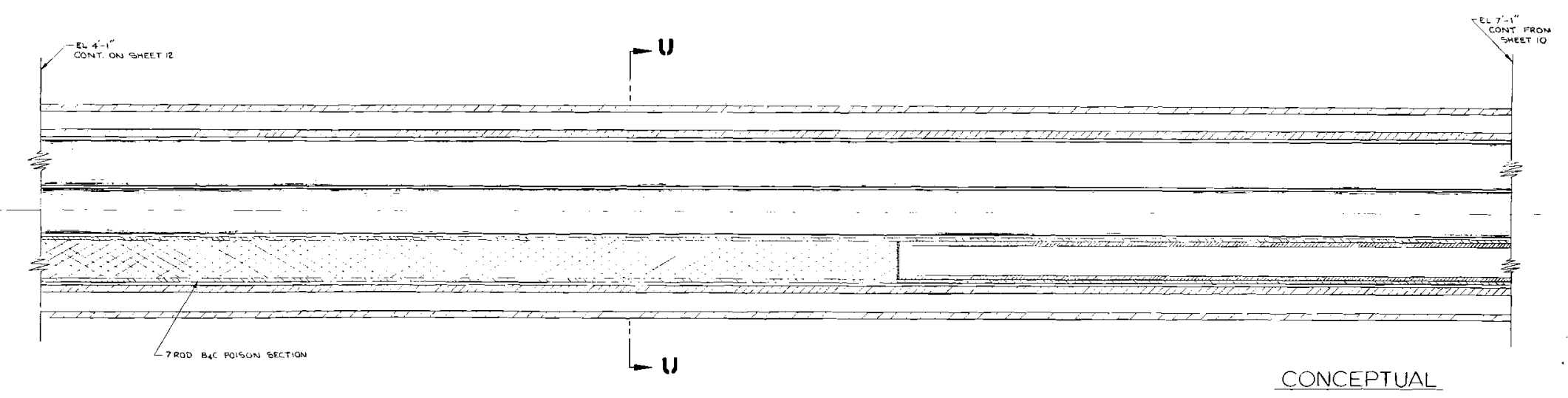

$S K-3-13278$

Sheet 11 of 15 


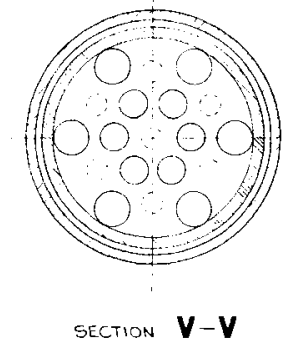

$\stackrel{?}{\stackrel{5}{口}}$

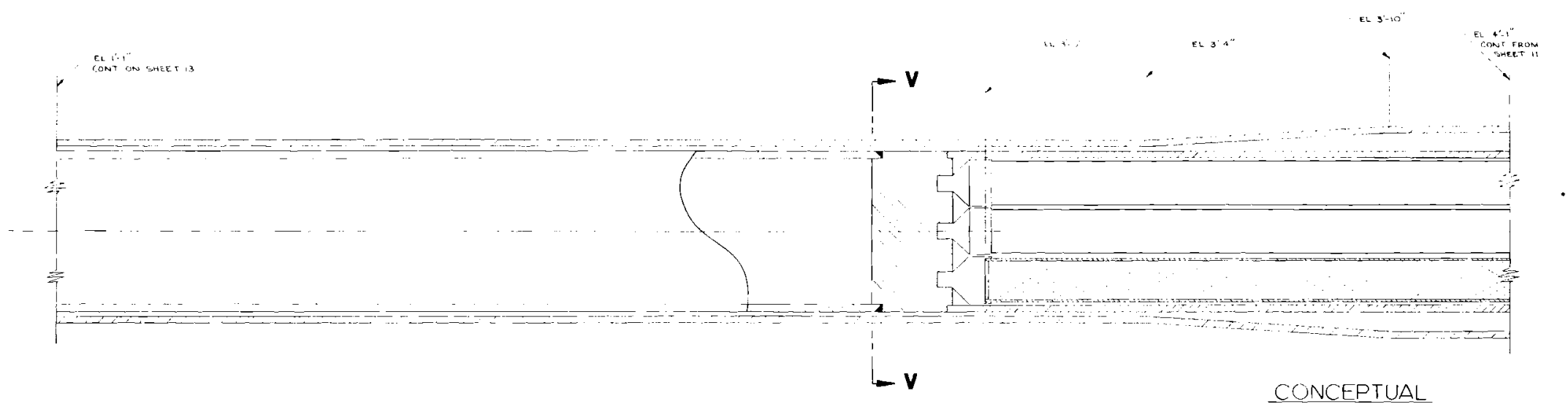

$S K-3-13278$

Sheet 12 of 15

兰
$\vdots$
1
0
0 
$?$
年
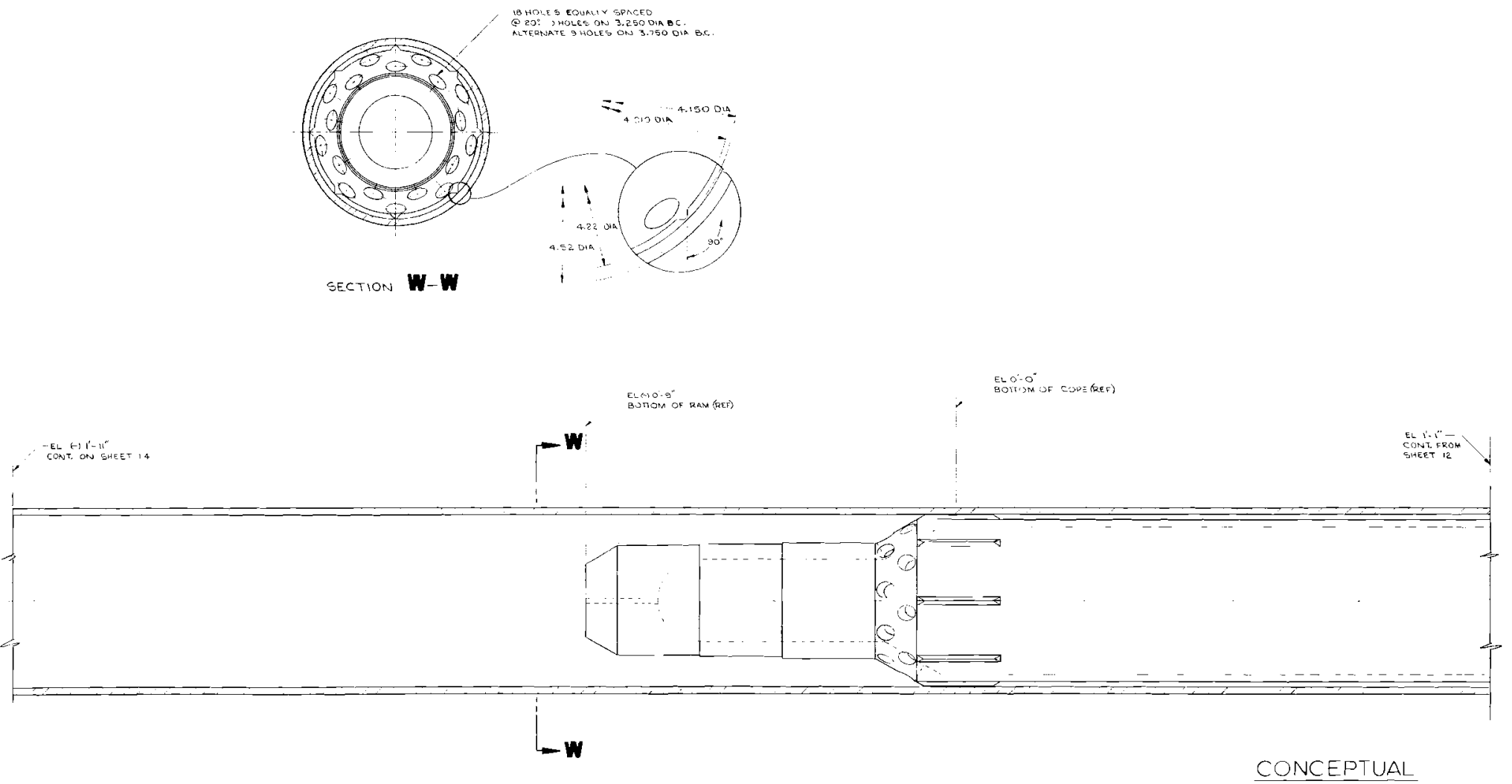

$S K-3-13278$

Sheet 13 of 15 


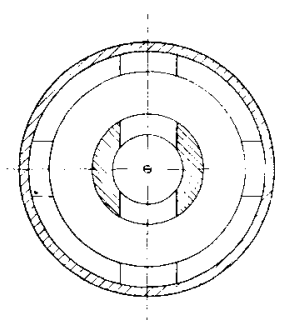

SECTION $\mathbf{Y}-\mathbf{Y}$

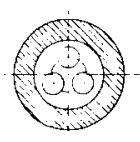

Section $\mathbf{Z}-\mathbf{Z}$

2
1
0

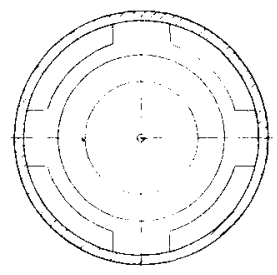

SECtion $\mathbf{X}-\boldsymbol{X}$

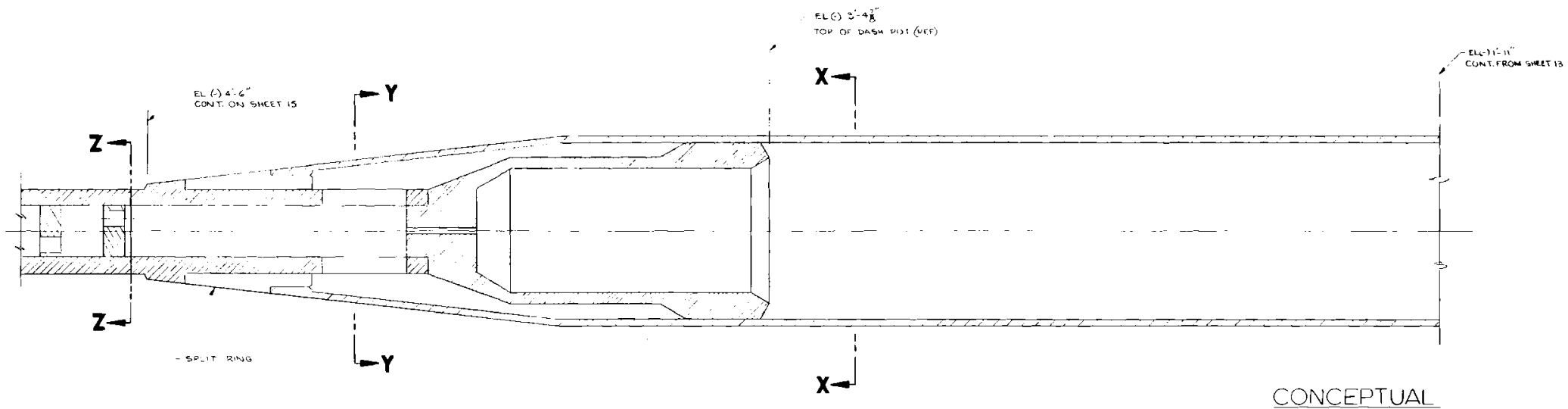

CONCEPTUAL

$S K-3-13278$

Sheet 14 of 15

$\sum^{\infty}$
1
0
0
0 

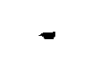

- 


\section{APPENDIX B}

ANALYSIS AND CALCULATIONS 


\section{APPENDIX B \\ ANALYSIS AND CALCULATIONS}

DESIGN ANALYSIS

An analysis was made of the dynamics and kinematics of the poison section during a scram so that the performance of the base design and modifications to the design could be evaluated. The equations of motion for the poison assembly and the drag force on the assembly were derived. Computer programs were written to compute drag force coefficients and to numerically solve the equations of motion. In addition, a limited parametric study was made.

EQUATIONS OF MOTION FOR POISON ASSEMBLY

$\sum$ Forces $=$ Time rate of change of momentum

or

$$
\begin{aligned}
\sum F & =\frac{d(M V)}{d t} \\
X & =\int V d t \\
A C & =\frac{d V}{d T}
\end{aligned}
$$

where

$$
\begin{aligned}
\sum \mathrm{F} & =\text { Summation of forces on the assembly } \\
\mathrm{AC} & =\text { Acceleration of the assembly } \\
\mathrm{V} & =\text { Velocity of the assembly } \\
\mathrm{X} & =\text { Distance traveled by the assembly } \\
\mathrm{M} & =\text { Mass of the assembly } \\
\mathrm{T} & =\text { Time }
\end{aligned}
$$

There are several major forces which may act on the poison assembly. These are a spring force, the assembly weight, bouyant force, a sliding friction force, and a fluid drag force. A constant scram assist force was also included to make the analysis more general. Substituting, we have 


$$
\begin{aligned}
\sum F= & K(S-X)+W-F b-F r i c t+F c o n \\
& -F d r a g=M \frac{d V}{d T}
\end{aligned}
$$

where

$$
\text { Fdrag }=C_{a} \frac{d V_{r}}{d T}+C_{v} V_{r}^{2}, V_{r}=V-V_{f g t}
$$

and

$$
\begin{aligned}
& K=\text { Spring constant } \\
& S=\text { Distance spring is compressed in the cocked } \\
& \text { position } \\
& W=\text { Poison assembly weight } \\
& \mathrm{Fb}=\text { Bouyant force } \\
& \text { Frict }=\text { Sliding friction force } \\
& \text { Fcon }=\text { Constant scram assist force } \\
& \text { Fdrag = Fluid drag force } \\
& \mathrm{V}_{\mathrm{r}}=\text { Velocity of poison assembly relative to the } \\
& \text { velocity of the fluid in the guide tube ahead of } \\
& \text { the assembly } \\
& V_{f g t}=\text { Velocity of the fluid in the guide tube ahead of } \\
& \text { the assembly } \\
& \mathrm{C}_{\mathrm{a}}=\text { Drag coefficient due to acceleration of the fluid } \\
& \text { with respect to time } \\
& \mathrm{C}_{\mathrm{v}}=\text { Drag coefficient due to viscous fluid effects } \\
& \mathrm{G}=\text { Gravitational acceleration. }
\end{aligned}
$$


The exact solution of these equations for location, velocity, acceleration, and drag force as a function of time is not known. An approximate solution was obtained by expressing the equations in finite difference form and programming a digital computer to perform the required numerical integrations and differentiations. In finite difference form we have:

$$
\begin{aligned}
K\{S & \left.-\frac{[X(I)+X(I+1)]}{2}\right]+W-F_{B}-\text { Frict }+ \text { Fcon } \\
- & C\left\{\frac{V(I+1)-V(I)}{\Delta T}\right\}-\frac{C_{v}}{4}\left[V(I)-V_{f g t}+V(I+1)-V_{f g t}\right]^{2} \\
& =\frac{W}{G}\left\{\frac{V(I+1)-V(I)}{\Delta T}\right\}, \\
X(I+1) & =X(I)+\{[V(I+1)+V(I)] / 2\} \Delta T . \\
A C(I+1 / 2) & =[V(I+1)-V(I)] / \Delta T, \\
\Delta T & =T(I+1)-T(I),
\end{aligned}
$$

where the spring force during a time increment, $\Delta \mathrm{T}$, is taken as the average of the force at $T(I+1)$ and $T(I)$. The velocity used in calculating the viscous drag force is derived similarly. Substituting for $X(I+1)$ and simplifying we can solve the resulting quadratic for $V(I+1)$.

$$
V(I+1)=\frac{-B \pm \sqrt{B^{2}-4 C A}}{2 A}
$$

where,

$$
\begin{aligned}
& A=\frac{-C_{v} \Delta T}{4} \\
& B=\frac{-K \Delta T^{2}}{4}-C_{a}-\frac{V(I) C_{v} \Delta T}{2}+V_{f g t} C_{v} \Delta T-\frac{W}{G} \\
& C=K S \Delta T-K X(I) \Delta T-\frac{K V(I) \Delta T^{2}}{4}+W \Delta T-F_{b} \Delta T+C_{a} V(I)
\end{aligned}
$$




$$
\begin{aligned}
& -\frac{C_{v} \Delta T V(I)^{2}}{4}+C_{v} \Delta T V(I) V_{f g t}-C_{v} \Delta T V_{f g t}{ }^{2} \\
& +\frac{W V(I)}{G}-\text { Frict } \Delta T+F \operatorname{Fcon} \Delta T .
\end{aligned}
$$

of the two possible roots

$$
V(I+1)=\frac{-B-\sqrt{B^{2}-4 C A}}{2 A},
$$

describes the velocity of the poison assembly.

Previous experimental work by Battelle-Northwest has shown that constant deceleration can be approximated during travel in the dashpot. The kinematic and dynamic analysis of the poison assembly was based on constant deceleration in the dashpot.

A listing of the computer program RODDYN, which calculates poison assembly kinematics and dynamics, is included (Figure B-1). Input variables with associated dimensional units are defined at the beginning of the listing. The accuracy of the numerical solution depends on the size of the time step. Time steps of $0.01 \mathrm{sec}$ were shown to give a close approximation to the solution for cases solved in the parametric study. This was demonstrated by comparing the solutions for time steps of 0.01 and $0.001 \mathrm{sec}$.

\section{FLUID DRAG FORCE}

The fluid drag force on the poison assembly during a scram can only be determined exactly by actual experimentation. However, an approximation to the actual drag forces can be obtained by considering the fluid dynamics involved.

The force acting on a submerged body moving relative to an undisturbed stream is equal to the sum of the surface integral of normal pressure and the tangential shear stresses acting on it. The drag force is the component of that force in the direction of the flow of the undisturbed fluid relative to the body. The lift force is the component normal to the drag force. 


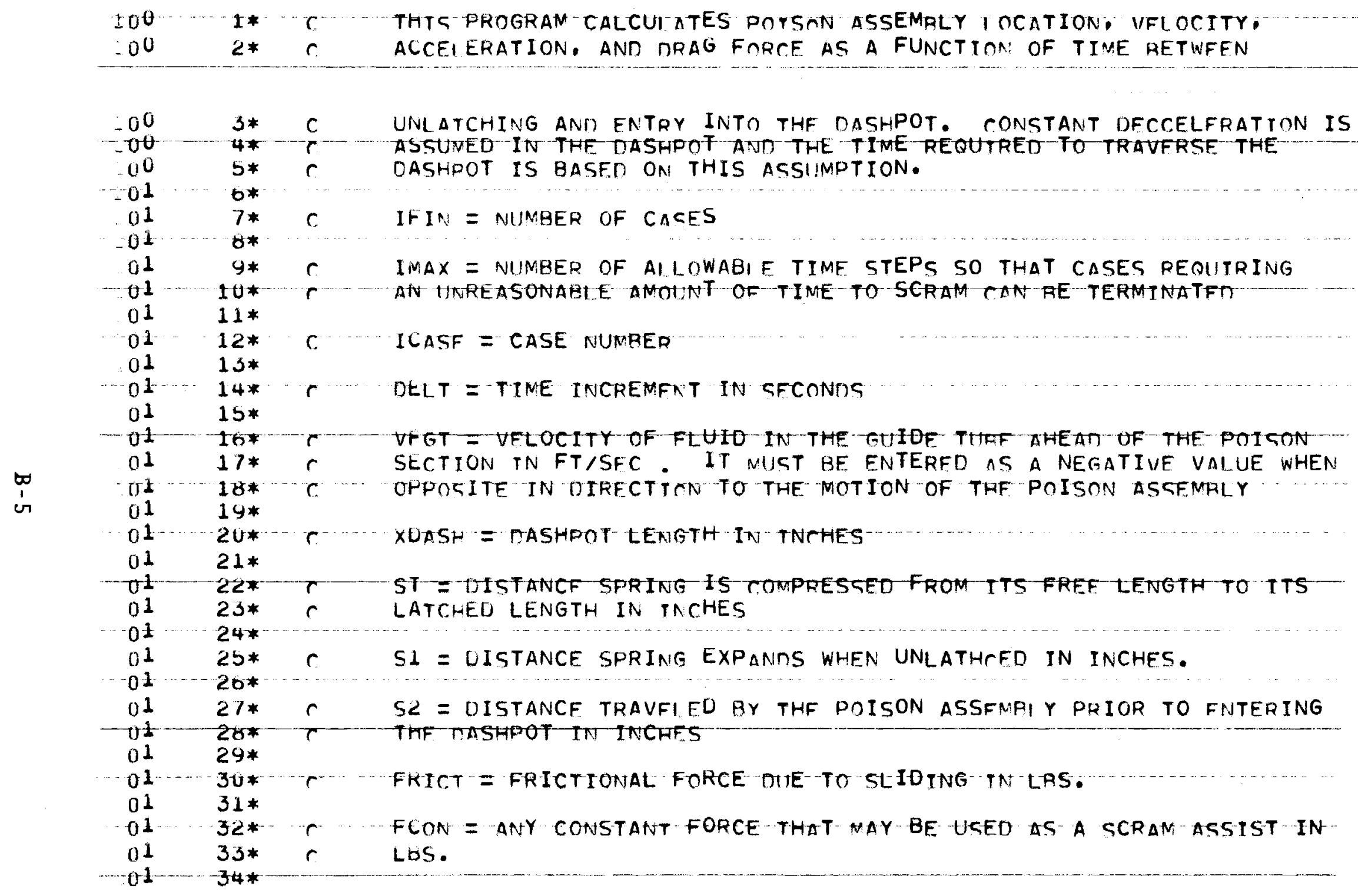




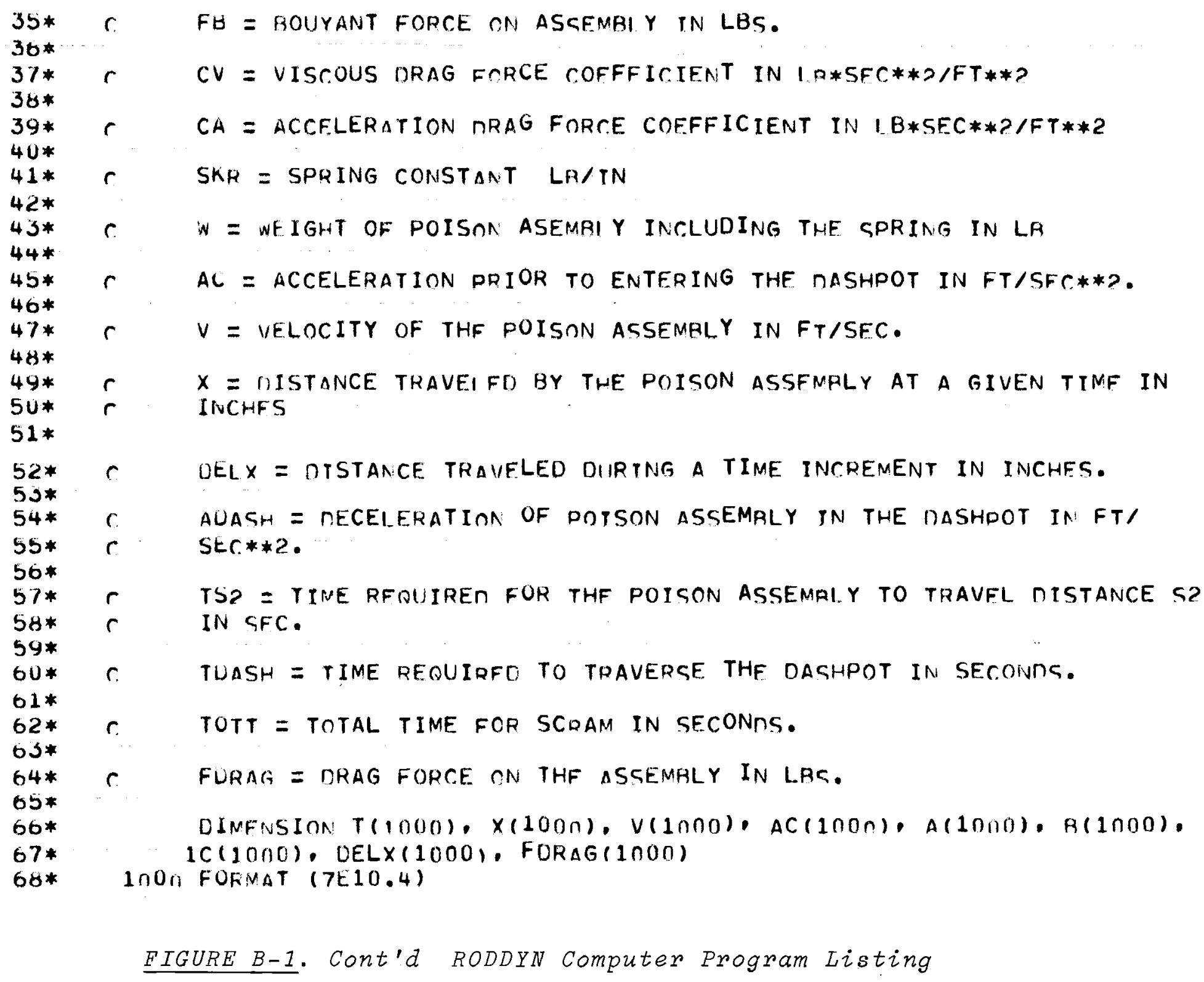

FIGURE B-1. Cont'd RODDYN Computer Program Listing 


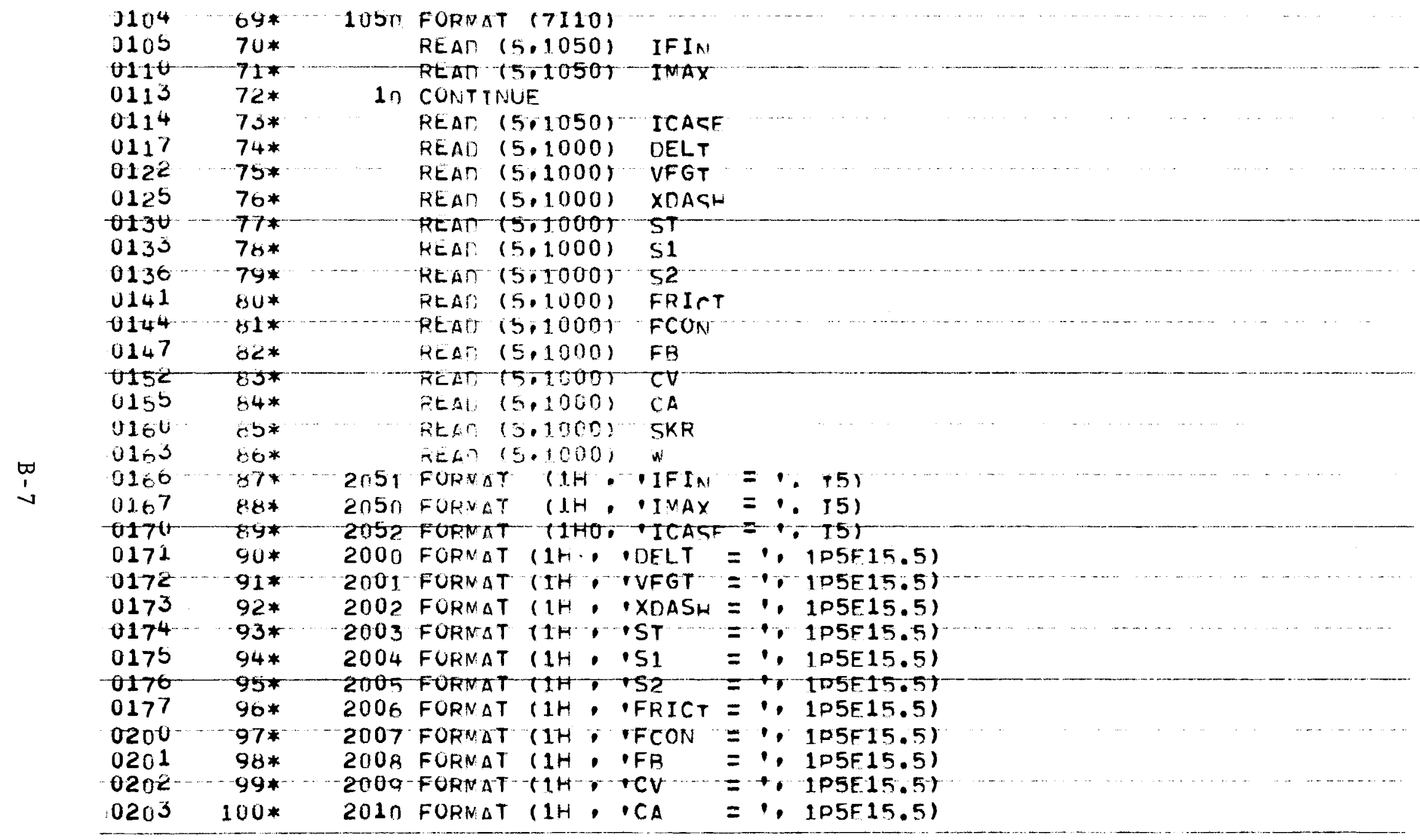

FIGURE B-1. Cont'd RODDYN Computer Program Listing 


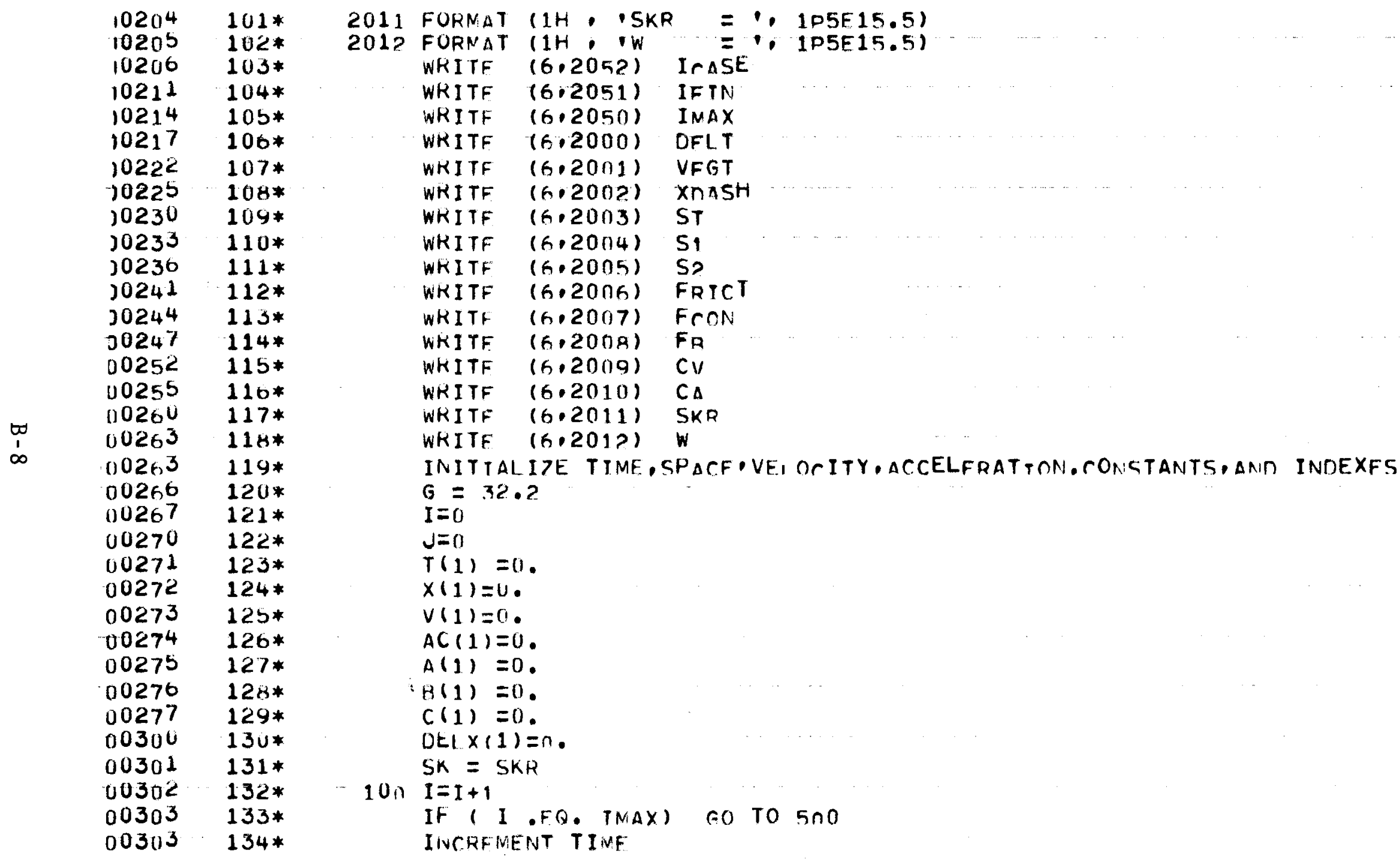

FIGURE B-1. Cont'd RODDYN Computer Program Listing 


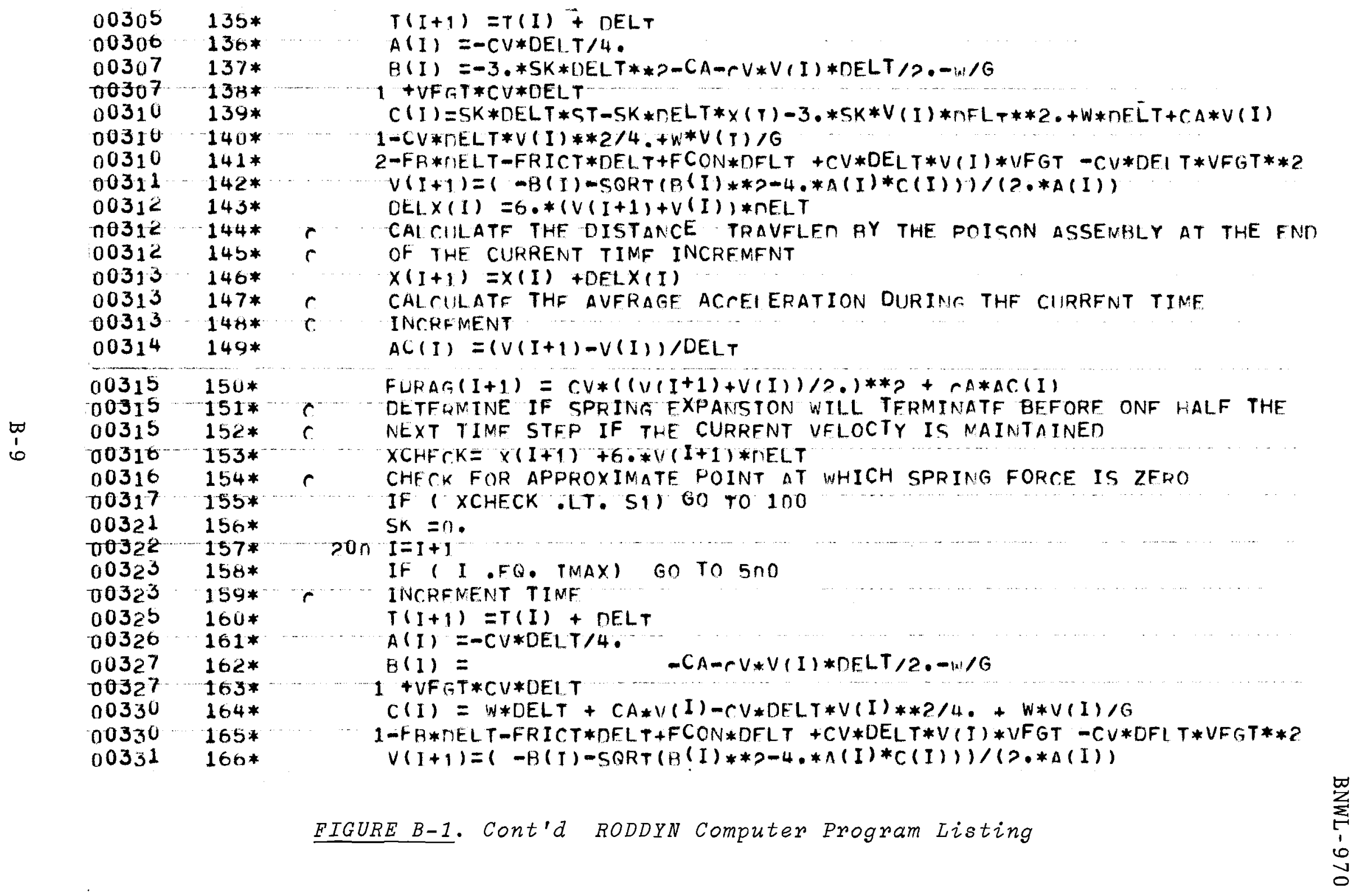




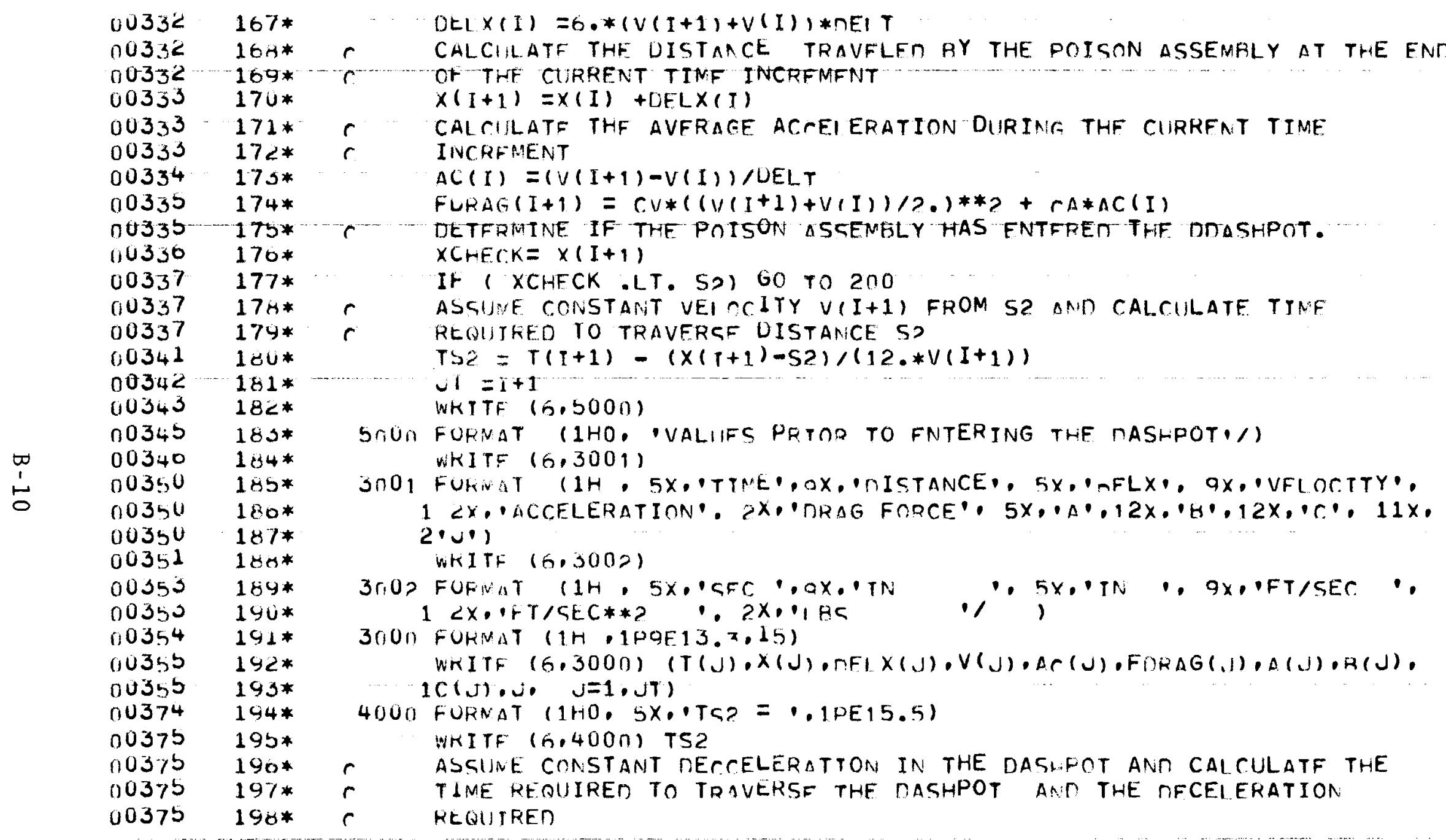

FIGURE B-1. Cont'd RODDYN Computer Program Listing 


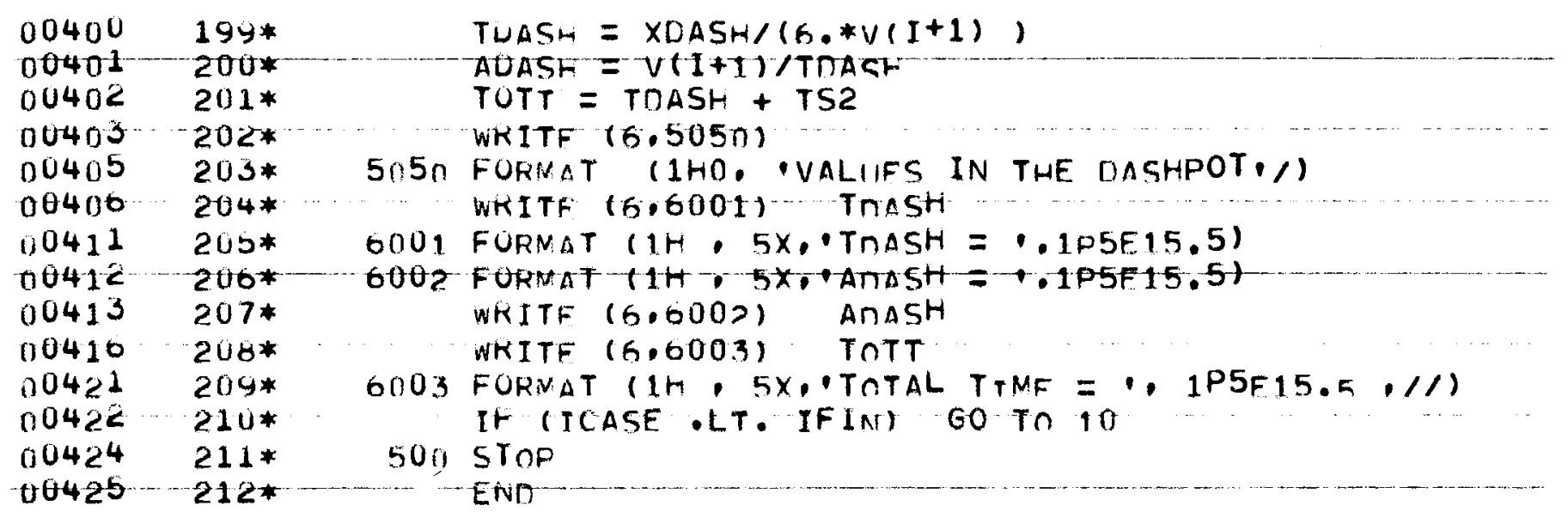


The drag force can be broken into two categories. The first is the pressure or form drag due to a pressure difference across parallel projected surface areas of the body. The second is the shear drag which is caused by the friction of the fluid on the surface of the body.

If the poison assembly scram occurred at constant velocity, the drag force would be due to viscous effects only and steady state viscous fluid dynamics could be applied. However, the scram is unsteady and therefore the effects of acceleration of the fluid with respect to time must be considered. The major effect of fluid acceleration with respect to time is to alter the steady state form drag with some interaction with the shear drag.

The simultaneous solution for the drag force due to acceleration and viscous effects is complex. In order to simplify the problem the viscous effects were treated independently of the acceleration effects. The drag force was thus broken into two components, a steady state viscous component and an unsteady state nonviscous component.

\section{VISCOUS FORCE COMPONENT}

The steady state viscous component will now be discussed. The total steady state viscous component is made up of the two categories, form drag and shear drag. However, the total

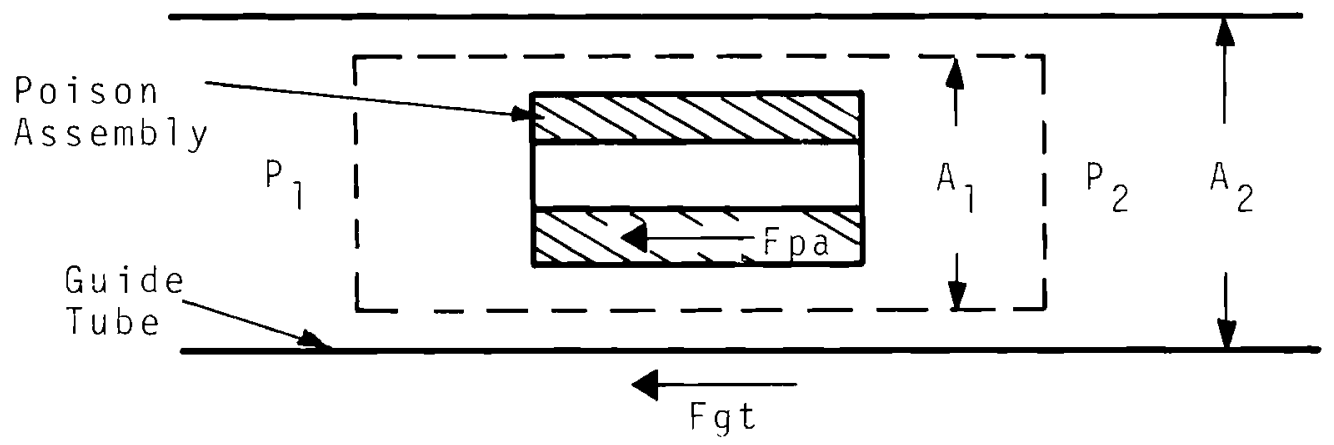


viscous drag force on the poison assembly, Fpa, and the guide tube, Fgt, is opposed by an equal and opposite force on the fluid column surrounding the poison assembly, or

$$
\mathrm{Fpa}+\mathrm{Fgt}=\left(\mathrm{P}_{1}-\mathrm{P}_{2}\right) \mathrm{A}_{2} \cdot
$$

The viscous drag on the poison section is

$$
F \text { pa }=\left(P_{1}-P_{2}\right) A_{1}=F \text { (viscous), }
$$

where $A_{1}$ is defined as the cross sectional area between the center of the guide tube and the line in the annular gap between the poison assembly and the guide tube on which the shear stresses are zero. For cases where the annular gap is small, this line may be taken at the center of the gap without causing significant error in the viscous drag force.

The total pressure drop across the assembly is the sum of the pressure drops across various locations along the assembly.

$$
\begin{aligned}
P_{1}-P_{2} & =\left(\sum \frac{\rho K V_{f}^{2}}{2 g}+\sum \frac{\rho f 1 V_{f}^{2}}{D 2 g}\right) \text { annulus } \\
& =\left(\sum \frac{\rho K V_{f}^{2}}{2 g}+\sum \frac{\rho f V_{f}^{2}}{D 2 G}\right) \text { Central flow path, }
\end{aligned}
$$

where $V_{f}$ is the fluid velocity relative to the assembly at a particular location. The guide tube was assumed to move at the velocity and acceleration of the assembly to simplify the formulation of both viscous and acceleration force components.

Using the continuity relationship we can solve for the pressure drop in terms of the velocity of the assembly relative to the fluid ahead of the assembly in the guide tube, $\mathrm{V}_{\mathrm{r}}$. Upon substitution, the viscous component of the drag force is derived in terms of a constant times $v_{r}^{2}$

$$
\mathrm{F}(\text { viscous })=\mathrm{C}_{\mathrm{v}} \mathrm{V}_{\mathrm{r}}^{2}
$$




\section{ACCELERATION FORCE COMPONENT}

The unsteady state nonviscous drag force component can be derived similarly. This force component is equal to the pressure difference across the assembly times the cross sectional area, Aax of the assembly.

$$
\mathrm{F}(\text { acceleration })=\left(\mathrm{P}_{1}-\mathrm{P}_{2}\right) \text { Aax }
$$

The pressure drop across the assembly is equal to the sum of the pressure drops across various locations along the assembly;

$$
\begin{aligned}
P_{1}-P_{2} & =\sum \rho L A C_{f} \text { (Annulus) } \\
& =\sum \rho L A C_{f} \text { (central flow path), }
\end{aligned}
$$

where $\mathrm{AC}_{f}$ is the absolute acceleration of the fluid at a particular location.

Differentiating the continuity relation, we can solve for the pressure drop in terms of the acceleration of the poison assembly relative to the fluid in the guide tube ahead of the assembly, AC.

$$
F(\text { acceleration })=C_{a} A C
$$

The calculation of the drag coefficients has been programmed on a digital computer and a listing of the program DRAG is included (Figure B-2). Input, including dimonsional units, is described in the listing.

\section{COMPARISON OF ANALYSIS TO EXPERIMENTAL RESULTS}

In order to evaluate the accuracy of the design analysis, an analysis was made of an experimental decelerator test stand used in a previous study and compared to experimental data. The test stand consisted of a vertical guide tube, a simulated poison section, a scram assist spring, and a dashpot to decelerate the simulated poison section. A velocity of 


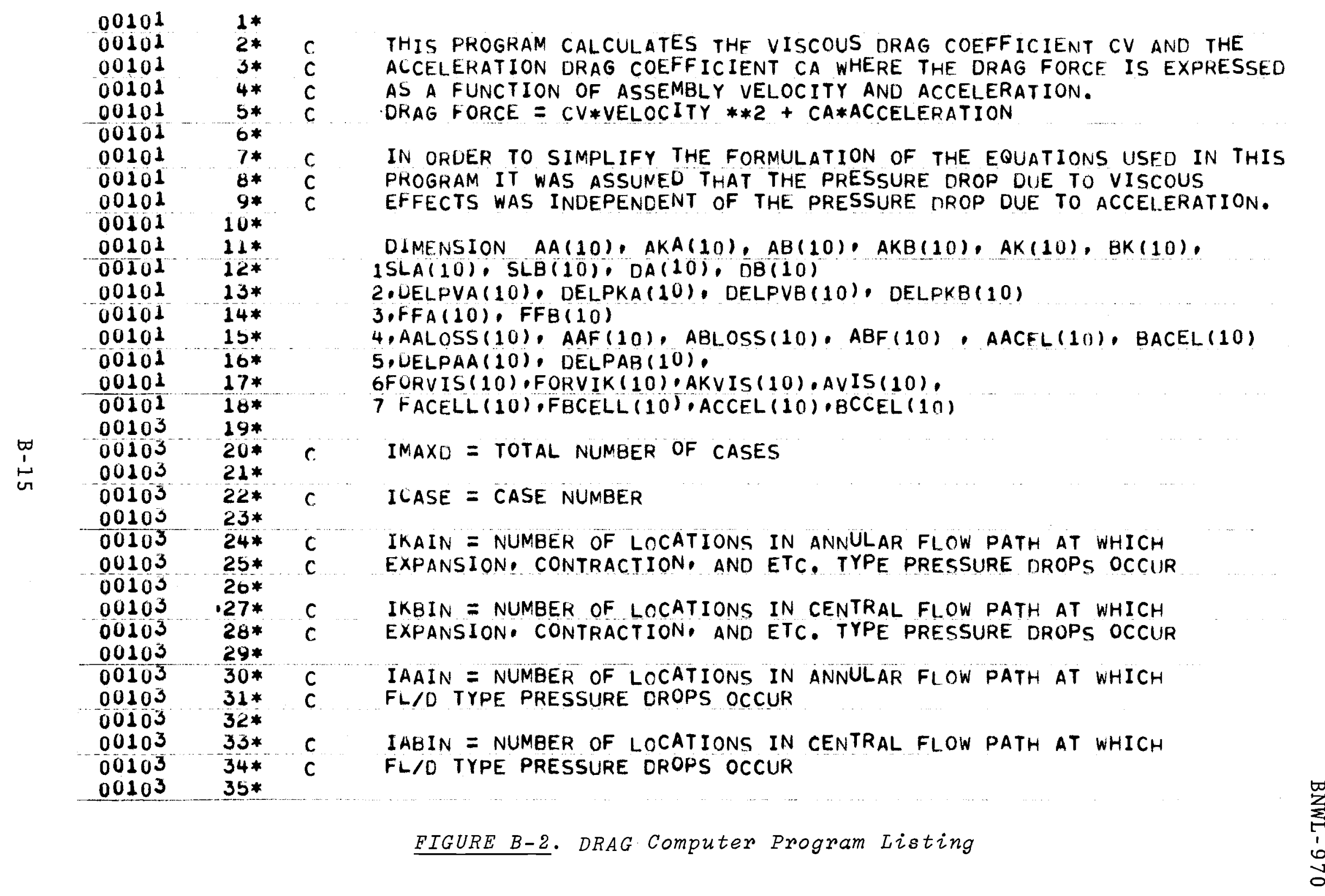




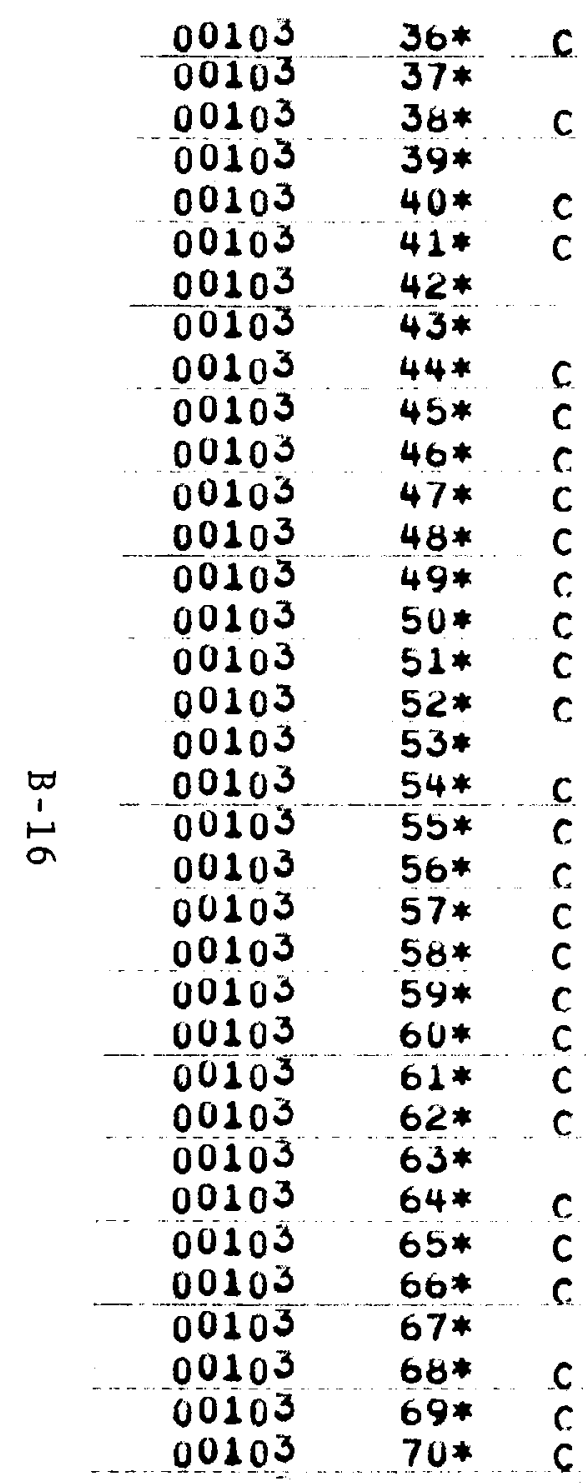

ML = MAXIMUM OF IKAIN IKBIN, IAAIN, IABIN

DEN = DENSITY OF THE FLUID IN THE GUIDE TUBE--(LB/FT**3)

AGT = FLOW AREA IN THE GUIDE TUBE AHEAD OF THE POISON ASSEMRLY (IN**2)

AVIS(I) = THE PORTION OF THE FLOW AREA IN THE GUIDE TUBE WHICH IS USED TO CALCULATE THE DRAG FORCE COEFFICIENT DUE TO VISCOUS EFFECTS CORRESPONDING TO DELPVA (I).

IT IS THE AREA LOCATED BETWEEN THE CENTER OF THE GUIDE TIIRE AND A POINT IN THE ANNULAR GAP (FORMED BY THE POISON ASSEMBLY AND THE GUIDE TUBE) AT WHICH THE FLUID SHEAR STRESS IS ZERO. FOR A SMALL ANNULAR GAP AREA RELATIVE TO GUIDE TUBE AREA ONLY A SMALL ERROR IN VISCOUS DRAG FORCE WILL RESULT BY ASSUMING ZERO SHEAR STRESS EXISTS AT THE CENTER OF THE ANNULAR GAP. (IN**2)

AKVIS(I) = THE PORTION OF THE FLOW AREA IN THE GUIDE TUBE WHICH IS USED TO CALCULATE THE DRAG FORCF COEFFICIENT DUE TO VISCOUS EFFECTS CORRESPONDING TO DELPKA (I).

IT IS THE AREA LOCATED BETWEEN THE CENTER OF THE GUIDE TIIBE AND A PUINT IN THE ANNULAR GAP (FORMED BY THE POISON ASSEMBLY AND THE GUIDE TUBE) AT WHICH THE FLUID SHEAR STRESS IS ZERO. FOR A SMALL ANNULAR GAP AREA RELATIVE TO GUIDE TUEE AREA ONLY A SMALL ERROR IN VISCOUS DRAG FORCE WILL RESULT BY ASSUMING ZERO SHEAR STRESS EXISTS AT THE CENTER OF THE ANNULAR GAP. (IN**2)

ACCEL (I) = CROSS SECTIONAL AREA OF THE POISON ASSEMBLY AT LOCATION (I) USED IN CALCULATING THE DRAG FORCE LOSS COEFFICIENT DUE TO ACCELERATION CORRESPONDING TO DELPAA (I). (IN**2)

BCCEL(I) = CROSS SECTIONAL AREA OF THE POISON ASSEMBLY AT LOCATION (I) USED IN CALCULATING THE DRAG FORCE LOSS COEFFICIENT DUE TO ACCELERATION CORRESPONDING TO DELPAB (I). (IN**2) 


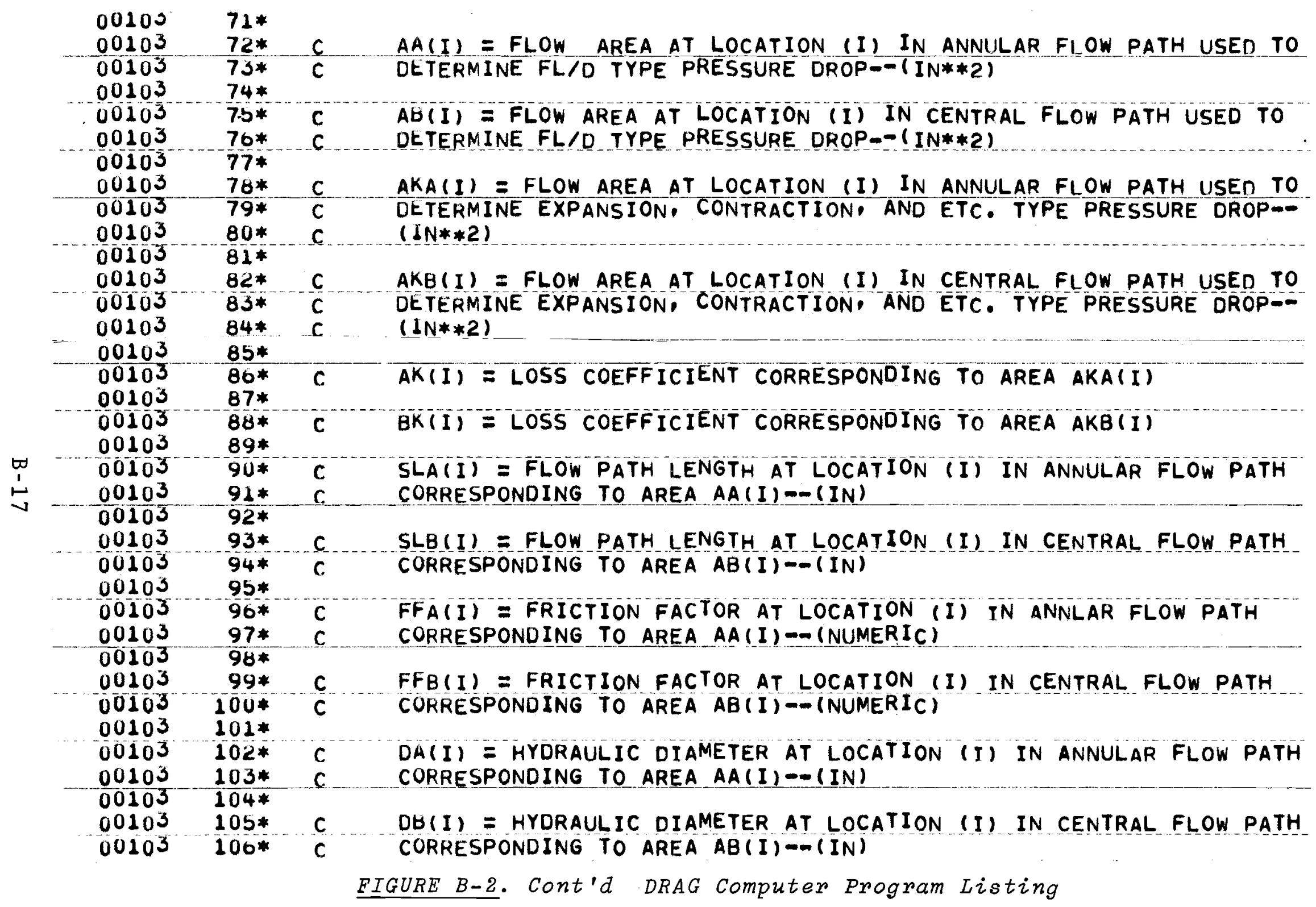









\begin{tabular}{ll}
00307 & $143 *$ \\
00310 & $144 *$ \\
00311 & $145 *$ \\
00312 & $146 *$ \\
00313 & $147 *$ \\
00314 & $148 *$ \\
00315 & $149 *$ \\
00316 & $150 *$ \\
00317 & $151 *$ \\
00320 & $152 *$ \\
00321 & $153 *$ \\
00322 & $154 *$ \\
00323 & $155 *$ \\
00324 & $156 *$ \\
00325 & $157 *$ \\
00326 & $158 *$ \\
00327 & $159 *$ \\
00330 & $160 *$ \\
00331 & $161 *$ \\
00332 & $162 *$ \\
003 & $163 *$ \\
00333 & $163 *$ \\
00334 & $164 *$ \\
\hline 00335 & $165 *$ \\
00336 & $166 *$ \\
0037 & $167 *$ \\
00337 & $168 *$ \\
00340 & $168 *$ \\
00343 & $169 *$ \\
00346 & $170 *$ \\
\hline 00351 & $171 *$ \\
00354 & $172 *$ \\
00357 & $173 *$ \\
00362 & $174 *$ \\
00365 & $175 *$ \\
00370 & $176 *$ \\
003 &
\end{tabular}

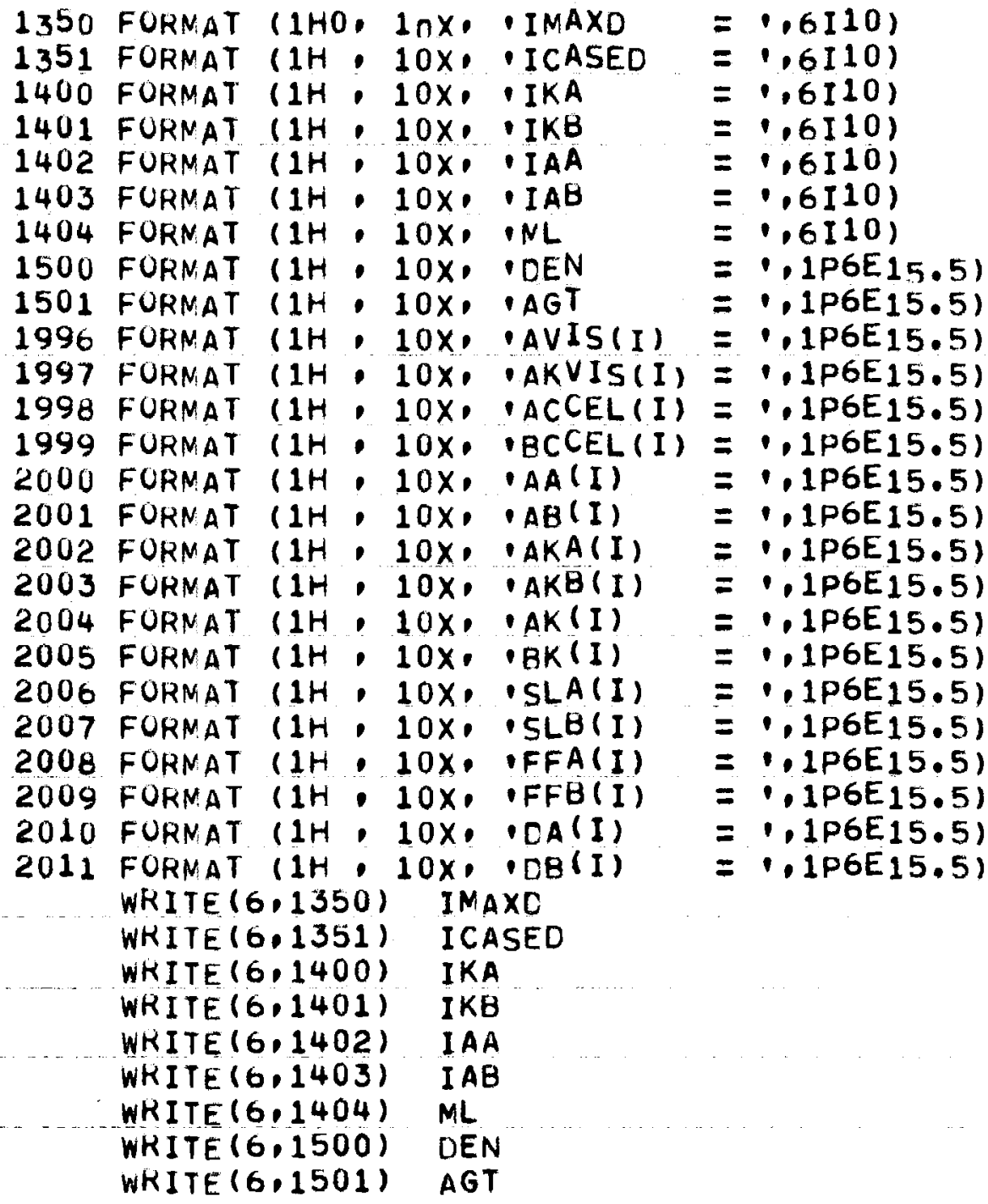




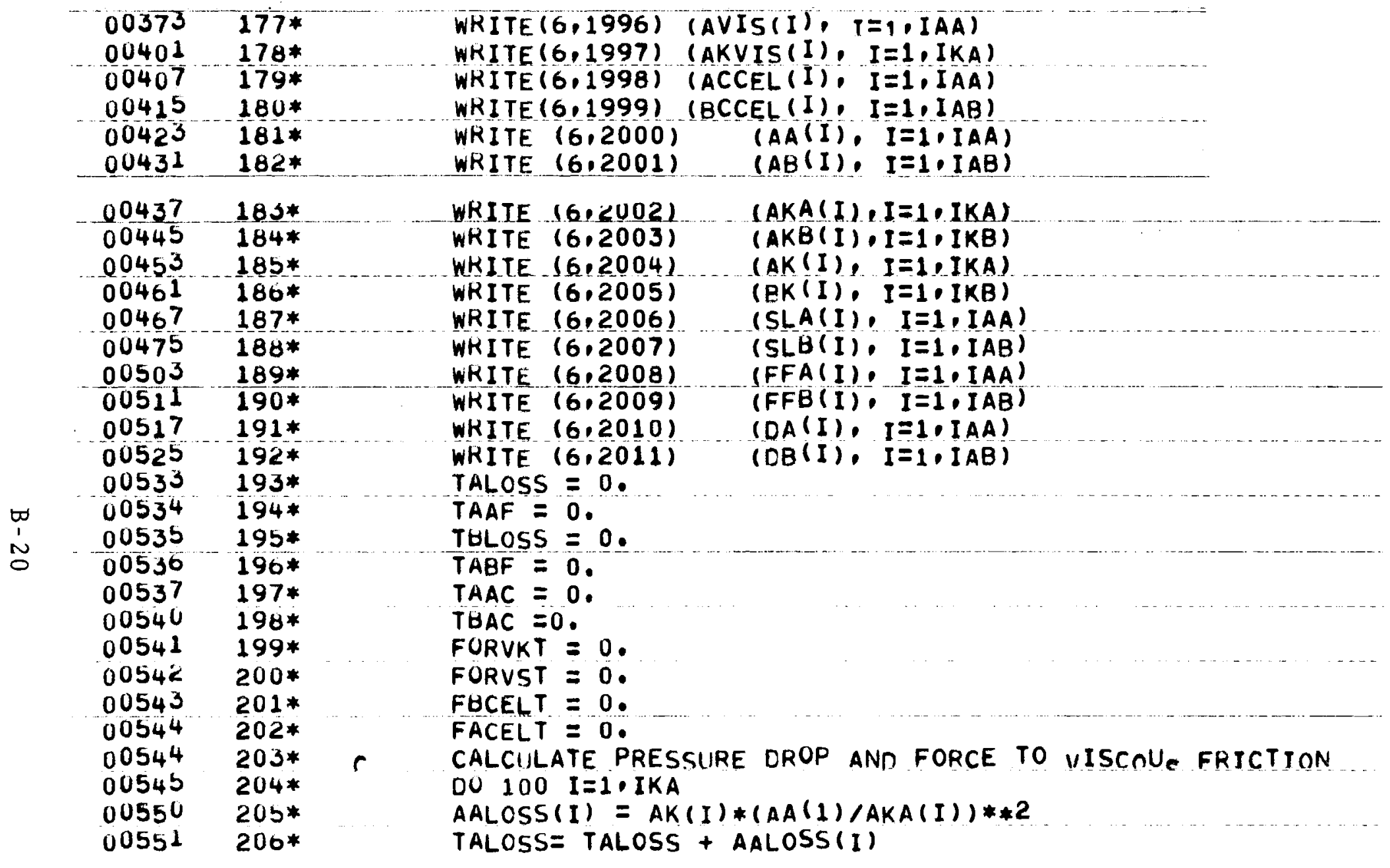

FIGURE B-2. Cont'd DRAG Computer Program Listing 


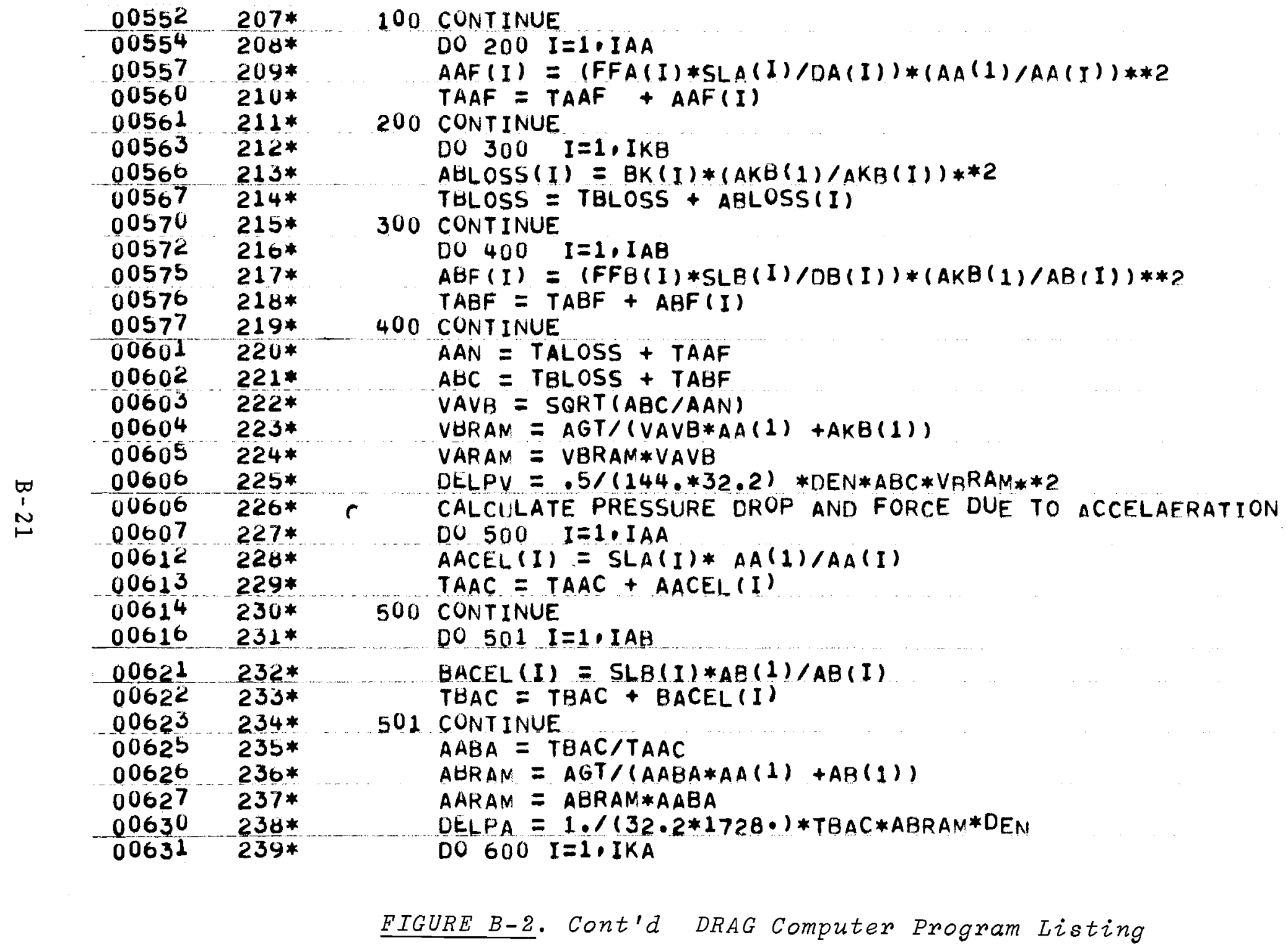




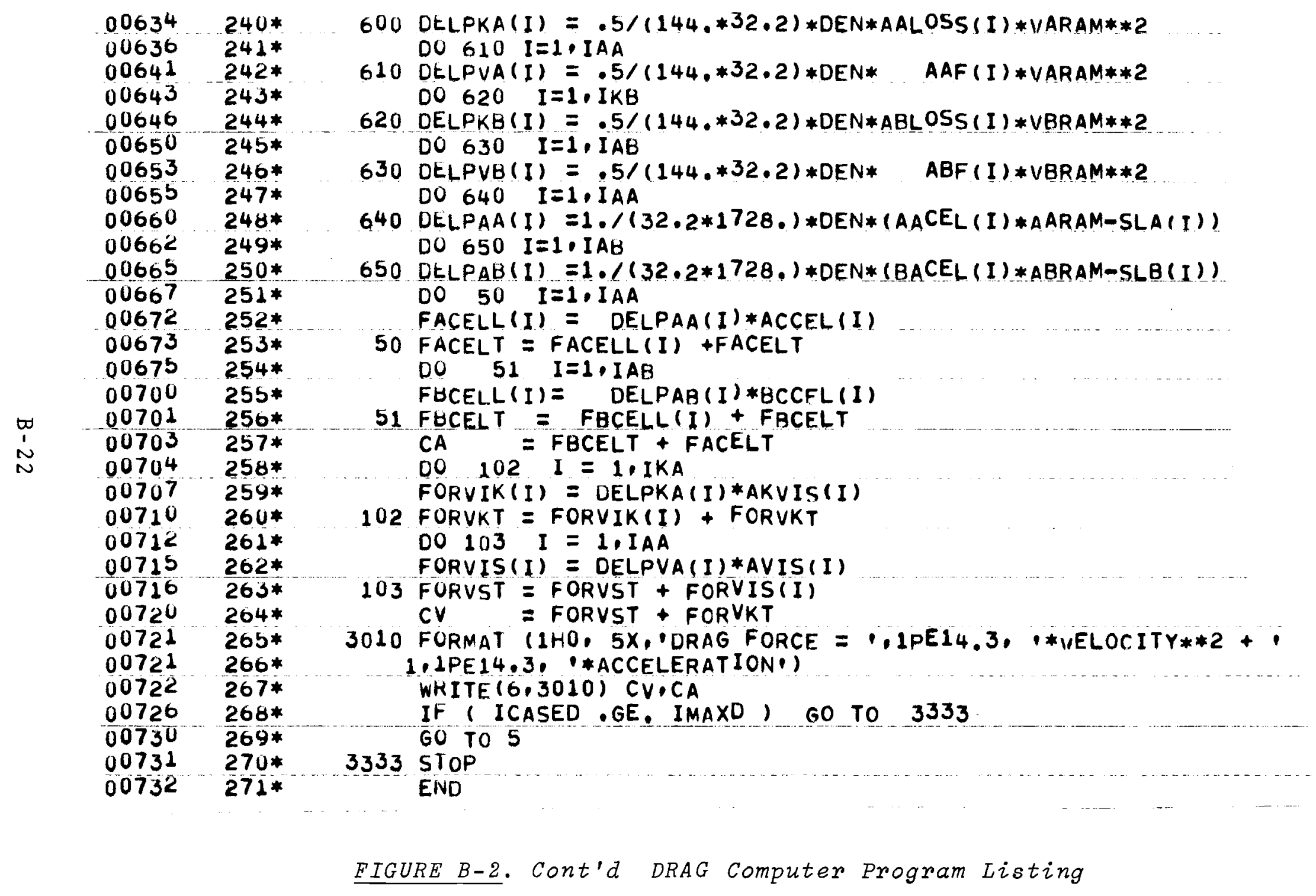


$10 \mathrm{ft} / \mathrm{sec}$ after 17.2 in. of travel was taken from experimental data. The design analysis predicted a velocity of $11.1 \mathrm{ft} / \mathrm{sec}$. The difference between the calculated and the experimental values is due to two main effects. First, sliding friction was assumed to be zero in the analysis. Second, drag coefficients were difficult to predict because of the problems associated with determining pressure drop loss coefficients (entrance, exit, turning) for the geometry of the simulated poison section. The entrance, exit and turning losses were significantly larger than the friction ( $f 1 / d$ ) losses in this case. In cases where $f 1 / d$ type losses are as great or greater than exit, entry, and turning losses, the method of analysis should predict better results, since fl/d type losses can be determined more accurately. Poison assemblies analyzed in the parametric study are of this latter case.

\section{PARAMETRIC ANALYSIS}

Various modifications to the poison section base design are possible. In order to evaluate and compare the performance of a few possible cases, a limited parametric study was made. A reference case of the base design was selected for a common point of comparison. The dynamics and kinematics for each case were calculated using the RODDYN and DRAG computer programs.

Reference Case of the Base Design

The reference case of the base design is the 7-rod bundle $\mathrm{B}_{4} \mathrm{C}$ assembly weighing $383 \mathrm{lb}$. Friction factors used to compute the viscous drag coefficient for this case were based on commercial steel roughness and a Reynolds number of $5 \times 10^{4}$. There is a tapered section in the guide tube 8 in. above the core. The guide tube is circuiar above and below the taper (see Drawing SK-3-13288). Flow path lengths in the annulus vary due to the difference in guide tube cross sectional area above and below the taper in the guide tube. 
As the poison assembly moves past the tapered section the annular flow path in the small section increases and the annular flow path in the large section decreases. To simplify the drag coefficient calculations for this geometry it was necessary to assume fixed flow path lengths in the annulus. They were based on poison section geometry after 10 in. of poison assembly travel. Drag on the scram assist spring assembly was neglected due to the large flow area in that section. Sodium properties were based on $1000^{\circ} \mathrm{F}$. The spring for the reference case has a free length of 97.5 in. The spring is assumed to be relaxed $25 \%$ to a cocking force of $6001 \mathrm{~b}$ and a preload of $2001 \mathrm{~b}$, from an initial cocking force of $800 \mathrm{lb}$ and a preload of $400 \mathrm{lb}$. Sliding friction forces were assumed to be zero. The assembly was assumed to be in a vertical position. Fluid velocity ahead of the assembly in the guide tube was assumed to be zero. Figure 4 of the reference case is typical of the kinematics of the cases compared.

Results of Parametric Study

The results of the parametric study are presented as plots of distance traveled by the poison assembly versus time. These will now be discussed.

Figure B-3 illustrates four different poison element geometries which contain two different poison materials, Boron Carbide $\left(\mathrm{B}_{4} \mathrm{C}\right)$ and Tantalum ( $\left.\mathrm{Ta}\right)$. These two materials represent the most probable poison materials for the FFTF. The differences illustrated in Figure B-4 are due to assembly weight and fluid drag force which is geometry dependent. For the reference case, the poison assembly and the small and large sections of the guide tube are circular. In the other cases the poison assembly and the small section of the guide tube are hex-shaped, with the large section of the guide tube remaining circular. A more compact geometry is possible with the hex-shape. 
7-Rod Bundle $\mathrm{B}_{4} \mathrm{C}$

Rod OD - 1.1283 in.

Poison Element Length - 90.5 in. Poison Element Length $-35.625 \mathrm{in}$.
7 -Rod Bundle Ta

Rod OD - 1.3 in.

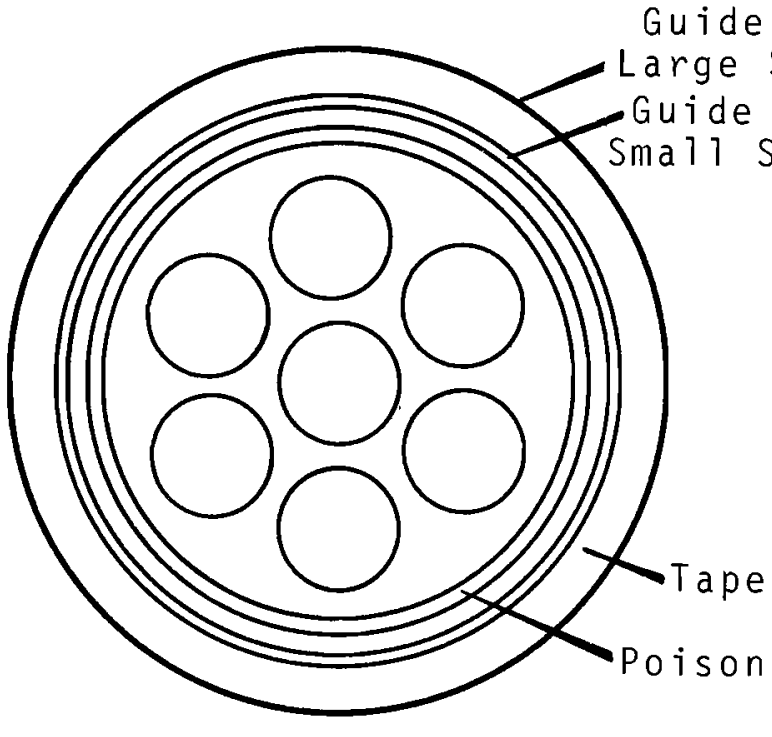

61 -Rod Bund 1 e $B_{4} C$

Rod OD - 0.416 in.

Poison Element Length - $90.5 \mathrm{in}$.

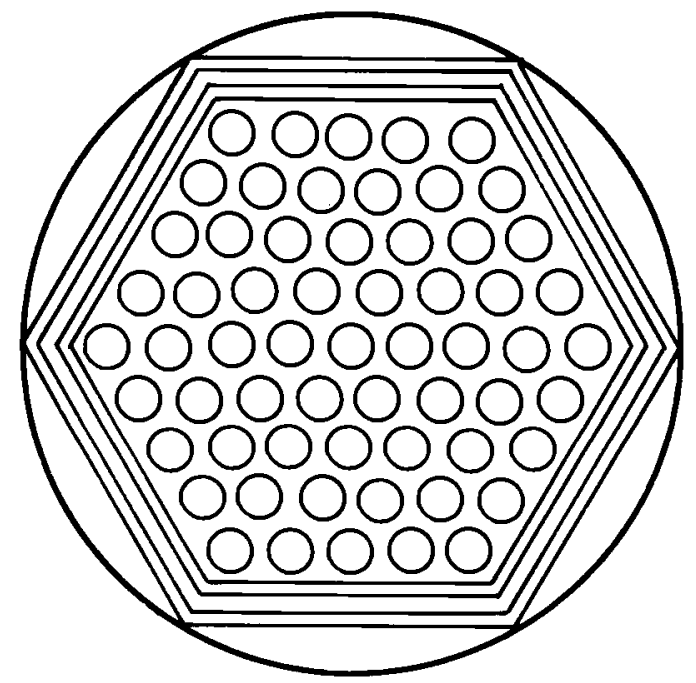

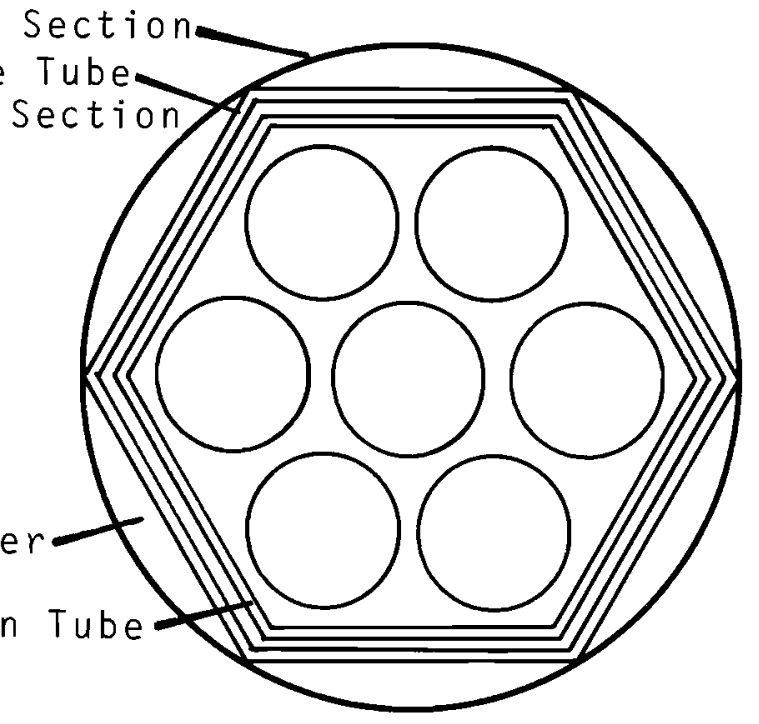

Billet Ta

Central Hole ID - 0.75 in.

Poison Element Length - 35.625

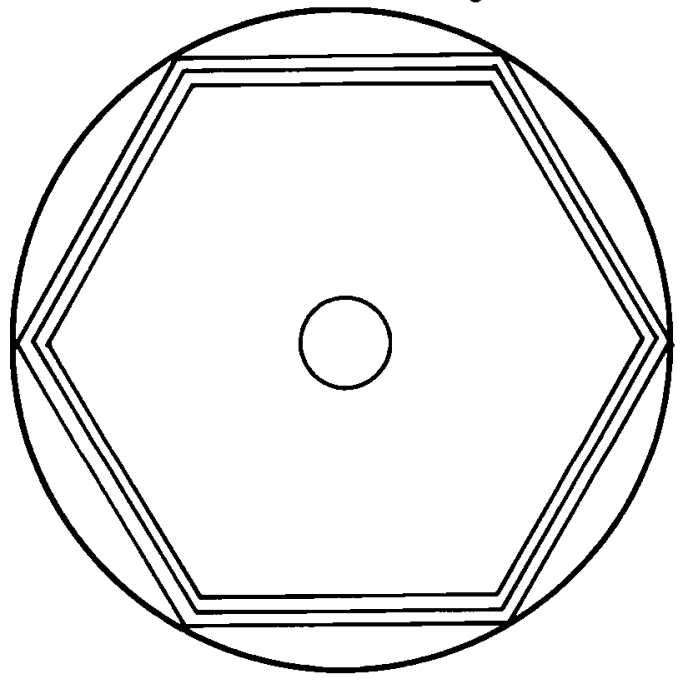

Genera 1: Poison Tube Wa11 Thickness - 0.1875 in.

Guide Tube Wa11 Thickness - 0.150 in.

Large Section of Guide Tube OD - 5.250 in.

Sma11 Section of Guide Tube: OD (Circular) - 4.52 in. Across outside flats (Hex) - 4.52 in.

Poison Tube: OD (Circular) - $4.010 \mathrm{in}$. Across outside flats (Hex) - $4.095 \mathrm{in}$.

FIGURE B-3. Various Poison Section Cross Sections 
BNWL -970

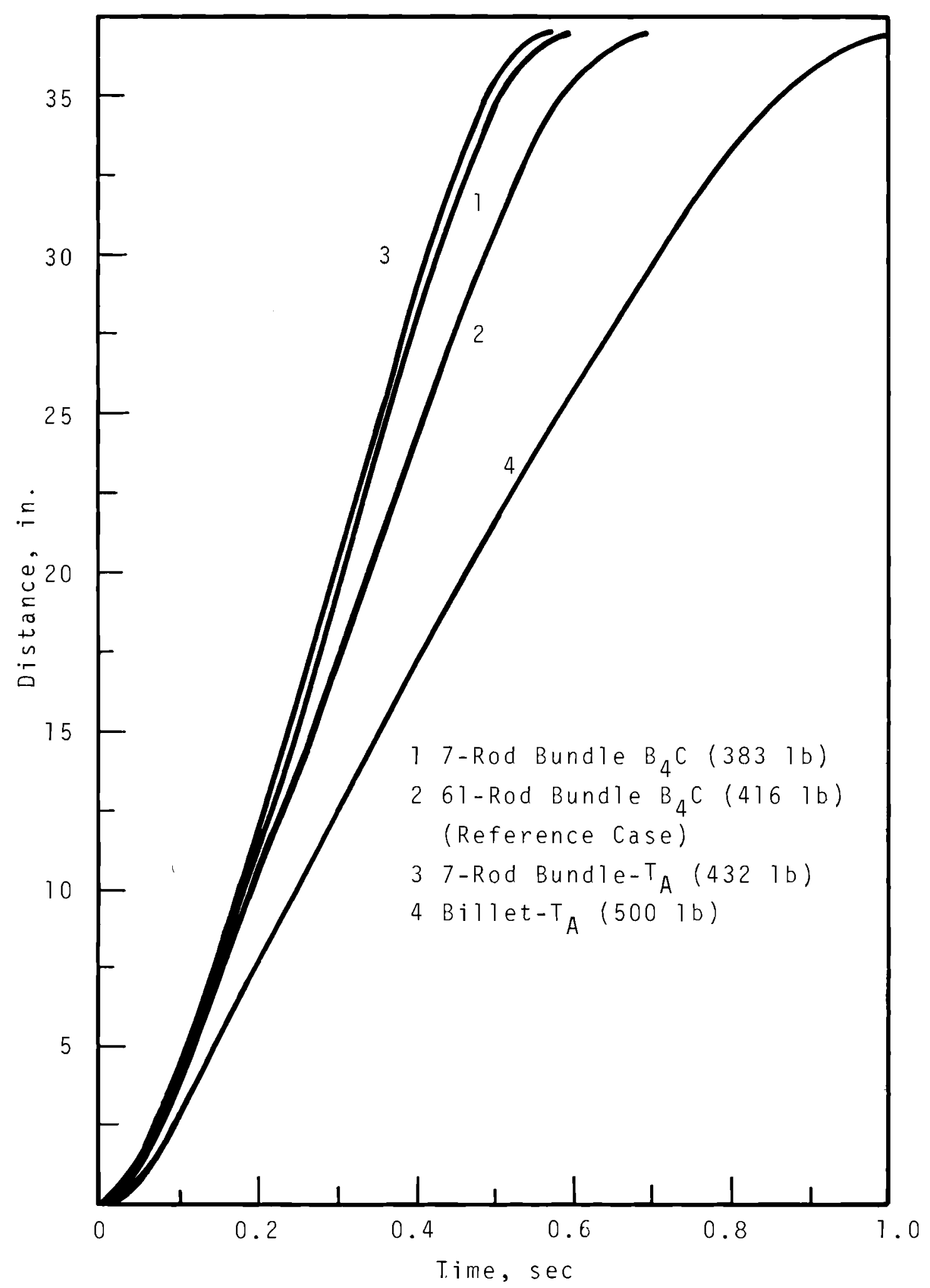

FIGURE B-4. Distance Versus Time for Various Poison Elements with Scram Assist 
Figure B-5 illustrates the effect on scram time of poison assembly surface roughness for the base design. If surface roughness used in predicting friction factors cannot be determined exactly for a particular case, predicted scram time could be bracketed by calculations based on smoothest and roughest possible cases.

Figure B-6 demonstrates the effect of spring relaxation on scram time. Approximately ten percent relaxation is anticipated due to thermal effects at $1200^{\circ} \mathrm{F}$ in the base design. However, it may be much larger due to combined effects of radiation and temperature.

The effect of reducing spring length is shown in Figure B-7. The neutron flux decreases as the distance above the core increases. The lower end of the spring is in a relatively high flux region. Therefore, removing the lower portion of the spring could reduce possible spring relaxation due to irradiation effects. Figure B-7 also illustrates the effect of eliminating the entire scram assist spring assembly. This would simplify the design if required scram times could be achieved by free fall.

A few comments will summarize. Drag forces in the cases studied are the major retarding force and are highly geometry dependent. The reference case scram assist reduced scram time $1 / 3$ from the free fall case. However, elimination of the scram assist would simplify the design. A review of the equations of motion show that increased assembly weight decreases acceleration when scram assist forces are greater than retarding forces. It increases acceleration when scram assist forces are less than retarding forces. Therefore, weight could be added to reduce the scram time of a free fall design. 
BNWL -970

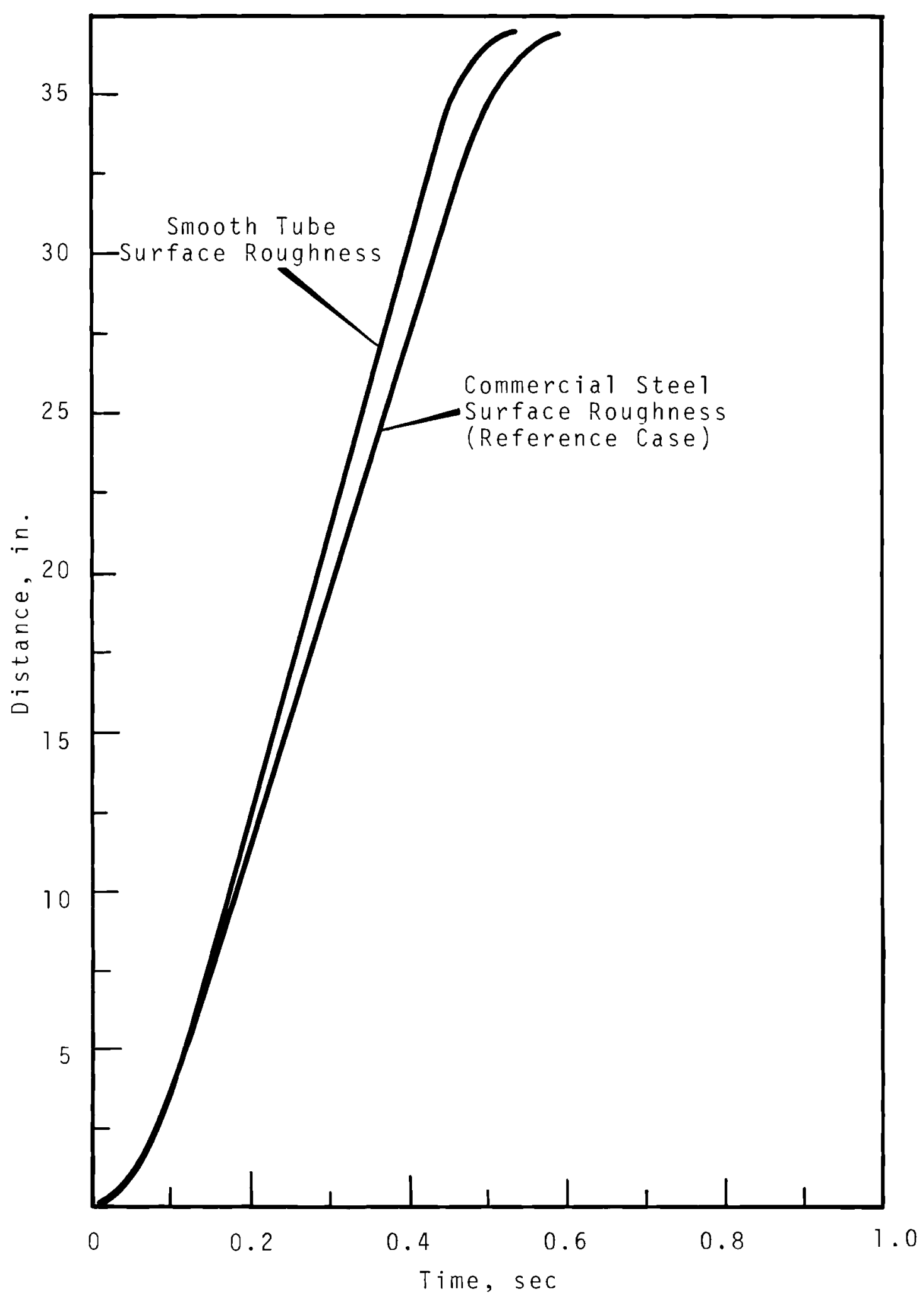

FIGURE B-5. Distance Versus Time for Base Design for Commerciat Steel and Smooth Tube Surface Roughness 
BNWL - 970

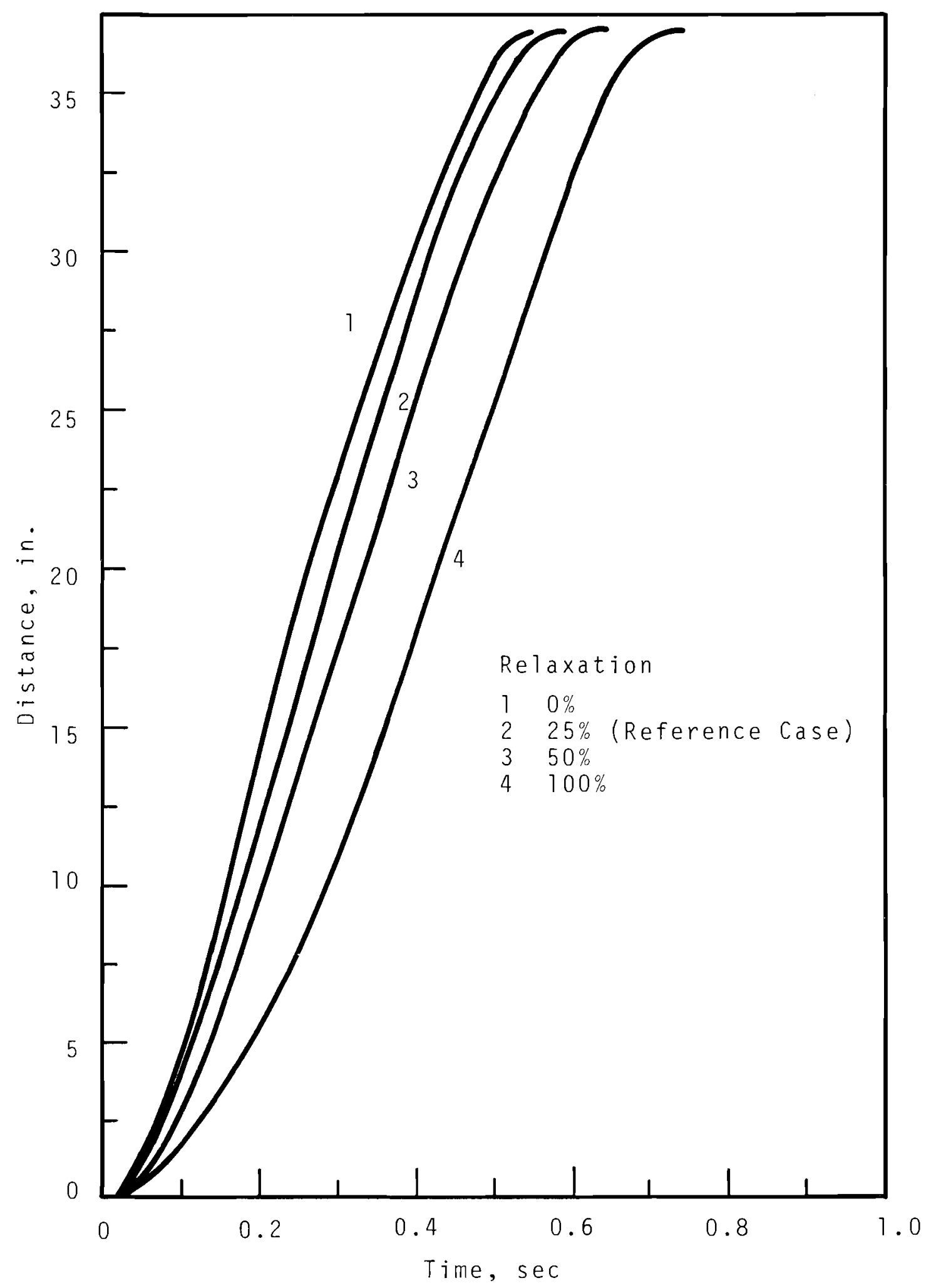

FIGURE B-6. Distance Versus Time for Various Percentage Relaxation of Scram Assist Spring for Base Design 


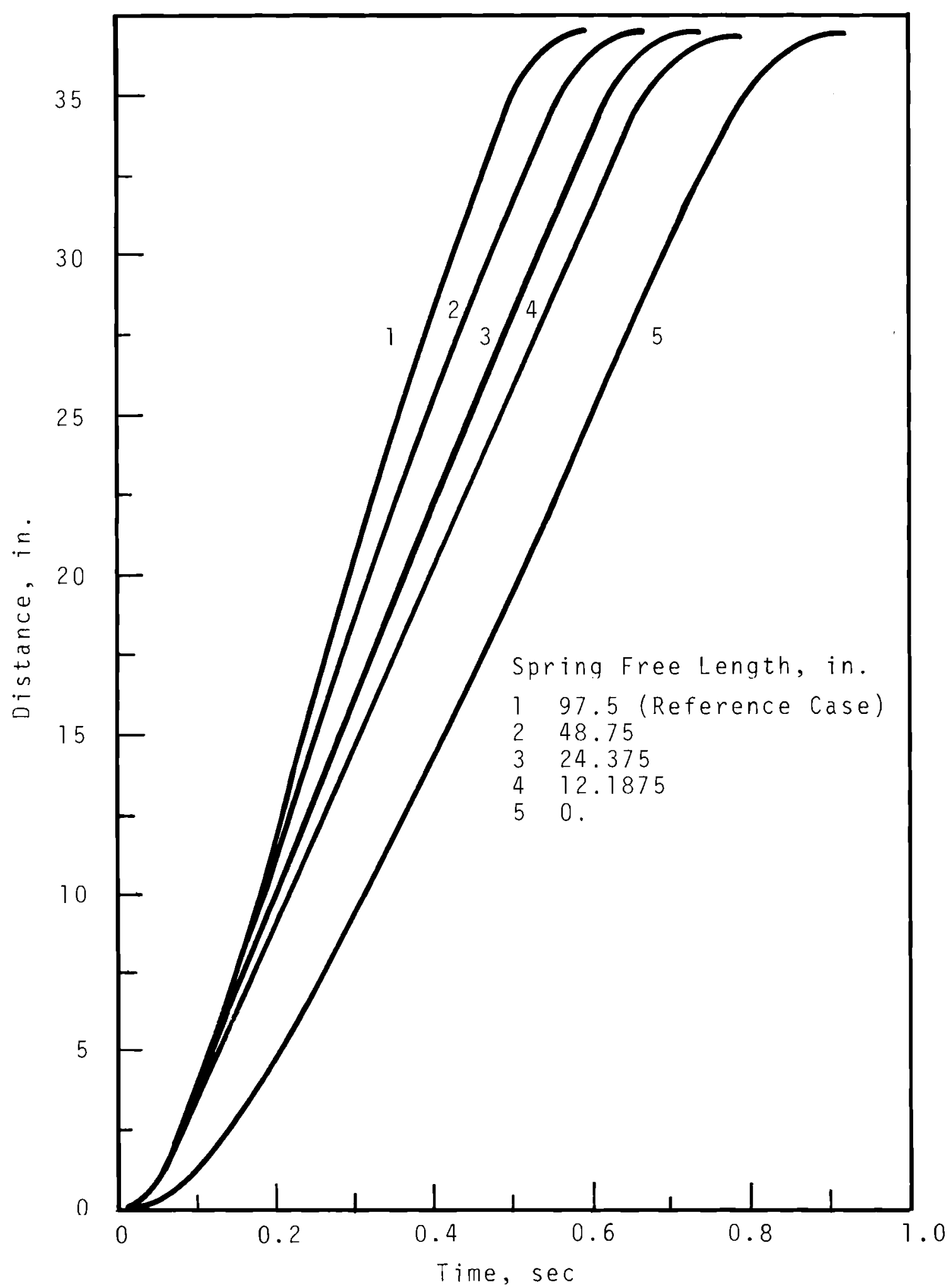

FIGURE B-7. Distance Versus Time for Various Free Lengths of Scram Assist Spring for Base Design 


\section{SPRING DESIGN}

Base Design Spring Description

A scram assist device may be required to obtain the necessary scram time in the FFTF. In keeping with the Fermi concept, the scram assist selected for the base design 7-rod bundle $\mathrm{B}_{4} \mathrm{C}$ poison assembly is a single spring. It is shown on Drawing SK-3-13278, Sheets 7,8, and 9. The material is Spring Temper Inconel X-750 which after cold coiling is solution treated at $2100^{\circ} \mathrm{F}$ for $2 \mathrm{hr}$ and aged at $1550^{\circ} \mathrm{F}$ for $24 \mathrm{hr}$ and $1300^{\circ} \mathrm{F}$ for $20 \mathrm{hr}$. The spring was designed for a cocked force of $800 \mathrm{lb}$ with a resulting torsional shear stress of $28,300 \mathrm{lb} /$ $\mathrm{in}^{2}$. and a preload of $400 \mathrm{lb}$ at an operating temperature of $1200^{\circ} \mathrm{F}$. Preloading gives the maximum amount of scram assist energy for a given amount of spring expansion and cocked force.

Since the modulus of rigidity changes with temperature the cocked force at room temperature is $1085 \mathrm{lb}$. This may tax the drive if cocking is required at room temperature since the maximum downward force available is $1060 \mathrm{lb}$ plus the weight of part of the drive extension (approximately $100 \mathrm{lb}$ ). This force must cock the scram assist spring and also compress the magnet spring (100 $1 \mathrm{~b}$ maximum). If room temperature tests are to be used to simulate reactor operation at high temperature, then another spring will have to be designed to give the simulated cocking force. Relaxation due to thermal effects is estimated at 1 ess than $10 \%$ for 1 year's operation at $1200^{\circ} \mathrm{F}$. This estimate was obtained by linearly extrapolating data taken up to $4300 \mathrm{hr} .^{(8)}$ Relaxation due to the combined effects of high temperature and irradiation are not known.

The spring could be modified to accommodate different poison sections or different scram assist forces. However, relaxation problems may be increased if the modification calls for higher torsional shear stresses. Relaxation due to the combined irradiation and high temperature effects may be 
reduced by eliminating the lower portion of the spring which will be exposed to higher neutron flux than the upper portion. The effect of shorter length springs and relaxation on base design kinematics and dynamics are discussed in the parametric analysis section. Modifications should not require the spring to operate at the sodium pool cover gas interface because of impurity deposition and thermal stress problems.

Spring Materials Selection

Six spring materials were considered for the design. These were Inconel 718, Inconel X-750, A-286, S-816, Rene-41 and L-605. The last three are cobalt alloys and were eliminated because of potential problems in mass transport and handling radioactive materials. The first three are listed in order of their resistance to relaxation from thermal effects of $1200^{\circ} \mathrm{F}$ in their optimum heat treatment condition. (8-13) Very limited data on Inconel 718 show it to be significantly more resistant to relaxation due to thermal effects than Inconel $\mathrm{X}-750 .(8-13)$ Significantly more relaxation data due to thermal effects is available on Inconel X-750 than the other two alloys, and it has seen reactor use including the Fermi Reactor. On this basis, it was selected for the base design.

There is not enough information on the relaxation of spring materials under the combined effects of irradiation and high temperature to assume that the scram assist spring design will meet FTR requirements. Neutron flux in the FTR at the bottom of the spring with the poison assembly in the fully withdrawn position has been estimated at $5 \times 10^{7} \mathrm{n} / \mathrm{cm}^{2}-\mathrm{sec}$ with energies of $10>\mathrm{MeV}>0.39 .^{(14)}$ Temperatures to $1200^{\circ} \mathrm{F}$ are possible. Irradiation effects on the relaxation of Inconel $\mathrm{X}-750$ at $600^{\circ} \mathrm{F}$ and an integrated flux of $4.2 \times 10^{19} \mathrm{nvt}$ fast are discussed by Mehan. (15) However, extrapolation of this data to $1200^{\circ} \mathrm{F}$ does not appear feasible. Irradiation of a similar spring material Nimonic $80 \mathrm{~A}$ showed relaxations of over 
$60 \%$ after $3800 \mathrm{hr}$ in a fast fluence $\left(0.6\right.$ to $\left.5.9 \times 10^{19} \mathrm{n} / \mathrm{cm}^{2}\right)$ at $525^{\circ} \mathrm{C} . \quad\left(\sim 976^{\circ} \mathrm{F}\right) \cdot(6)$

Relaxation is considered the major spring design problem. However, it is possible that a spring material could fail due to stress rupture if the material was highly relaxation resistant under irradiation and high temperature. The stress rupture properties of Inconel X-750 and A-286 under high temperature and irradiation are discussed by Collins. (16) RAM AND DASHPOT DESIGN

The function of the ram and dashpot is to decelerate the poison assembly to a smooth stop during the last 6 in. of travel. Minimum dynamic loading of the poison section will occur if the dashpot and ram are designed for constant deceleration of the poison assembly.

Previous experimental work by BNW has indicated that it may be possible to approach constant deceleration with a triple stepped piston. The function of the steps is to decrease the flow area between the ram and dashpot as the ram moves further into the dashpot. The pressure force on the ram plus the drag force on components other than the ram act with the other retarding forces to decelerate the assembly. The major force is the pressure force on the ram. Constant deceleration could therefore be obtained by maintaining constant retarding forces on the ram. This can be approximated by proper sizing of the ram step diameter and length.

Additional analysis is required to develop a basis for sizing the ram steps. The approach to formulate this basis would be to develop a relationship for the pressure in the dashpot and force on the ram as a function of ram location, velocity, and deceleration. This force relationship could be substituted into the equations of motion by modifying the RODDYN computer program. Deceleration performance of specific ram geometries could then be evaluated. 
BNWL - 970

\section{STRESS AND BUCKLING ANALYSIS}

Stress Analysis

Stress analysis of the poison section was limited to static and dynamic loading of the base design. Thermal strains and stresses and their effect on low cycle fatigue, fretting, etc., could be significant especially during the transient scram conditions. However, they were not evaluated during this study. Al1 parts of the base design are adequately designed to accommodate the static and dynamic loads placed on them. Modifications from the base design would have to be analyzed to insure their reliable operation. Only the most highly stressed components of the base design will be discussed.

The latch spool bolt is the most highly stressed component under static loading. The maximum static load would occur under the improbable occurrence of freeing a stuck poison assembly. The maximum load would be a drive 1 ift force of 1060 lb plus a cocked scram assist force of $800 \mathrm{lb}$. The stress under these conditions is $34801 \mathrm{~b} / \mathrm{in}^{2}$.

The dashpot support tube and dashpot wall are the most highly stressed components under dynamic loading. For the 383 1b base design assemb1y entering the dashpot at $6.3 \mathrm{ft} / \mathrm{sec}$, a maximum load of $867 \mathrm{lb}$ is imposed on the dashpot. Dashpot pressure is $123 \mathrm{lb} / \mathrm{in}^{2}$. Resulting dashpot support tube compressive stress is $7401 \mathrm{~b} / \mathrm{in}^{2}$. Hoop stress in the dashpot wall is $7341 \mathrm{~b} / \mathrm{in}^{2}$.

Available data on stainless steel $304^{(6)}$ suggest that there is a considerable margin of safety for the above loadings under the expected high temperatures and fast flux irradiation in the FTR. 
Buckling Analysis

Buckling of the poison assembly under static and dynamic loading is not a problem for the base design. The ratio of the length of the assembly to the radius of gyration is less than 56.0. A compressive stress greater than $90,0001 \mathrm{~b} / \mathrm{in}^{2}$. would be required to cause buckling. Stress this high is not anticipated under dynamic loading. Yielding or crushing would probably occur at stresses below this value. 


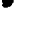




\section{APPENDIX C}

DESIGN CALCULATIONS 


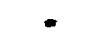




\section{APPENDIX C \\ DESIGN CALCULATIONS}

CONTROL ROD DRIVE CAPACITY

From curves on S10-Syn HS $400 \mathrm{~B}$ motor, at 150 steps/sec

(9 in./minimum linear translation)

$$
\mathrm{T}=600 \text { oz.-in. }
$$

For a ballscrew,

$$
\begin{aligned}
& \mathrm{T}=\frac{\mathrm{F} \ell}{2 \pi \mathrm{e}} \\
& \mathrm{F}=\frac{\mathrm{T} 2 \Pi \mathrm{e}}{\ell} \\
& \mathrm{e}=0.9 \quad \begin{array}{c}
\text { (ball screw manufacturer's } \\
\text { recommendations) }
\end{array} \\
& \ell=0.2 \mathrm{in} \quad\left(\begin{array}{c}
\text { orginaw } 0875-0200-\mathrm{SRT} \\
\text { or equivalent) }
\end{array}\right. \\
& \mathrm{F}=\frac{600 \mathrm{oz} \cdot-\mathrm{in} .2 \Pi(0.9)}{0.2 \text { in. }} \\
& \mathrm{F}=1060 \mathrm{ib}+
\end{aligned}
$$

at $1500 \mathrm{step} / \mathrm{sec}$ (90 in./minimum linear translation)

$$
\begin{aligned}
& \mathrm{T}=220 \mathrm{oz} \cdot-\mathrm{in} . \\
& \mathrm{F}=\frac{\frac{220}{16} 2 \Pi(0.9)}{0.2}=388 \mathrm{1b} \leftarrow
\end{aligned}
$$




Item

1. Guide tube

2. Dash pot

3. Drive assembly mounting head motor

motor cov.

ball screw

4. Ball nut and ext.

tube

electromagnet

case

magnet

latch rod

5. Extension tube

6. Latch

7. Shielding

tube

shielding

8. Control rod
Weight, 1b

294

9.2

36.3

12.5

16.5

10.6

20.3

17.3

13.5

15.8

45.5

40.0

127.5

48.2

400.0

$1107.21 \mathrm{~b}$

For miscellaneous items, add $15 \%$

$\mathrm{W}_{\mathrm{T}}=1.15(1107.2)=12701 \mathrm{~b}$ 


\section{SPRING SIZE CALCULATIONS}

\section{Stroke}

Stroke necessary is equal to difference in expansion between guide tube and reactor vessel.

Assume $300{ }^{\circ} \mathrm{F}$ difference in temperature between guide tube and reactor vessel.

Guide tube length $\approx 439$ in.

$$
\begin{aligned}
\delta & =\alpha \Delta \mathrm{T} \ell \\
\ell & =439 \mathrm{in} . \\
\Delta \mathrm{T} & =300{ }^{\circ} \mathrm{F} \\
\alpha & =9.0 \times 10^{-6} \mathrm{in} . / \mathrm{in} .{ }^{\circ} \mathrm{F} \\
\delta & =\left(9.0 \times 10^{-6}\right)(300)(439) \\
\delta & =1.185 \mathrm{in} .
\end{aligned}
$$

Make stroke $=2$ in.

For static loads,

$$
\begin{aligned}
S_{S} & =K_{S} \frac{8 F D}{\Pi d^{3}} \\
F & =\frac{2}{3}(1270)=8471 b\left(\begin{array}{l}
\text { Design spring to carry 2/3 } \\
\text { of total weight, 1et tube } \\
\text { sheet carry other } 1 / 3
\end{array}\right)
\end{aligned}
$$$$
\mathrm{D} \approx 6 \mathrm{in} .
$$$$
K_{S} \approx 1
$$

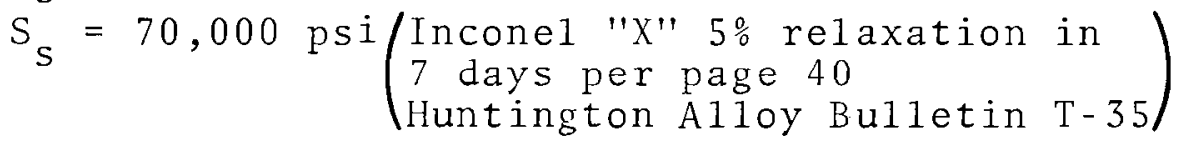

Solve for d

$$
\begin{aligned}
d^{3} & =\frac{K_{s} 8 F D}{\Pi S S} \\
d & =0.57 \text { in. }
\end{aligned}
$$

If $0.625 \mathrm{in.}$ rod is used,

$$
\begin{aligned}
& \mathrm{d}=0.625 \mathrm{in} . \\
& \mathrm{D}=6.125 \mathrm{in} .
\end{aligned}
$$




$$
\begin{aligned}
\mathrm{F} & =8471 \mathrm{~b} \\
\mathrm{~K}_{\mathrm{S}} & =1+\frac{.5}{\mathrm{C}} \\
\mathrm{C} & =\frac{\mathrm{D}}{\mathrm{d}}=\frac{6.125}{0.625}=9.8 \\
\mathrm{~K}_{\mathrm{S}} & =1+\frac{.5}{9.8}=1.051 \\
\mathrm{~S}_{\mathrm{S}} & =\frac{(1.051)(8)(847)(6.125)}{\Pi(0.625)^{3}} \\
\mathrm{~S}_{S} & =57,000 \mathrm{psi}
\end{aligned}
$$

NUMBER OF ACTIVE COILS

$$
\begin{aligned}
& y=\frac{8 \mathrm{FD}^{3} \mathrm{~N}}{\mathrm{~d}^{4} \mathrm{G}} \\
& N=\frac{y^{4} G^{3}}{8 F D^{3}} \\
& y=2 \text { in. } \\
& \mathrm{d}=0.625 \mathrm{in} \text {. } \\
& \mathrm{G}=10.5 \times 10^{6} \mathrm{psi} \quad \text { Incone1 " } \mathrm{X} \text { " } 600^{\circ} \mathrm{F} \text { page } 6 \\
& \text { Huntington Alloys Bulletin T-35 } \\
& \mathrm{F}=8471 \mathrm{~b} \\
& \mathrm{D}=6.125 \mathrm{in} \text {. } \\
& N=2.07
\end{aligned}
$$

Increase deflection to 4 in.

$$
\begin{aligned}
& y=4 \text { in. } \\
& N=\frac{4}{2} 2.07=4.14 \text { active coils }
\end{aligned}
$$

DRIVE EXTENSION COLUMN LOAD CAPACITY CALCULATIONS

Critical load was calculated assuming two different end conditions:

1. Ends hinged

2. Ends fixed 
1. Ends hinged

at

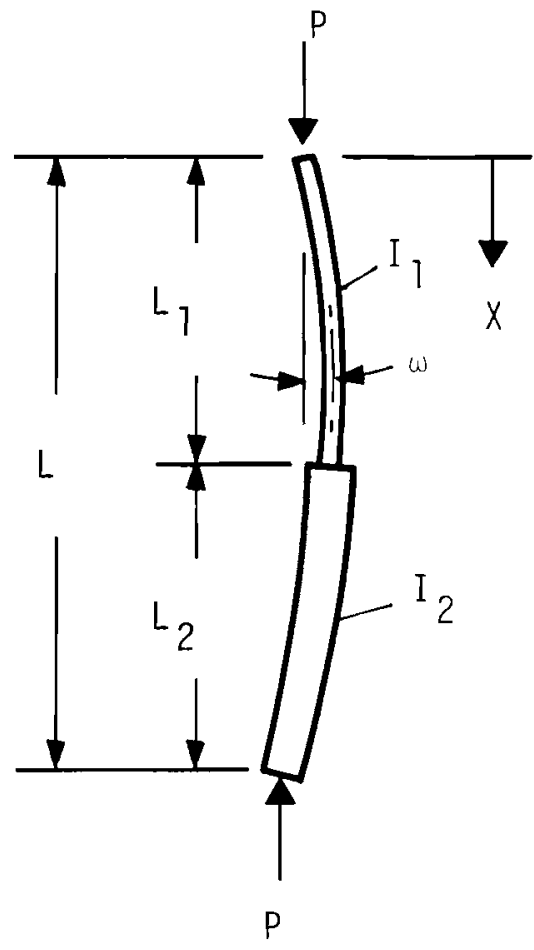

$$
\frac{d^{2} \omega}{d x^{2}}=0
$$

Equation of equilibrium

$$
\begin{aligned}
& \frac{\mathrm{EI}_{1} \mathrm{~d}^{2} \omega_{1}}{d x^{2}}+P \omega_{1}=0 \text { when } 0 \leq x \leq \mathrm{L}, \\
& \frac{\mathrm{EI}_{2} \mathrm{~d}^{2} \omega_{2}}{\mathrm{dx} \mathrm{x}^{2}}+\mathrm{P} \omega_{2}=0 \text { when } \mathrm{L}_{1} \leq x \leq \mathrm{L}
\end{aligned}
$$

Let $K_{1}^{2}=\frac{P}{\mathrm{EI}_{1}}$ and $\mathrm{K}_{2}^{2}=\frac{\mathrm{P}}{\mathrm{EI}_{2}}$

$$
\begin{aligned}
& { }^{\omega_{1}}=\mathrm{C}_{1} \sin \mathrm{K}_{1} \mathrm{X}+\mathrm{C}_{2} \cos \mathrm{K}_{1} \mathrm{X} \text { when } 0 \leq x \leq \mathrm{L}_{1} \\
& \omega_{2}=\mathrm{C}_{5} \sin \mathrm{K}_{2} \mathrm{X}+\mathrm{C}_{6} \cos \mathrm{K}_{2} \mathrm{X} \text { when } \mathrm{L}_{1} \leq \mathrm{x} \leq \mathrm{L}_{2}
\end{aligned}
$$

where $C_{1}, C_{2}, C_{5}$, and $C_{6}$ are constants of integration.

$$
\mathrm{C}-5
$$


Substitution of end conditions and simultaneous solution results in the following:

$$
\begin{aligned}
\frac{\tan \mathrm{K}_{1} \mathrm{~L}_{1}}{\tan \mathrm{K}_{2} \mathrm{~L}_{2}} & =-\frac{\mathrm{K}_{1}}{\mathrm{~K}_{2}} \\
\operatorname{per} & =\frac{\mathrm{m}^{2} \mathrm{EI}_{2}}{\mathrm{~L}^{2}}
\end{aligned}
$$

where $\mathrm{m}^{2}$ is a numerical factor depending on the ratios

$$
\alpha_{1}=\frac{\mathrm{L}_{1}}{\mathrm{~L}} \text { and } \alpha_{2}=\sqrt{\frac{\mathrm{I}_{2}}{\mathrm{I}_{1}}}
$$

substituting,

$$
\begin{aligned}
\frac{\tan m \alpha_{1} \alpha_{2}}{\tan m\left(1-\alpha_{1}\right)} & =-\alpha_{2} \\
L_{1} & =39 \mathrm{in} . \\
L^{2} & =84 \mathrm{in.} \\
\alpha_{1} & =0.464 \\
I_{1} & =0.0265 \mathrm{in} .{ }^{4} \text { (Ba11 screw) } \\
I_{2} & =0.537 \mathrm{in} .{ }^{\text {(Extension tube) }} \\
\alpha_{2} & =4.5
\end{aligned}
$$

substituting,

$$
\frac{\tan 2.09 m}{\tan 0.536 m}=-4.5
$$

By trial and error solution,

$$
\begin{aligned}
\mathrm{m} & =0.935 \\
\mathrm{P}_{\mathrm{Cr}} & =\frac{\mathrm{m}^{2} \mathrm{EI} 2}{\mathrm{~L}^{2}} \\
\mathrm{E} & =30 \times 10^{6} \mathrm{psi} \\
\mathrm{P}_{\mathrm{cr}} & =19901 \mathrm{~b}
\end{aligned}
$$




\section{Ends fixed}

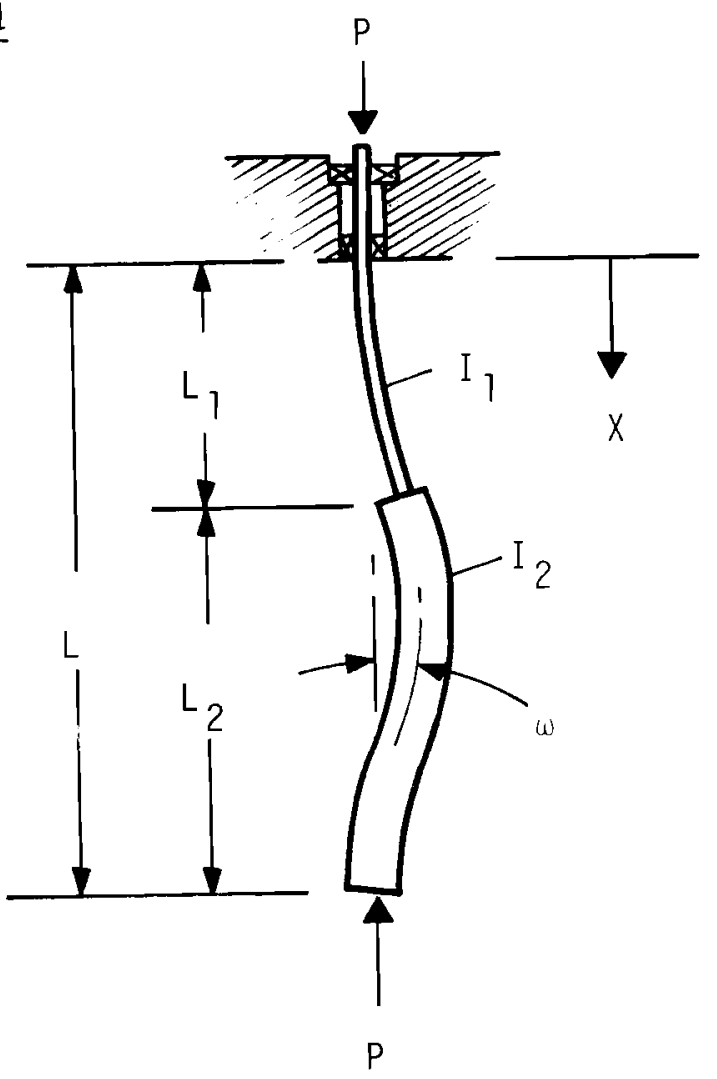

Equations of Equilibrium

$$
\begin{aligned}
& \frac{\mathrm{EI}_{1} \mathrm{~d}^{2} \omega_{1}}{\mathrm{dx} x^{2}}+P \omega_{1}=M_{0} \text { for } 0 \leq x \leq L_{1} \\
& \frac{\mathrm{ET}_{2} \mathrm{~d}^{2} \omega_{2}}{\mathrm{dx} \mathrm{x}^{2}}+P \omega_{2}=M_{0} \text { for } L_{1} \leq x \leq L
\end{aligned}
$$

Again, letting $\mathrm{K}_{1}{ }^{2}=\frac{\mathrm{P}}{\mathrm{EI}_{1}}$ and $\mathrm{K}_{2}{ }^{2}=\frac{\mathrm{P}}{\mathrm{EI}_{2}}$

General solution is;

$$
\begin{aligned}
& \omega_{1}=C_{1} \sin k_{1} X+C_{2} \cos k_{1} X+C_{3} \\
& \omega_{2}=C_{5} \sin k_{2} x+C_{6} \cos k_{2} X+C_{7}
\end{aligned}
$$

where $C_{1}, C_{2}, C_{3}, C_{5}, C_{6}$ and $C_{7}$ are constants of integration. 
Substitution of end conditions and simultaneous solution results in the following:

$$
\begin{array}{ll} 
& \frac{\left(\tan K_{1} L_{1}\right)\left(\tan \frac{K_{1} L_{1}}{2}\right)}{\tan \frac{K_{2} L_{2}}{2}}=-\frac{K_{1}}{K_{2}} \\
\text { Let } & P_{c r}=\frac{m^{2} I_{2}}{L^{2}}
\end{array}
$$

where $\mathrm{m}^{2}$ is a numerical factor depending on the ratios

$$
\alpha_{1}=\frac{\mathrm{L}_{1}}{\mathrm{~L}} \quad \text { and } \quad \alpha_{2}=\sqrt{\frac{\mathrm{I}_{2}}{\mathrm{I}_{1}}}
$$

substituting,

$$
\begin{aligned}
& \frac{\left(\tan m \alpha_{1} \alpha_{2}\right)\left(\tan \frac{m{ }^{\alpha}{ }_{2}}{2}\right)}{\tan \frac{m\left(1-\alpha_{1}\right)}{2}}=-\alpha_{2} \\
& \mathrm{~L}_{1}=39 \mathrm{in} \text {. } \\
& \mathrm{L}=84 \mathrm{in} \text {. } \\
& \alpha_{1}=0.464 \\
& \mathrm{I}_{1}=0.0265 \text { in. }{ }^{4} \text { (Ball screw) } \\
& \mathrm{I}_{2}=0.537 \mathrm{in.}^{4} \text { (Extension tube) } \\
& \alpha_{2}=4.5 \\
& \frac{(\tan 2.09 \text { in. })(\tan 1.045 \text { in. })}{\tan 0.268 \text { in. }}=-4.5
\end{aligned}
$$

By trial and error solution,

$$
\begin{aligned}
\mathrm{m} & =1.47 \\
\mathrm{E} & =30 \times 10^{6} \mathrm{psi} \\
\mathrm{P}_{\mathrm{Cr}} & =\frac{\mathrm{m}^{2} \mathrm{EI} 2}{\mathrm{~L}^{2}}
\end{aligned}
$$




$$
\begin{aligned}
\mathrm{P}_{\mathrm{Cr}} & =4,9301 \mathrm{~b} \\
\mathrm{~F} & =\mathrm{KB}^{2} \mathrm{~A} \\
\mathrm{~K} & =\frac{1}{7.213 \times 10^{7}}, \frac{1 \mathrm{~b}-\mathrm{in}^{2}}{1 \mathrm{ine}^{2}} \\
\mathrm{~B} & =\text { Flux density, lines } / \mathrm{in}^{2} \\
\mathrm{~A} & =\text { Cross sectional area, in. }{ }^{2} \\
\mathrm{~F}_{\max } & =6001 \mathrm{~b} \text { (based on 1atch load of } 1900 \mathrm{lb}) \\
N I & =\frac{\text { Bl }}{\mu} \\
\ell & =\text { Effective path length, in. } \\
\mu & =\text { Permeability } \\
N I & =\text { Magnetomotive force, amp-turns }
\end{aligned}
$$

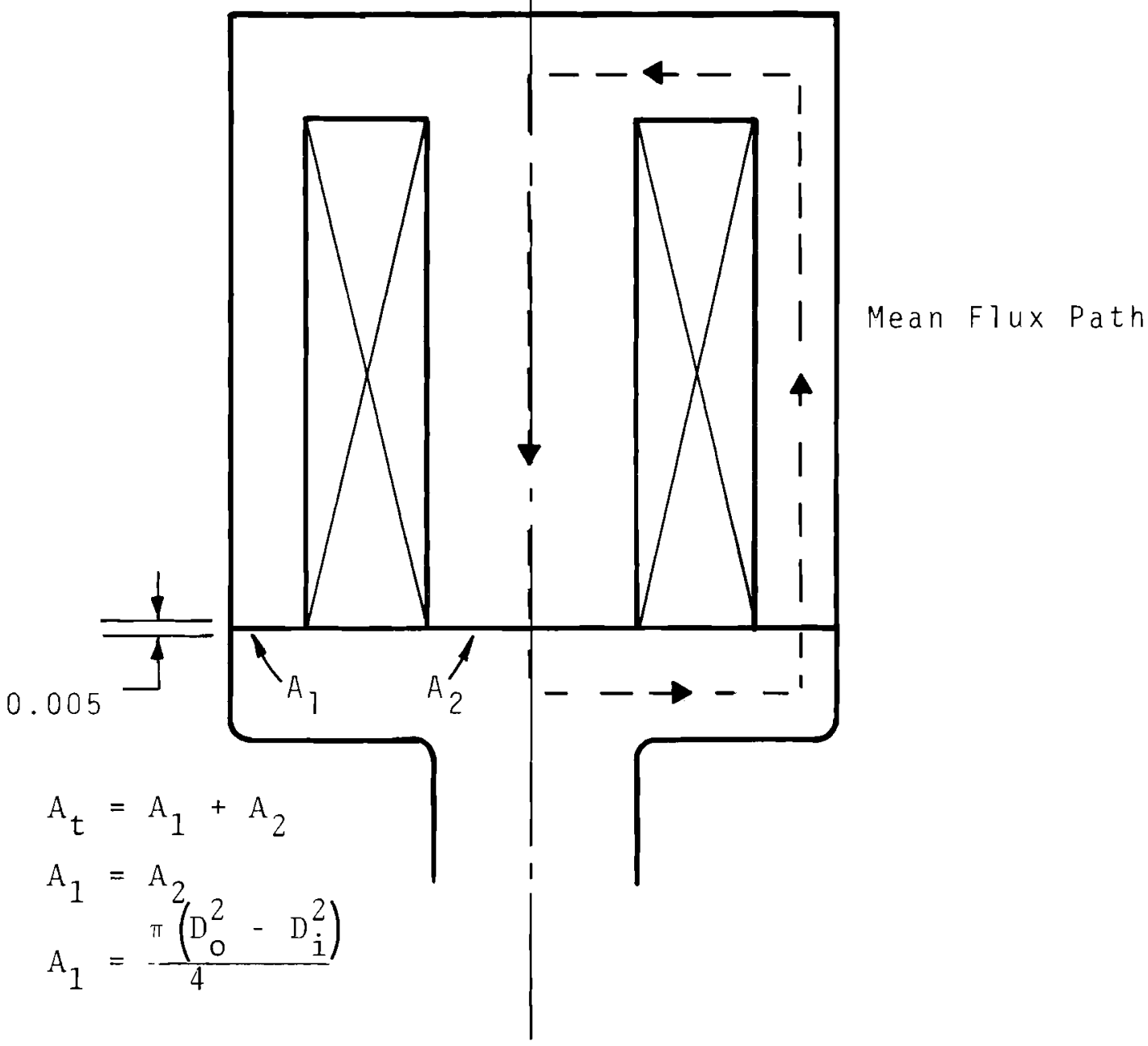




$$
\begin{aligned}
\mathrm{A}_{2} & =\frac{\pi \mathrm{D}_{2}^{2}}{4} \\
\frac{\pi \mathrm{D}_{2}^{2}}{4} & =\frac{\pi\left(\mathrm{D}_{0}^{2}-\mathrm{D}_{\mathrm{i}}^{2}\right)}{4} \\
\mathrm{D}_{2}^{2} & =\mathrm{D}_{0}^{2}-\mathrm{D}_{\mathrm{i}}^{2} \\
\mathrm{D}_{0} & =3.5 \mathrm{in} . \\
\mathrm{D}_{2} & =2.2 \mathrm{in} . \\
\mathrm{D}_{i} & =2.72 \mathrm{in} . \\
\mathrm{A}_{t} & =7.7 \mathrm{in.} .^{2}
\end{aligned}
$$

Let $D_{0}=3.5$ in.

Solve for $B$ required

$$
\begin{aligned}
& B=\sqrt{\frac{F}{\mathrm{KA}}} \\
& F=6001 \mathrm{~b} \\
& K=\frac{1}{7.213 \times 10^{7}}\left(\frac{1 \mathrm{~b}-\mathrm{in}^{2}}{1 \mathrm{ine}^{2}}\right)
\end{aligned}
$$

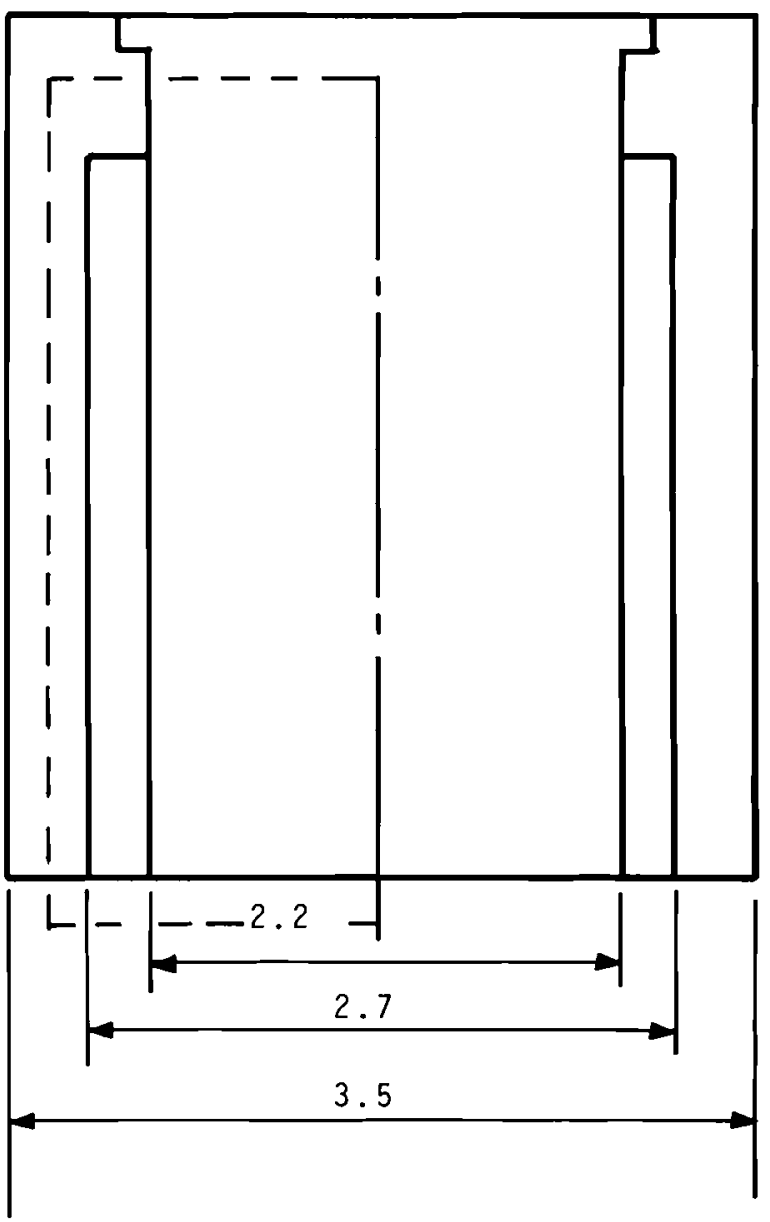

$$
\begin{aligned}
\mathrm{B}=7.49 \times 10^{4} \text { 1ines } / \text { in. }^{2} & =1.16 \times 10^{4} 1 \text { ines } / \mathrm{cm}^{2} \\
& =11.6 \mathrm{~K}-\text { GAUSS }
\end{aligned}
$$

From Armco Iron data,

$$
\begin{aligned}
\mathrm{B} & =11.6 \mathrm{~K} \text {-GAUSS } \\
\mathrm{H} & =4 \text { Oersteds } \\
\ell_{i} & =11.2 \mathrm{in} . \\
\ell & =0.005 \text { in. (air gap) } \\
\mathrm{NI} & =\mathrm{H}_{i} \ell_{i}+2(0.313 \mathrm{~B} \ell) \\
& =325.6 \text { amp-turns } \\
\mathrm{NI} & =325.6 \text { amp-turns }
\end{aligned}
$$


Calculate number of turns for different size wires Cross sectional area

$$
\begin{aligned}
A_{c} & =\left(\frac{D_{i}-D_{i}}{2}\right)^{h} \\
D_{i} & =2.7 \mathrm{in} . \\
D_{i} & =2.2 \mathrm{in} . \\
h & =3.375 \mathrm{in} . \\
A_{c} & =0.843 \mathrm{in.}{ }^{2}
\end{aligned}
$$

Assume close packing,

$$
\begin{aligned}
A_{w} & =A_{c} f \\
A_{c} & =\text { cross sectional area of space } \\
A_{w t} & =\text { cross sectional area of wires } \\
f & =\text { packing factor }=0.907 \\
A_{w t} & =0.762 \text { in. } 2 \\
n & =\frac{A_{w t}}{A_{w i}} \\
A_{w i} & =\frac{\pi D_{0}^{2}}{4} \\
n & =\frac{A_{w t}}{\pi D_{0}^{2}} \\
h & =\frac{4 A_{w t}}{\pi D_{o}^{2}} \\
n & =\frac{0.973}{D_{0}^{2}}
\end{aligned}
$$

Solve for length of wire

$$
\begin{aligned}
& V_{c}=\frac{\pi\left(D_{i}^{2}-D_{2}^{2}\right)}{4} \ell \\
& V_{c}=6.5 \mathrm{in} .3
\end{aligned}
$$




$$
\begin{aligned}
V_{W} & =f V_{c} \\
V_{W} & =5.87 \text { in. }{ }^{2} \\
l_{W} & =\frac{V_{W}}{A_{W i}} \\
l_{W} & =\frac{V_{W}}{\pi D_{O}^{2}} \\
l_{W} & =\frac{0.623}{D_{0}^{2}} \mathrm{ft} \\
N I & =325.6 \text { amp-turns } \\
I & =\frac{325.6}{n} \\
E & =\frac{I R}{n} \\
E & =\frac{325.6}{n} \mathrm{R}
\end{aligned}
$$

$\begin{array}{cccclll}\text { Size, AWG } & \text { n, turns } & & \mathrm{R}^{1}, \mathrm{ohm}^{(\mathrm{a})} & & \mathrm{R}^{1} / \mathrm{n} & \mathrm{E} \\ 20 & 885 & & 9.7 & & 0.011 & 3.58 \\ 21 & 1093 & 15.0 & 0.0137 & 4.46 \\ 22 & 1380 & 24.2 & 0.0176 & 5.72 \\ 23 & 1710 & 37.6 & 0.022 & 7.16 \\ 24 & 2150 & 60.7 & 0.0282 & 9.18\end{array}$

a. $600^{\circ} \mathrm{F}, \alpha=2.18 \times 10^{-3} /{ }^{\circ} \mathrm{F}$ for copper

\section{Current Requirements}

$\begin{array}{crrrr}\text { Size, AWG } & \text { R, ohm } & \text { E, volt } & & \text { I, amp } \\ 20 & 9.7 & 3.58 & 0.369 \\ 21 & & 15.0 & 4.46 & 0.297 \\ 22 & 24.2 & 5.72 & 0.236 \\ 23 & 37.6 & 7.16 & 0.190 \\ 24 & 60.7 & 9.18 & 0.152\end{array}$

$$
C-12
$$




\section{LATCH ROD COLUMN CALCULATIONS}

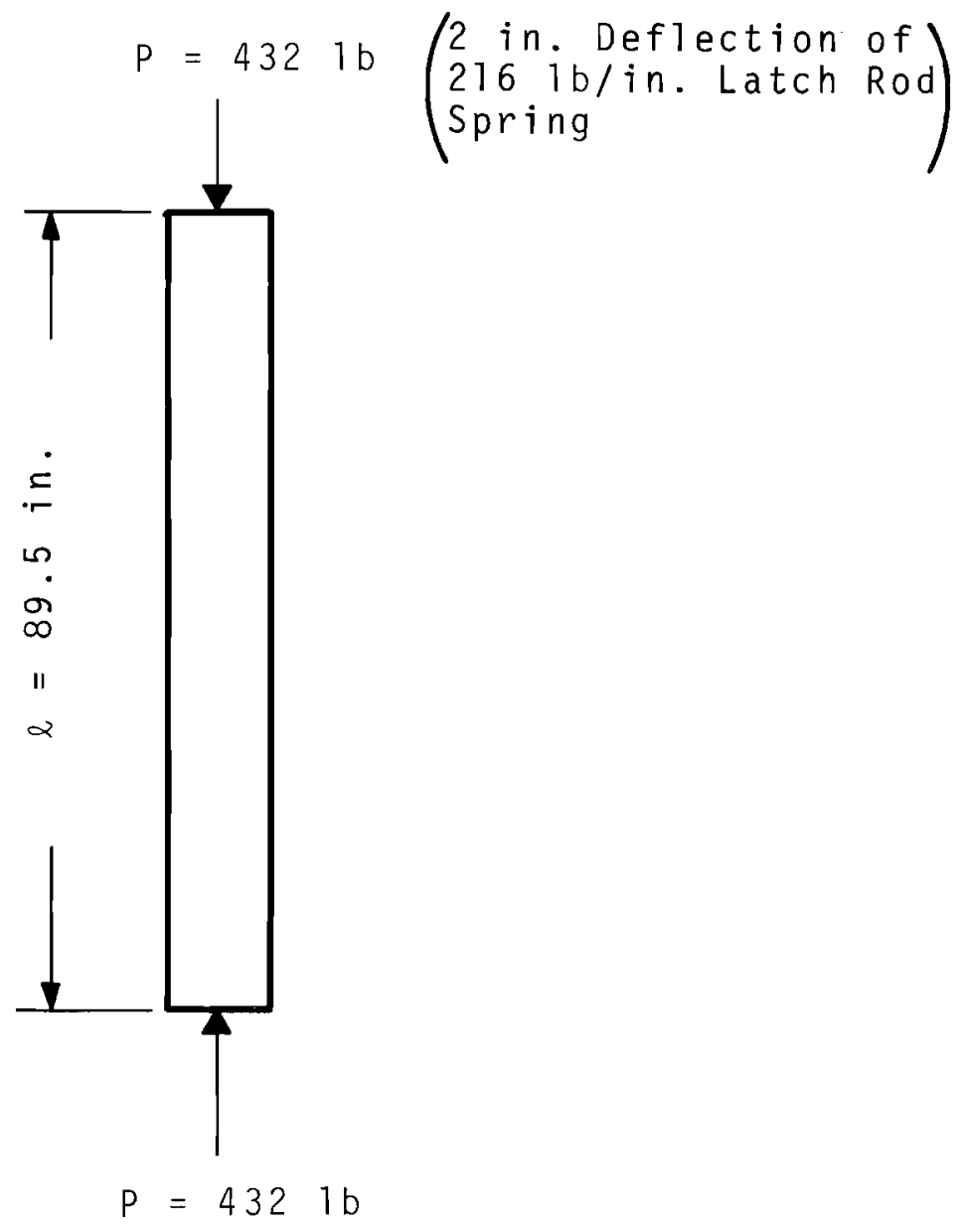

$$
\begin{aligned}
P_{c r} & =\frac{\pi^{2} E I}{\ell^{2}} \\
P_{c r} & =(f . s .) P \\
P & =4321 \mathrm{~b} \\
I & =0.310 \mathrm{in} .4(11 / 2 \text { schedule 40) } \\
E & =29 \times 10^{6} \text { psi (SS) } \\
\ell & =89.5 \mathrm{in} .
\end{aligned}
$$

Solve for f.s.

$$
\begin{aligned}
& \text { f.s. }=\frac{\pi^{2} E I}{\mathrm{Pl}^{2}} \\
& \text { f.s. }=2.57
\end{aligned}
$$




\section{STRESS-LATCH FINGER}

$$
\mathrm{F}_{\text {max }}=\frac{\mathrm{F}_{1 \mathrm{atch}}}{3}
$$

The divisor of 3 is to account for 3 fingers

$$
\begin{aligned}
F_{1 a t c h} & =F_{s}+F_{d} \\
F_{s} & =6001 b\left(\begin{array}{l}
\text { Safety rod } \\
\text { accelerating } \\
\text { spring 3G } \\
\text { acceleration }
\end{array}\right) \\
F_{d} & =13001 \mathrm{~b}\left(\begin{array}{l}
\text { Drive 1ifting } \\
\text { capacity }
\end{array}\right) \\
F_{\max } & =8331 \mathrm{~b}\left(\begin{array}{l}
\text { Would occur } \\
\text { with stuck rod }
\end{array}\right)
\end{aligned}
$$

Section A

$$
\begin{aligned}
\sigma_{A} & =\frac{F}{A}+\frac{M c}{I} \\
F & =833 \mathrm{\#} \\
A & =(0.5)(0.375)=0.1875 \mathrm{in}^{2} \\
M & =\mathrm{Fd} \\
d & =0.5 \mathrm{in} . \\
M & =583 \mathrm{in} .-1 \mathrm{~b} \\
C & =\frac{0.375}{2}=0.1875 \mathrm{in} . \\
I & =\frac{b h^{3}}{12}=0.0022 \mathrm{in} .4 \\
\sigma_{A} & =\frac{833}{0.1875}+\frac{583}{0.0} \frac{(0.1875)}{022} \\
& =4,450+49,700 \\
\sigma_{A} & =54,150 \mathrm{psi}
\end{aligned}
$$

For Stellite 6B

$$
\begin{aligned}
{ }^{\sigma} \mathrm{YP} & =60,600 \mathrm{psi} \text { at } 1250^{\circ} \mathrm{F} \text {, short term } \\
& \\
\sigma_{\mathrm{ULT}} & =114 \text { Union Carbide wear }
\end{aligned}
$$




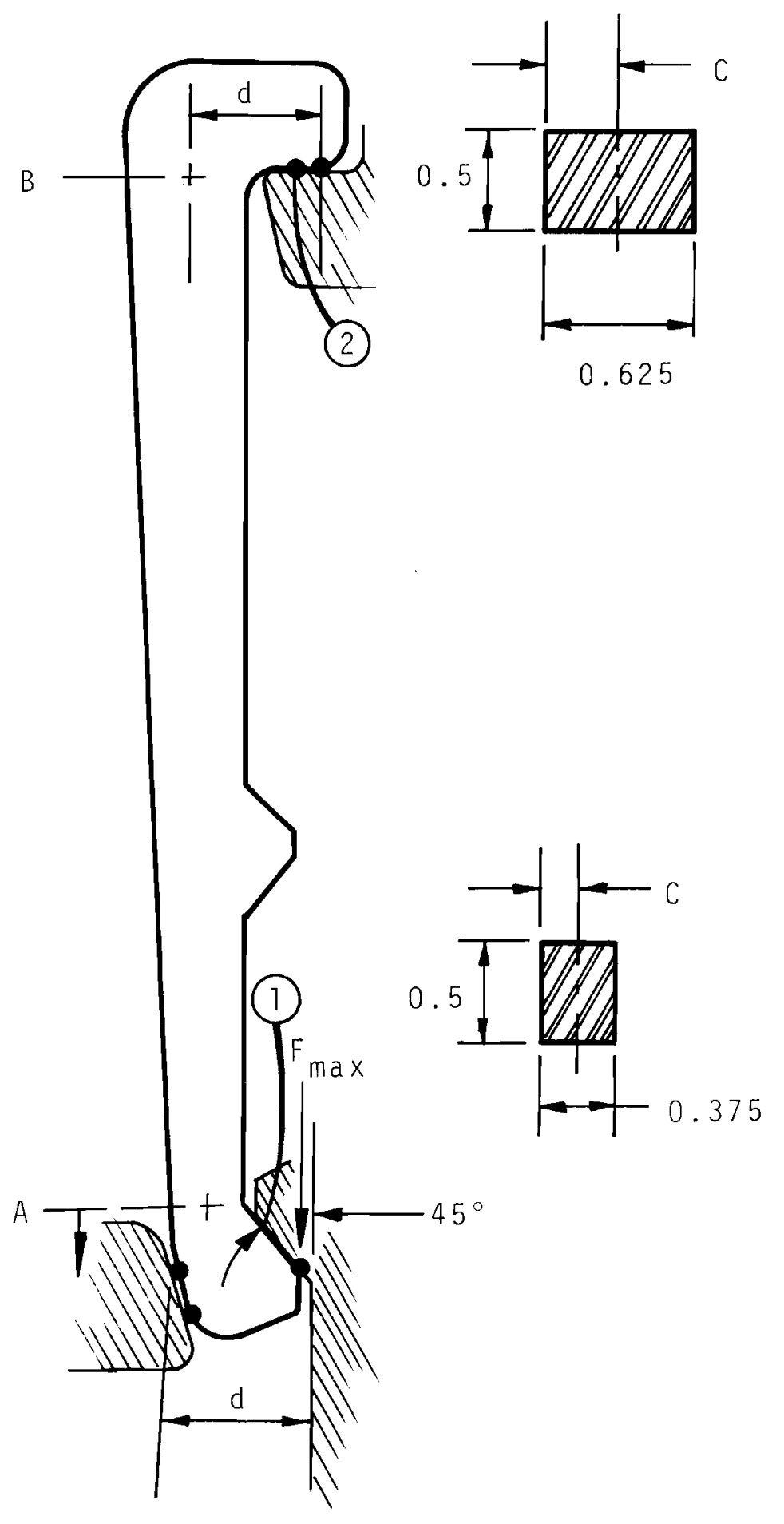




$$
\begin{aligned}
& \mathrm{f} . \mathrm{s} \cdot \mathrm{YP}=\frac{{ }^{\sigma} \mathrm{YP}}{\sigma}=\frac{60,600}{54,150}=1.12 \\
& \mathrm{f.s} \cdot \mathrm{ULT}_{\mathrm{T}}=\frac{115,000}{54,150}=2.12
\end{aligned}
$$

Note: Once finger yields slightly, load on cam would be redistributed with the cam surface absorbing the bending moment leaving only the direct tensile load.

After yielding,

$$
\begin{aligned}
\sigma & =4,450 \mathrm{psi} \\
\mathrm{f} . \mathrm{s} \cdot \mathrm{YP} & =\frac{60,600}{4,450}=13.6 \\
\mathrm{f} . \mathrm{s} \cdot \mathrm{ULT} & =25.9
\end{aligned}
$$

Section B

$$
\begin{aligned}
& \sigma_{B}=\frac{F}{A}+\frac{M c}{I} \\
& F=8331 \mathrm{~b} \\
& A=(0.5)(0.625)=0.3125 \mathrm{in.}^{2} \\
& \mathrm{M}=\mathrm{Fd} \\
& \mathrm{d}=0.7 \text { in. } \\
& C=0.3 \mathrm{in} \text {. } \\
& I=\frac{\mathrm{bh}^{3}}{12}=0.0102 \mathrm{in.}^{4} \\
& \sigma=\frac{833}{0.3125}+\frac{(833)(0.7)(0.3)}{0.0102} \\
& \sigma=19,870 \mathrm{psi} \\
& \text { f.s.YP }=\frac{60,600}{19,870}=3.04 \\
& \mathrm{f} . \mathrm{s} \cdot \mathrm{ULT}=\frac{115,000}{19,870}=5.8 \\
& F=\frac{F_{\text {rod normal }}}{3}=\frac{F_{\mathrm{RN}}}{3}
\end{aligned}
$$




$$
\begin{aligned}
\mathrm{F}_{\mathrm{RN}} & =\mathrm{F}_{\mathrm{S}}+\mathrm{W} \\
\mathrm{F}_{\mathrm{S}} & =6001 \mathrm{~b} \quad \text { (accelerating spring) } \\
\mathrm{W} & =2001 \mathrm{~b} \quad \text { (safety rod weight) } \\
\mathrm{F}_{\mathrm{RN}} & =600+200=8001 \mathrm{~b} \\
\mathrm{~F} & =\frac{800}{3}=2661 \mathrm{~b}
\end{aligned}
$$

For Section A

$$
\begin{aligned}
\mathrm{f} . \mathrm{s} \cdot \mathrm{YP} & =\frac{833}{266} 1.12=3.51 \\
\mathrm{f} \cdot \mathrm{s} \cdot \mathrm{ULT} & =\frac{833}{266} 2.12=6.34
\end{aligned}
$$

For Section B

$$
\begin{aligned}
f . s \cdot Y P & =\frac{833}{266}(3.04)=9.53 \\
f . s \cdot{ }_{U L T} & =\frac{833}{266}(5.8)=18.2
\end{aligned}
$$

\section{CONTACT STRESSES}

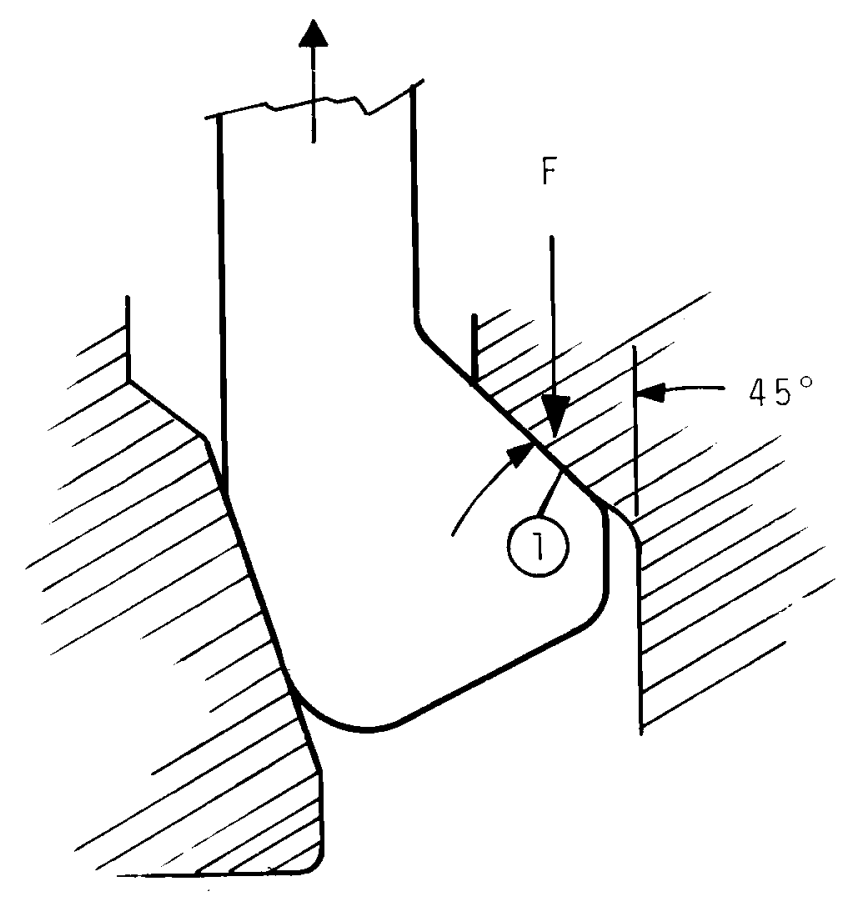


Surface 1

$$
\begin{aligned}
\sigma & =\frac{\mathrm{P}}{\mathrm{A}} \\
\mathrm{P} & =\mathrm{F} \sin 45^{\circ} \\
\mathrm{F} & =8331 \mathrm{~b} \quad(\max i m u m \text { 10ad) } \\
\mathrm{A} & =(0.3)(0.5) \\
& =0.15 \mathrm{in} .^{2} \\
\sigma & =\frac{833 \mathrm{sin} 45}{0.15}=3920 \mathrm{psi}
\end{aligned}
$$

Surface 2

$$
\begin{aligned}
& \sigma=\frac{\mathrm{P}}{\mathrm{A}} \\
& \mathrm{P}=\mathrm{F}=8331 \mathrm{~b} \quad(\operatorname{maximum} 10 \mathrm{ad}) \\
& \mathrm{A}=(0.2)(0.5)=0.1 \mathrm{in}^{2} \\
& \sigma=\frac{833}{0.1}=8,330 \mathrm{psi}
\end{aligned}
$$

Factor of safety based on yield point

$$
\begin{aligned}
& \text { f.s. }{ }_{1}=\frac{60,600}{3920}=15.4 \\
& \mathrm{f} \cdot \mathrm{s} \cdot 2=\frac{60,600}{8,330}=7.26 \\
& \Sigma F_{Y}=F_{m}-F_{o}-W+F_{f y}=0 \\
& \mathrm{~F}_{\mathrm{m}}=\mathrm{F}\left(\sin 45^{\circ}\right)^{2}(\cos \theta) \\
& \mathrm{F}_{\mathrm{f}}=\mu \mathrm{F}_{\mathrm{m}} \\
& \mu=0.4 \text { to } 0.8 \text { (coefficient of friction } \\
& \text { stellite } 6 \mathrm{~B} \text { on } 6 \mathrm{~B} \text { ) } \\
& F_{f y}=\mu F(\sin 45)^{2}(\cos \theta)^{2} \\
& \mathrm{~F}_{\mathrm{O}}=\mathrm{F}_{\mathrm{m}} \underline{\sin \theta \quad \mathrm{F}_{\mathrm{O}}} \\
& F_{m}=W+F\left(\sin 45^{2}(\cos \theta)(\sin \theta)-F(\sin 45)^{2}(\cos \theta)^{2}\right. \\
& =w+F(\sin 45)^{2}(\cos \theta)^{2}\left(\frac{\sin \theta}{\cos \theta}-\mu\right) \\
& =W+F(\sin 45)^{2}(\cos \theta)^{2}(\tan \theta-\mu)
\end{aligned}
$$




\section{LATCH OPENING FORCES}

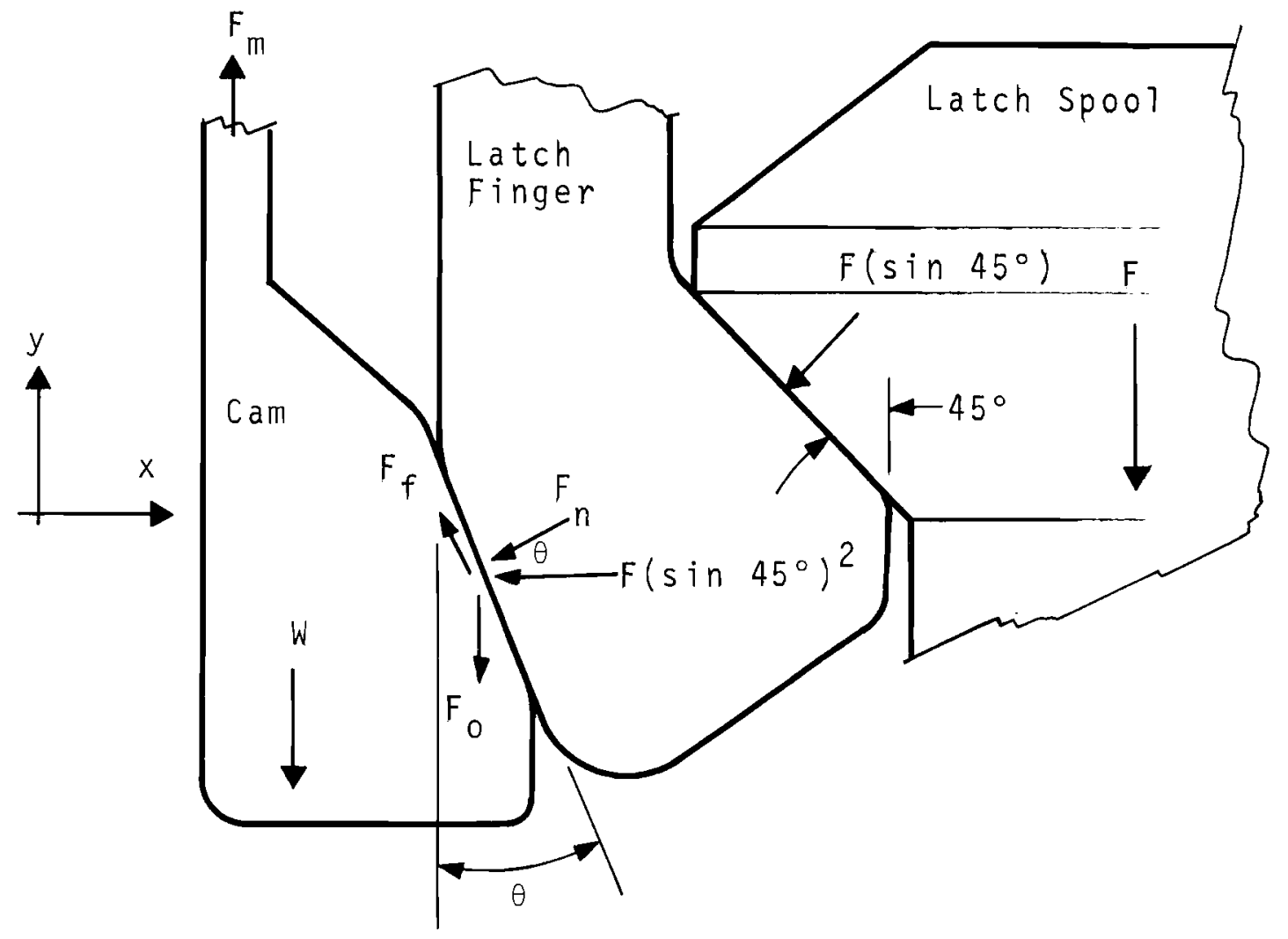


Calculate $\frac{F_{m}-W}{F}$ for different $\theta^{\prime} s$

holding $\mu=0.4$

$$
\begin{aligned}
\frac{\mathrm{F}_{\mathrm{m}}-W}{\bar{F}} & =(\sin 45)^{2}(\cos \theta)^{2}[(\tan \theta)-\mu] \\
& =(0.707)^{2}(\cos \theta)^{2}[(\tan \theta)-0.4] \\
& =0.5(\cos \theta)^{2}[(\tan \theta)-0.4]
\end{aligned}
$$

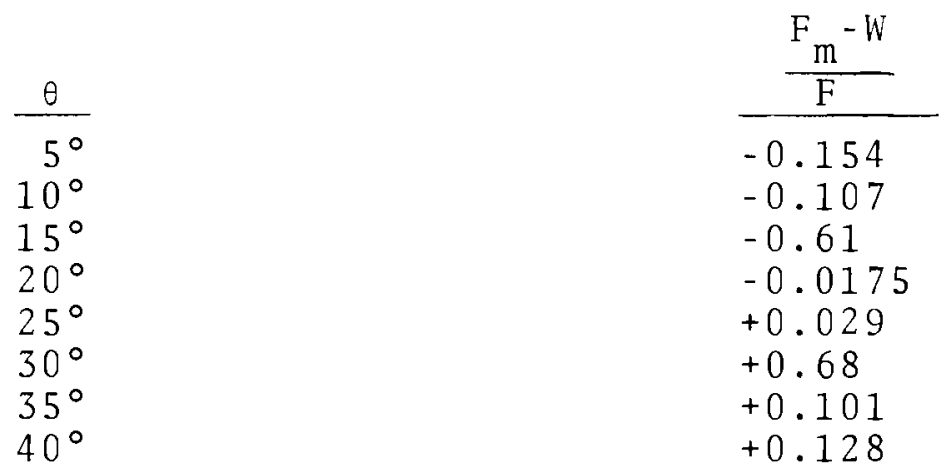

for $\mu=0.8$

\begin{tabular}{r}
$\theta$ \\
\hline 5 \\
10 \\
15 \\
20 \\
25 \\
30 \\
35 \\
40 \\
45
\end{tabular}

\begin{tabular}{l}
$\frac{F_{m}-W}{F}$ \\
\hline-0.354 \\
-0.301 \\
-0.248 \\
-0.194 \\
-0.137 \\
-0.082 \\
-0.034 \\
+0.018 \\
+0.05
\end{tabular}

EST IMATE-LATCH ROD ASSEMBLY WEIGHT

Cam

$3.5 \phi$
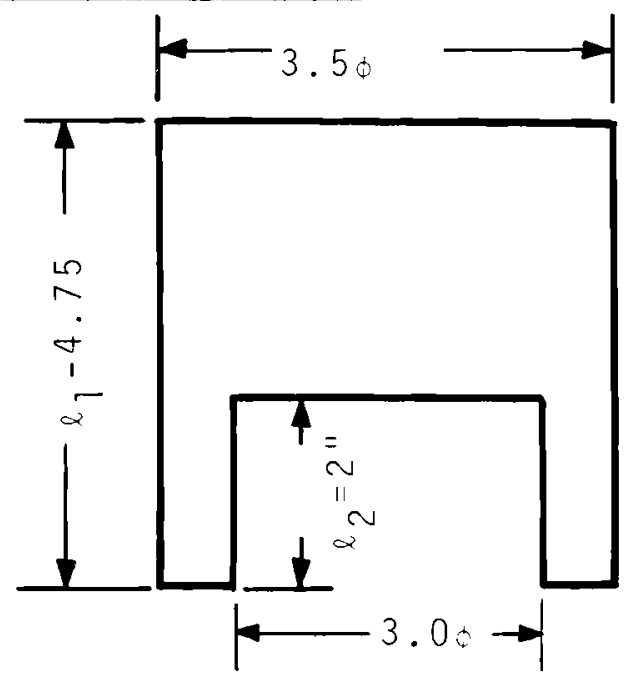

C -20 


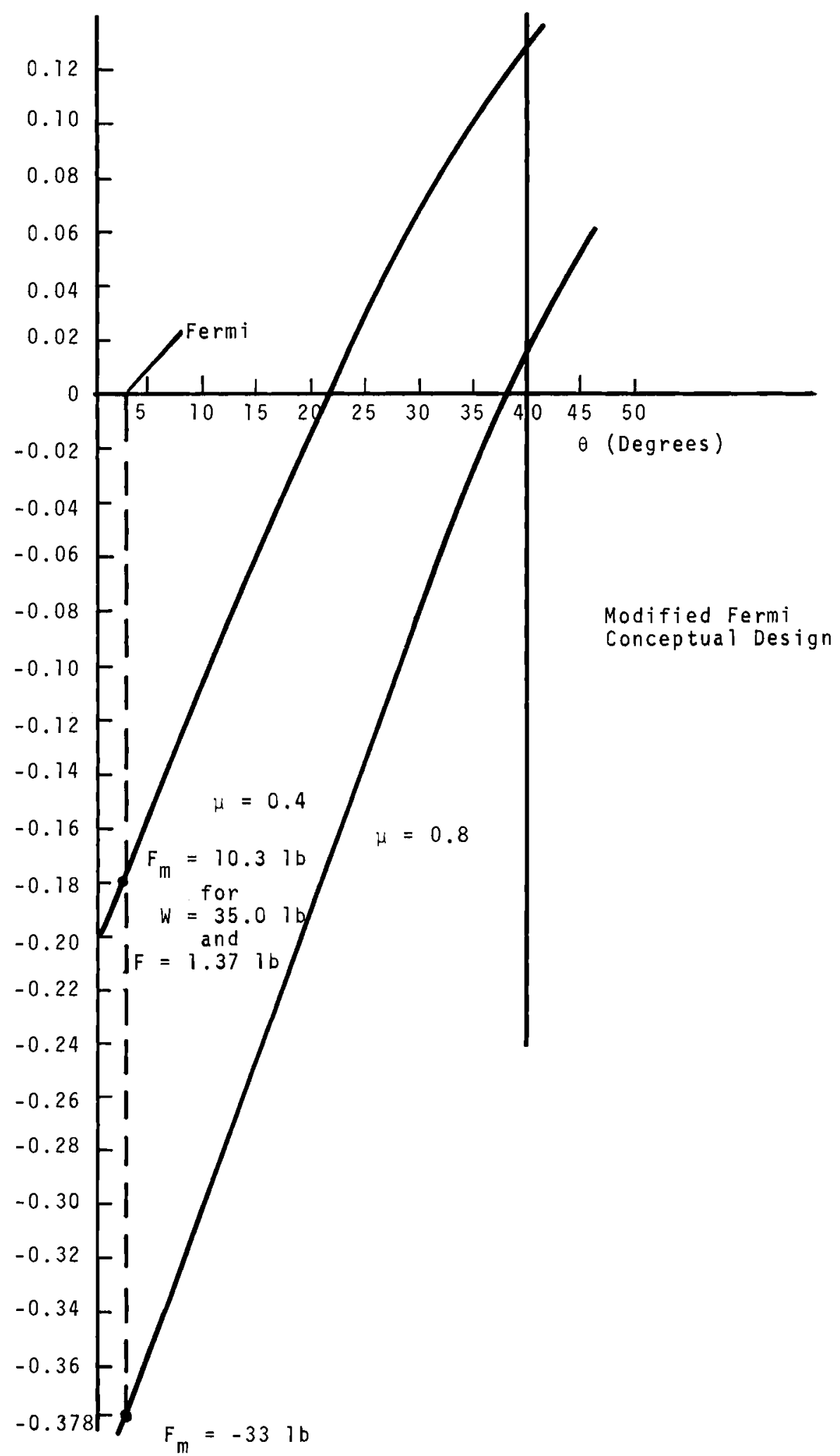




$$
\begin{aligned}
& W=\left[\frac{\pi D_{0}^{2} l_{1}}{4}-\frac{\pi D_{1}^{2} l_{2}}{4}\right] \rho \\
& \left.\rho=0.303 \mathrm{lb} / \mathrm{in} .^{3} \text { (Stel1ite } 6 \mathrm{~B}\right) \\
& W=9.58 \mathrm{lb}
\end{aligned}
$$

Latch rod

$$
\begin{aligned}
W & =\ell \omega \\
\ell & =20 \mathrm{ft} \text { (approx.) } \\
\omega & =2.7 \mathrm{lb} / \mathrm{ft}(1 \mathrm{l} / 2 \mathrm{in.} \text { SS Sched. } 40 \text { pipe) } \\
W & =54 \mathrm{lb}
\end{aligned}
$$

Magnet Armature

$$
\begin{aligned}
& W=\left[\frac{\pi D_{1}^{2} l_{1}}{4}+\frac{\pi D_{2}^{2} l_{2}}{4}\right] \rho \\
& \rho=0.281 \mathrm{~b} / \mathrm{in}^{3} \text { (Armco Iron) } \\
& W=16.91 \mathrm{~b}
\end{aligned}
$$

Partial total

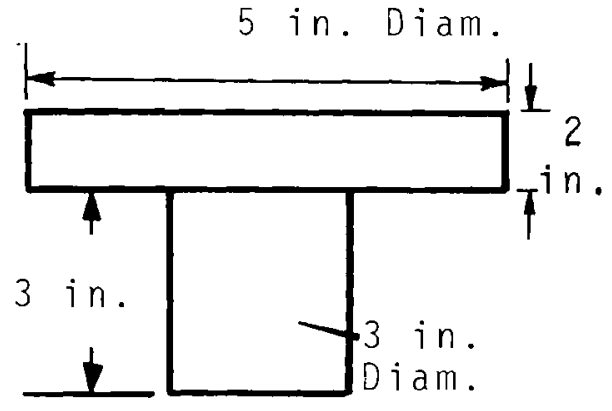

$$
W_{p t}=9.6+54+16.9=80.5
$$

add about $20 \%$ miscellaneous,

$$
\underset{\text { total }}{\text { weight }}=W_{\text {tot }} \approx 1001 \mathrm{~b}
$$

\section{SCRAM TIME CALCULATION}

There are 3 phases in scram cycle:

1. Decay of magnetic flux

2. Delatch

3. Rod travel into core

1. Decay of magnetic flux

Estimated $0.050 \mathrm{sec}$

2. Delatch

$$
\begin{aligned}
& s=\frac{1}{2} a t^{2} \\
& t=\sqrt{\frac{2 s}{a}} \\
& F=m a \\
& a=\frac{F_{a}}{m}
\end{aligned}
$$




$$
\begin{aligned}
t & =\sqrt{\frac{25 \mathrm{~m}}{F_{a}}} \\
\mathrm{~s} & =0.75 \mathrm{in} . \\
\mathrm{m} & =\frac{\mathrm{W}}{\mathrm{g}} \\
\mathrm{W} & =601 \mathrm{~b} \text { (Latch rod, armature, cam) } \\
\mathrm{g} & =386 \mathrm{in} . / \mathrm{sec}^{2} \\
\mathrm{~F}_{\mathrm{a}} & =\mathrm{W}+\frac{\mathrm{F}}{2} \\
\mathrm{~F}_{\mathrm{s}} & =1001 \mathrm{~b} \\
\mathrm{~F}_{\mathrm{a}} & =1101 \mathrm{~b} \\
\mathrm{t} & =0.046 \mathrm{sec}
\end{aligned}
$$

3. Trave 1

$$
\begin{aligned}
& \text { From Figure } 4, \\
& \text { time }=0.6 \mathrm{sec} \\
& \text { tota1 time }=0.050+0.046+0.6 \\
&=0.696, \text { or about } 0.7 \mathrm{sec}
\end{aligned}
$$

SCRAM ASSIST SPRING CALCULATIONS

Design Parameters

$$
\begin{aligned}
& \text { Cocked force, }{ }^{\mathrm{F}_{\mathrm{C}}}{ }_{1200{ }^{\circ} \mathrm{F}}=8001 \mathrm{~b} \\
& \text { Preload, } \mathrm{F}_{\mathrm{PL}_{1200}{ }^{\circ} \mathrm{F}}=4001 \mathrm{~b} \\
& \text { Maximum Operating Temp, To }=1200^{\circ} \mathrm{F} \\
& \text { Modulus Rigidity, } \mathrm{G}_{1200}{ }^{\circ} \mathrm{F}=8.1 \times 10^{6} \frac{\mathrm{lb}}{\mathrm{in} .}{ }^{2} \\
& \mathrm{G}_{80}{ }^{\circ} \mathrm{F}=11 \times 10^{6} \frac{1 \mathrm{~b}}{\mathrm{in}} \cdot 2
\end{aligned}
$$

Material, Incone $1 \mathrm{X}-750$

Relaxation of Inconel X-750 at $1200^{\circ} \mathrm{F}$ and $30,0001 \mathrm{~b} / \mathrm{in} .^{2}$ is approximately $10 \%$ year due to thermal effects. 
Allowable Torsional Shearing

Stress, ${ }^{2} 1200{ }^{\circ} \mathrm{F} 30,000 \mathrm{lb} / \mathrm{in} .{ }^{2}$

Irradiation effects on relaxation not known.

Design Equations

$\tau=\frac{K 8 F_{C} D}{\pi d^{3}} \quad, \quad K=\frac{4 C-1}{4 C-4}+\frac{0.615}{C}$

$C=D / d$

$\mathrm{D}=$ Mean spring diamete $\mathrm{r}$

$\mathrm{d}=$ Wire diameter

$y=\frac{8 F_{C} D^{3} N}{4}$

d G

$y=$ Distance spring is compressed

$N=$ Number of active coils

$\mathrm{L}=\mathrm{Nd}+\mathrm{N}^{1} \mathrm{~d}+\left(\mathrm{N}^{1}+\mathrm{N}-1\right) \mathrm{CL}+\mathrm{y}$

$\mathrm{L}=$ Free 1 ength

$\mathrm{N}^{1}=$ Number of dead coils

$\mathrm{CL}=\mathrm{Clearance}$ between coils when spring is compressed.

Solution for Spring Size by Trial and Error

As s ume

$$
\begin{aligned}
\mathrm{d} & =0.70, \mathrm{D}=4.0 \\
\mathrm{C}=\frac{4.0}{0.7}=5.72 & \\
\mathrm{~K}=\frac{22.8-1}{22.8-4}+\frac{0.615}{22.8} & =1.16+0.027 \\
& =1.19
\end{aligned}
$$

For $1200^{\circ} \mathrm{F}$ operating conditions

$$
\begin{aligned}
& d^{3}=\frac{1.19(8)(800)(4)}{\pi 30,000}=0.323 \\
& d^{\prime \prime}=0.685
\end{aligned}
$$

Therefore solution for d lies between 0.685 and 0.70 . Use $d=0.70$ for conservative design. 


$$
\begin{aligned}
N & =\frac{20(0.7)^{4}(8.1)\left(10^{6}\right)}{(8)(800)(4)^{3}}=95 \\
\tau_{1200{ }^{\circ} \mathrm{F}} & =\frac{1.19(800)(8)(4)}{\pi(0.7)^{3}}=28,300 \mathrm{lb} / \mathrm{in} .^{2}
\end{aligned}
$$

As sume

$$
\begin{aligned}
& \mathrm{N}^{1}=2 \\
& \mathrm{C}_{\mathrm{L}}=0.1 \text { in. }
\end{aligned}
$$

Free length

$$
\begin{aligned}
L & =95(0.7)+2(0.7)+20+96(0.1) \\
& =97.5 \mathrm{in} .
\end{aligned}
$$

Preload Length,

$$
\mathrm{L}_{\mathrm{PL}}=87.5 \mathrm{in} \text {. }
$$

Cocked length,

$$
\mathrm{L}_{\mathrm{C}}=77.5 \mathrm{in} \text {. }
$$

For room temperature conditions

$$
\begin{aligned}
& \tau_{80}{ }^{\circ} \mathrm{F}=\tau_{1200}{ }^{\circ} \mathrm{F}\left(\frac{\mathrm{G}_{80}{ }^{\circ} \mathrm{F}}{{ }^{G} 1200^{\circ} \mathrm{F}}\right)=28,300\left(\frac{11 \times 10^{6}}{8.1 \times 10^{6}}\right) \\
& =38,400 \mathrm{lb} / \mathrm{in}^{2} \\
& \mathrm{~F}_{\mathrm{C}_{80}{ }^{\circ} \mathrm{F}}=\mathrm{F}_{\mathrm{C}_{1200}{ }^{\circ} \mathrm{F}}\left(\frac{\mathrm{G}_{80}{ }^{\circ} \mathrm{F}}{\mathrm{G}_{1200^{\circ} \mathrm{F}}}\right)=800\left(\frac{11 \times 10^{6}}{8.1 \times 10^{6}}\right) \\
& =10851 \mathrm{~b}
\end{aligned}
$$




\section{POISON SECTION ALLOWABLE BOW CALCULATIONS}

Annular Clearance

Fermi $C_{L}=0.020$ in.

Scaling up to FTR

FTR $C_{L}=0.035$ in.

Assume: (Conservative Assumptions)

Distance between front pad and cocking shoulder to be $20 \mathrm{ft}$.

Distance between front pad and central land to be $10 \mathrm{ft}$.

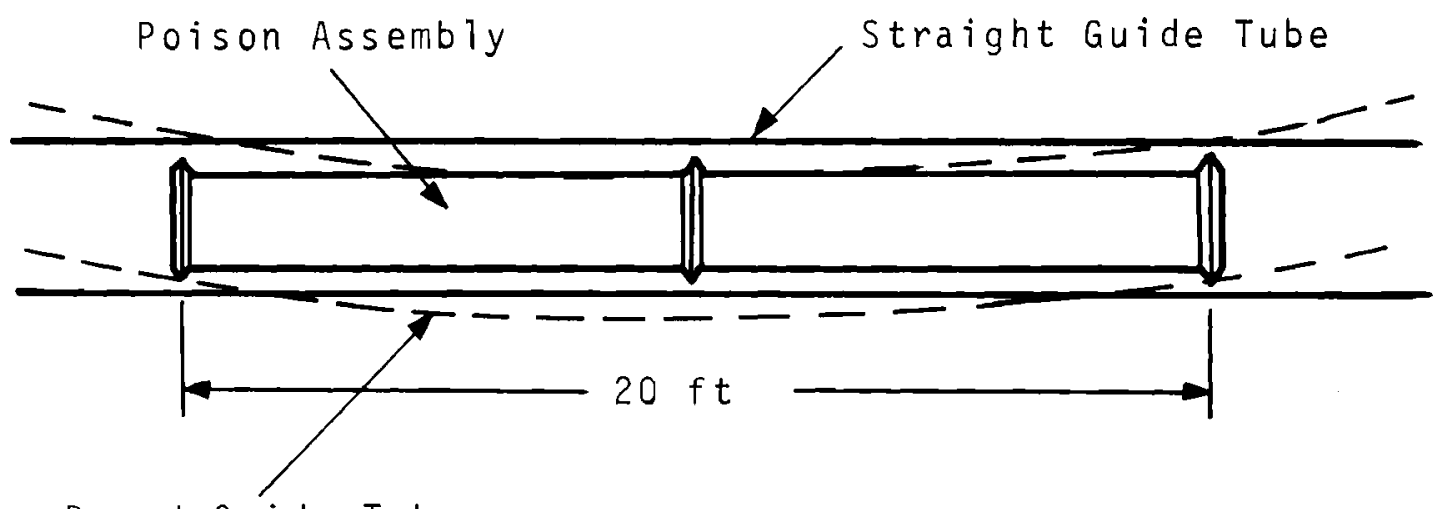

Bowed Guide Tube

Allowable Bow $=0.070 \mathrm{in.} / 20 \mathrm{ft}$ 


\section{POISON SECTION STRESS CALCULATIONS}

Component

Spoo1 bolt

Spring guide tube

Poison tube and test section

Dashpot support tube

Dashpot wall

Maximum Static Load

Occurs at spool bolt during the unlikely occurrence of trying to free a stuck control rod. It is equal to the maximum drive lift force of 1060 lb plus spring force of $8001 \mathrm{~b}$.

\section{Maximum Static Load $=18601 \mathrm{~b}$}

Maximum Dynamic Load

Occurs due to deceleration of the poison assembly.

$\mathrm{L}_{\text {Dynamic }}=$ Weight + Mass $\times$ Deceleration

For the conceptual design base design reference case

$$
\begin{aligned}
\mathrm{V} & =6.375 \mathrm{ft} / \mathrm{sec} \text { (Velocity at entrance to the } \\
\mathrm{S} & =6 \mathrm{in} \text {. (Trave1 in the dashpot) } \\
\mathrm{A} & =\frac{\mathrm{V}^{2}}{2 \mathrm{~S}}=\frac{6.375^{2} \mathrm{ft}^{2} / \mathrm{sec}^{2} \times 12 \mathrm{in} / \mathrm{ft}}{2 \times 6 \mathrm{in} .} \\
& =40.6 \mathrm{ft} / \mathrm{sec}^{2} \\
W & =383 \mathrm{lb} \text { (Weight of assemb1y) }
\end{aligned}
$$

Dynamic Load

$$
L_{D}=383+383 \times \frac{40.6}{37.2}=867 \mathrm{Ib}
$$


Pressure in the Dashpot

Inside Dashpot Diameter $=3$ in.

$P=\frac{F}{A}=\frac{8671 b}{\frac{\pi}{4}(3)^{2} \text { in. } .^{2}}=1231 \mathrm{~b} /$ in. $^{2}$

Stress on Most Highly Stressed Components

Spool bolt

Tensile Stress, $\sigma=\mathrm{L}_{\mathrm{D}} / \mathrm{A}$

$$
\sigma=\frac{1860 \mathrm{lb}}{0.535 \mathrm{in.}^{2}}=3480 \mathrm{lb} / \mathrm{in.}^{2}
$$

Dashpot Support Tube

Compressive stress, $\sigma=\mathrm{L}_{\mathrm{D}} / \mathrm{A}$

$$
\sigma=\frac{867}{1.17}=740 \mathrm{lb} / \mathrm{in.}^{2}
$$

Dashpot wall

Hoop stress, $\sigma=\frac{P D}{t}$

$$
\sigma=\frac{123(3)}{0.5}=734 \mathrm{lb} / \mathrm{in}^{2}
$$

\section{POISON ASSEMBLY BUCKLING CALCULATIONS}

Assume the poison assembly is a column made up of the spring guide tube $20 \mathrm{ft}$ long without perforations. (Conservative assumption)

Buckling Relations

1. Assuming pinned ends

$$
\begin{aligned}
P / A & =\frac{\pi^{2} E}{(L / K)^{2}} \\
E & =30 \times 10^{6} \mathrm{lb} / \mathrm{in} .^{2} \\
L & =240 \mathrm{in} . \\
K & =\sqrt{\mathrm{I} / \mathrm{A}} \\
A & =\frac{\pi}{4}\left(\gamma_{2}{ }^{2}-\gamma_{1}{ }^{2}\right)
\end{aligned}
$$




$$
\begin{aligned}
& I=\frac{\pi}{4}\left(r_{2}{ }^{4}-r_{1}{ }^{4}\right) \\
& \gamma_{1}=2.8875 \\
& \gamma_{2}=3.1875 \\
& A=\pi / 4(10.2-8.35)=1.45 \mathrm{in}^{2} \\
& I=\pi / 4(103.5-69.7)=26.5 \text { in. }^{4} \\
& K=\sqrt{I / A}=\sqrt{\frac{26.5}{1.45}}=4.28 \text { in. } \\
& \mathrm{L} / \mathrm{K}=\frac{240}{4.28}=56.0 \\
& P / A=\sigma=\frac{\pi^{2} E}{(L / K)^{2}} \\
& =\frac{\pi^{2}\left(30 \times 10^{6}\right)}{(56)^{2}}=94,250 \mathrm{lb} / \mathrm{in}^{2}
\end{aligned}
$$

Buckling will not be possible for stresses under 94,250. Stresses this large under dyramic loading is not anticipated. Yielding or crushing would occur before buckling. 
BNWL- 970

APPENDIX D

COMPONENT SPECIFICATIONS 

APPENDIX D

\section{COMPONENT SPECIFICATIONS}

Specifications for the major purchased components selected for the Modified Fermi Conceptual Design are outlined so that their capabilities may be reviewed when operating conditions are better defined.

1. Potentiometer

\begin{tabular}{|c|c|}
\hline Type & Fairchild Type 990 \\
\hline Resistance Range & $5000 \Omega$ \\
\hline $\begin{array}{l}\text { Independent } \\
\text { Linearity }\end{array}$ & $0.2 \%$ F.S. $(294 \Omega$ a11oy $)$ \\
\hline Resolution & $0.015 \% \mathrm{~F} . \mathrm{S}$ \\
\hline Resistance Tolerance & $2 \%$ \\
\hline $\begin{array}{l}\text { Power Dissipation } \\
\text { @ } 85 \%\end{array}$ & $2 W$ \\
\hline Electrical Angle & $\begin{aligned} 3600^{\circ} & +4^{\circ} \\
- & 2^{\circ}\end{aligned}$ \\
\hline Mechanical Rotation & $\begin{aligned} 3600^{\circ} & +10^{\circ} \\
& -0^{\circ}\end{aligned}$ \\
\hline Torque & 0.35 in. $/ 0 z$ \\
\hline Backlash & $1^{\circ}$ \\
\hline $\begin{array}{l}\text { Ambient Operating } \\
\text { Temperature }\end{array}$ & $150^{\circ} \mathrm{C}\left(300^{\circ} \mathrm{F}\right)$ \\
\hline Radiation & Unknown \\
\hline Potentiometer Speed $\mathrm{F}$ & educer \\
\hline Type & PIC U2-5 \\
\hline Ratio & $20: 1$ \\
\hline Max. Output Torque & 65 oz-in. \\
\hline Backlash & $0.5^{\circ}$ \\
\hline $\begin{array}{l}\text { Ambient Operating } \\
\text { Temperature }\end{array}$ & $250^{\circ} \mathrm{F}$ \\
\hline Radiation & Unknown \\
\hline
\end{tabular}


3. Shaft Encoder

Type

Mechanical Shaft

Speed, Max.

Shaft Angular

Acceleration

Ambient Operating

Temperature

Operating Life, Min.

Count Cycles per

Shaft Rev.

Radiation

4. Stepping Motor

Type

Holding Torque

Max. Stepping Rate

Steps per Revolution

Max. Running Torque

Stepping Accuracy

Ambient Operating Torque

Radiation
Dynamics Research Corp.

Mode1 29

$3000 \mathrm{rpm}$

$10^{6} \mathrm{radian} / \mathrm{sec}^{2} \max$.

$140^{\circ} \mathrm{F}$

$2 \times 10^{8} \mathrm{rev}$ or $10,000 \mathrm{hr}$

200

Unknown

S1o-Syn HS-400B

850 oz-in.

1670 steps/sec

200

600 oz-in. at 250 steps/sec

$\pm 0.090^{\circ}$ nonaccumulative

$100{ }^{\circ} \mathrm{C}\left(212^{\circ} \mathrm{F}\right)$ Radiation

Resistant Mode 1

$130{ }^{\circ} \mathrm{C}\left(266^{\circ} \mathrm{F}\right) \mathrm{High}$

Temperature Model

3000 Mrads (Radiation

Resistant Mode1) 
5. Ball Screw

$\begin{array}{ll}\text { Type } & \text { Saginaw 0875-0200-SRT } \\ \text { Lead of Thread } & 0.200 \text { in. } \\ \text { Thread } & \text { Right Hand, Rolled } \\ \text { Operating Load Cap. } & 10001 \mathrm{~b} \text { for } 10^{6} \mathrm{in} . \\ \text { Max. Static Load } & 9,800 \mathrm{bb} \\ \text { Lead Accuracy } & 0.0015 \mathrm{in./in} . \\ \text { Backlash } & 0.005 \mathrm{in} . \\ \text { Material } & \text { AISI } 8620\end{array}$



BNWL - 970

\section{REFERENCES}

1. J.W. Hess. Design and operating Experience with the Control and Safety Rod Drive Mechanisms for the Enrico Fermi Fast Breeder Reactor, APDA 301. Atomic Power Development Associates, Inc. June 1, 1966.

2. J. G. Duffy, J.W. Hess, M. E. Leibson, and J. Matte, III. Design, Test, and Performance of the Control Rod Drives for the Enrico Fermi Fast Breeder Reactor, MD-64-1065, pF. 20-25. Atomic Power Development Associates, Inc., Detroit, Michigan, october, 1964.

3. W. J. Freede, L. Newcomb, and R. S. Kennedy. Static and Sliding Contact Behavior of Materials in Sodium Environments at Elevated Temperatures, NAA-SR-12446. Atomics International, Liquid Metal Engineering Center, September $29,1967, \mathrm{p} .50$.

4. J. K. Balkwizl. Literature and Experience Survey: Mechanical Elements operating in Alkali Metal Environments, NAA-SR-12448. Atomies International, Liquid Metal Engineering Center, June 16, 1967.

5. J. E. Lempges. Memo to R. H. Jones, Entitied APDA Test Memorandum No.25 (Control Rod Drop Test), Atomic Fower Development Associates, Ine., Apriz 29, 1960.

6. M. Kangizaski. The Effects of Neutron Irradiation on Structural Materials, REIC-45. Battelie Memorial Institute, June 30, 1967.

7. E. Hutter, J. E. Sulzivan, and G. D. Giorgis. Faret Control Drive Mechanisms, ANL-7158, p. 35. Argonne National Laboratory, June 1966.

8. High Nickel Alloy Helical Springs, Technical Buzletin T-35, p. 31. Huntington Alloy Products Division, International Nickel Co., Ine., New York, N.Y., January 31, 1960.

9. Robert Matters. The Selection of Materials for High Temperature springs. Allis Chalmers Manufacturing Co.

10. V. A. Stanton. The Best Spring Material for High Temperature. Product Engineering, January 18, 1962. p. 31.

11. Razph Moezzer. Coiz springs Above $400^{\circ} \mathrm{F}$. Product Engineering, october 25, 1965. pp.3-4. 
12. Ralph Moelzer. "High Temperature Alloys for High Temperature springs," Spring Technology, vol: 4, no. 2. october, 1965.

13. Inconel Azzoy 718. Huntington Alzoy Products Division, International Nickel Co., Inc., New York, 1968.

14. C. A. Mansius. Unpublished Data. Pacific Northwest Laboratory, Richland, Washington, September 30, 1968. (Letter from C. A. Mansius to J. C. Noakes. Subject: Neutron Flux above FTR Core.)

15. R. T. Mehan. "Irradiation of Haynes-25 and Inconez-X Compression Springs in High-Temperature, High-Pressure Water," Trans. ASME, p. 226. June, 1959.

16. C. G. Cozzins, W. H. Couts, G. L. Hammons, and F. C. Robertshaw. Radiation Effects on the Stress Rupture Properties of Inconel-X and A-286. APEX-676. Nuclear Materials and Propulsion operation, Flight Propulsion Laboratory Department, General Electric, December, 1961. 


\section{DISTRIBUTION}

No. of

Copies

OFFSITE

AEC Division of Reactor Development and Technology

M. Shaw, Director, RDT

Asst Dir for Nuclear Safety

Analysis and Evaluation Br, RDT:NS

Environmental and Sanitary Engrg Br, RDT:NS

Research and Development Br, RDT:NS

Asst Dir for Plant Engrg, RDT

Facilities $\mathrm{Br}$, RDT:PE

Components $\mathrm{Br}, \mathrm{RDT}: \mathrm{PE}$

Instrumentation and Control Br, RDT:PE

Liquid Metal Systems $\mathrm{Br}$, RDT:PE

Asst Dir for Program Analysis, RDT

Asst Dir for Project Mgmt, RDT

Liquid Metals Projects Br, RDT:PM

FFTF Project Manager, RDT:PM (3)

Asst Dir for Reactor Engrg, RDT

Control Mechanisms Br, RDT:RE

Core Design Br, RDT:RE (2)

Fuel Engineering $\mathrm{Br}$, RDT:RE

Fuel Handling $\mathrm{Br}$, RDT : RE

Reactor Vesse1s Br, RDT:RE

Asst Dir for Reactor Tech, RDT

Coolant Chemistry Br, RDT: RT

Fuel Recycle Br, RDT:RT

Fuels and Materials Br, RDT:RT

Reactor Physics Br, RDT:RT

Special Technology $\mathrm{Br}$, RDT:RT

Asst Dir for Engrg Standards, RDT

1 AEC Chicago Patent Group

G. H. Lee, Chief

1 AEC Idaho Operations Office

Nuclear Technology Division

C. W. Bills, Director

1

AEC San Francisco Operations Office

Director, Reactor Division 
No. of

Copies

4

AEC Site Representatives

Argonne National Laboratory

Atomics International

Atomic Power Development Assoc.

General Electric Co.

Argonne National Laboratory

R. A. Jaross

LMFBR Program office

N. J. Swanson

Atomic Power Development Associates, Inc.

Document Librarian

Atomics International

D. J. Cockeram

Liquid Metal Information Center

J. J . Droher

2

Babcock and Wilsox Co.

Atomic Energy Division

S. H, Esleeck

G. B. Garton

Bechte1 Corporation

J. J. Teachnor, Project Administrator, FFTF (8)

D. H. Weiss (Richland)

1 Combustion Engineering

1000 MWe Follow-On Study

W. P. Staker, Project Manager

5 General Electric Co.

Advanced Products Operation

Karl Cohen (3)

Bertram Wolfe

Nuclear Systems Programs

D. H. Ahmann

Distr-2 
No. of

Copies

2 Gulf General Atomic Inc. General Atomic Div

D. Coburn

1 Idaho Nuclear Corporation

D. R. deBoisblanc

1 BNW Representative

N. A. Hill (ZPR-III)

1 Oak Ridge Nationa1 Laboratory

W. O. Harms

1 Stanford University

Nuclear Division

Division of Mechanical Engrg

R. Sher

1 United Nuclear Corporation

Research and Engineering Center

R. F. DeAngelis

11 Westinghouse Electric Corp

Atomic Power Division

Advanced Reactor Systems

J. C. R. Kelly (10)

R. Strzelecki (Richland)

ONSITE -

HANFORD

1 AEC Chicago Patent Group

R. K. Sharp (Richland)

4 AEC RDT Site Representative

P. G. Holsted 
No. of

Copies

3

AEC Richland Operations Office

FFTF Program

J. M. Shivley

(3)

3 Batte11e Memorial Institute

61 Batte11e-Northwest

E. R. Astley

J. M. Batch

J. R. Carre11

J. C. Cockran

D. L. Condotta

G. M. Dalen

L. M. Finch

F. W. Fox

B. C. Fryer (5)

F. C. Gronemeyer

P. L. Hofmann

W. S. Kelly

D. Marinos

J. R. McBride (5)

W. B. McDonald

J. S. McMahon

R. A. Moen

C. A. Munro

J. C. Noakes

A. Padilla

L. T. Pedersen

D. E. Rasmussen

D. E. Simpson

J. C. Tobin

R. C. Walker

J. F. Wett

FFTF Files (10)

FFTF Technical Report office

Technical Information (5)

Technical Publications (2) 